\title{
Wall shear stress in human arteries : a study based on non-invasive ultrasound
}

Citation for published version (APA):

Samijo, S. K. (2001). Wall shear stress in human arteries : a study based on non-invasive ultrasound. [Doctoral Thesis, Maastricht University]. Universiteit Maastricht. https://doi.org/10.26481/dis.20010504ss

Document status and date:

Published: 01/01/2001

DOI:

10.26481/dis.20010504ss

Document Version:

Publisher's PDF, also known as Version of record

\section{Please check the document version of this publication:}

- A submitted manuscript is the version of the article upon submission and before peer-review. There can be important differences between the submitted version and the official published version of record.

People interested in the research are advised to contact the author for the final version of the publication, or visit the DOI to the publisher's website.

- The final author version and the galley proof are versions of the publication after peer review.

- The final published version features the final layout of the paper including the volume, issue and page numbers.

Link to publication

\footnotetext{
General rights rights.

- You may freely distribute the URL identifying the publication in the public portal. please follow below link for the End User Agreement:

www.umlib.nl/taverne-license

Take down policy

If you believe that this document breaches copyright please contact us at:

repository@maastrichtuniversity.nl

providing details and we will investigate your claim.
}

Copyright and moral rights for the publications made accessible in the public portal are retained by the authors and/or other copyright owners and it is a condition of accessing publications that users recognise and abide by the legal requirements associated with these

- Users may download and print one copy of any publication from the public portal for the purpose of private study or research.

- You may not further distribute the material or use it for any profit-making activity or commercial gain

If the publication is distributed under the terms of Article $25 \mathrm{fa}$ of the Dutch Copyright Act, indicated by the "Taverne" license above, 


\section{WALL SHEAR STRESS in HUMAN ARTERIES}

A study based on non-invasive ultrasound 


\title{
WALL SHEAR STRESS in HUMAN ARTERIES
}

\author{
A study based on non-invasive ultrasound
}

\author{
PROEFSCHRIFT \\ ter verkrijging van de graad van doctor \\ aan de Universiteit Maastricht, \\ op gezag van de Rector Magnificus, \\ Prof. Dr. A.C. Nieuwenhuijzen Kruseman, \\ volgens het besluit van het College van Decanen, \\ in het openbaar te verdedigen op \\ vrijdag 4 mei 2001 om 14.00 uur
}

door

Stefano Kliwon Samijo

geboren op 14 maart 1965 te Paramaribo. 


\section{Promotores:}

Prof. dr. ir. A.P.G. Hoeks

Prof. dr. P.J.E.H.M. Kitslaar

Prof. dr. R.S. Reneman

\section{Beoordelingscommissie:}

Prof. dr. K.M.L. Leunissen (voorzitter)

Prof. dr. ir. M.E.H. van Dongen (Technische Universiteit Eindhoven)

Prof. dr. J.G.R. de Mey

Dr. M.G.A. Oude Egbrink

Dr. J.H.M. Tordoir

Financial support by the Netherlands Heart Foundation for the publication of this thesis is gratefully acknowledged.

De publicatie van dit proefschrift werd mede mogelijk gemaakt door: Pie Medical, Ortomed, Stryker Howmedica en DeFauwes Orthopedie. 
Aan: mijnoudersen grootouders 



\section{Contents}

Chapter 1

General introduction

1.1 Introduction 11

1.2 Aims of the study 15

$\begin{array}{lll}1.3 & \text { References } & 16\end{array}$

Chapter 2

Wall shear stress in arteries

2.1 Historical aspects 21

2.2 Wall shear stress and arterial fluid mechanics 25

2.3 The viscosity of blood 30

2.4 Wall shear stress related to biochemical factors 32

2.5 Wall shear stress and gene regulation 36

2.6 Wall shear stress and vessel wall remodelling 36

2.7 Wall shear stress and vessel wall pathology 39

2.8 Conclusions 40

2.9 References 45

\section{Chapter 3}

The Shear Rate Estimating System (SRES)

3.1 Basic principles of ultrasound

3.2 Assessment of blood flow velocity with pulsed ultrasound 65

3.3 The Shear Rate Estimating System 68

$\begin{array}{lll}3.4 & \text { References } & 76\end{array}$ 
Reproducibility of shear rate and shear stress assessment by means of ultrasound in the common carotid artery of young human males and females

\section{Chapter 5}

Wall shear stress in the human common carotid artery as function of age and gender

\section{Chapter 6}

Chronic smoking does not affect the basal level of arterial wall shear stress

\section{Chapter 7}

Wall shear stress in the common carotid artery of end stage renal failure patients

\section{Chapter 8}

Is wall shear stress in the common carotid and the brachial artery at the same level?

\section{Chapter 9}

General discussion, conclusions and recommendations

Glossary

Summary

Samenvatting 
Chapter 1

General introduction

1.1 Introduction

1.2 Aims of the study

1.3 References 
General introduction 


\subsection{Introduction}

Atherosclerosis is a disease of the great arterial vessels related to risk factors such as smoking, high serum cholesterol, homocysteinemia and diabetes mellitus. Because hypertension is recognised as a major risk factor for developing atherosclerosis, biomechanical aspects of the arterial system have also been considered in atherogenesis. Additional evidence of biomechanical causes is presented by the fact that atherosclerosis only appears in the (high blood pressure) arterial system and not in the (low blood pressure) venous system. Due to the focal appearance of atherosclerosis it is also inferred that local hemodynamic factors are related to the development of this disease.

The basic internal mechanical forces in the circulation system acting upon the vessel wall are transmural pressure and shear stress (figure 1.1). Transmural pressure is induced by the (cyclic) blood pressure, which acts perpendicular to the wall and produces a (cyclic) stretch of the vessel wall. Wall shear stress represents the force field exerted by the flowing blood on the inner vessel wall tangential to the vessel wall.

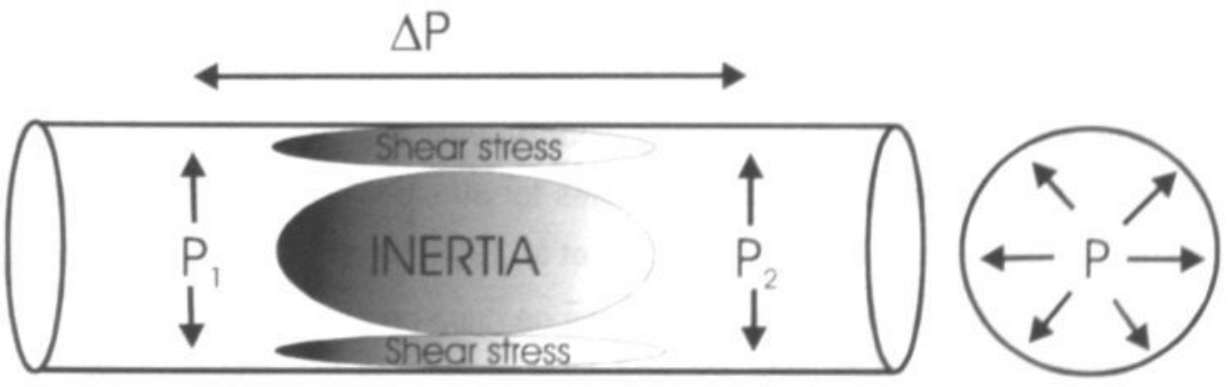

Figure 1.1

$P_{1}$ and $P_{2}$ are the blood pressures perpendicular to the vessel wall. Wall shear stress is the force field tangential to the vessel wall. $\Delta P$ is the pressure difference which is the driving force to induce flow, while wall shear stress and the inertia of blood form the opposite to flow. 
Due to the focal and time dependent character of wall shear stress and its direct interaction with the inner vessel wall, this hemodynamic factor is considered to be of importance in atherogenesis. Pathology studies indeed indicate that atherosclerotic lesions are mainly found at branches and bends of the arterial tree (Nerem 1992) where temporal and spatial variations of wall shear stress are dominant and mean shear stress is low relative to the pulsatile component. A causal role of wall shear stress is less obvious, but it is generally accepted that this hemodynamic factor modulates the pathobiologic processes, via interaction with the endothelium of the arterial wall, which are inherent to the development of atherosclerosis.

Experimental findings in dogs (Fry 1968) indicated that atherosclerotic lesions in the aorta occur preferentially at arterial walls subjected to high wall shear stress (35-40 $\mathrm{Pa}$ ). It was suggested that such high wall shear stresses resulted in mechanical damage of the arterial endothelium thereby initiating vessel wall pathology. This hypothesis was known as the high shear stress theory.

In contrast Caro et al. (Caro et al. 1971) proposed that low wall shear stress had to be considered of significance in the pathogenesis of atherosclerosis. They analysed in detail in post-mortem specimens the relation between the localisation of plaques and local hemodynamics. It was demonstrated that early atherosclerotic lesions in human arteries were predominantly observed in low shear regions. These investigators suggested that low shear stress interferes with mass transport between endothelium and blood thereby inducing vessel wall pathology. Ever since it is generally accepted that predilection sites for atherosclerosis are related to low wall shear stress (Friedman et al. 1981, Ku et al. 1985, Nerem 1992, Nerem 1995).

The presently accepted studies for wall shear stress in the arterial system are based on principles of minimum work (Murray's law). This law refers to an optimally designed system that requires the least power to perform its function. Calculations based on Murray's law show that in the arterial system wall shear stress values are on the order of $1.5 \mathrm{~Pa} \pm 50 \%$ (Kamiya et al. 1984, Zamir 1977). 
In other words, wall shear stress is of such a small magnitude (a factor of ten thousand smaller than blood pressure) that probably only endothelial cells are affected by wall shear stress, while other cells in the vascular wall, such as smooth muscle cells, remain unaffected. After Furchott and Zawadski (Furchott and Zawadski 1980) discovered that endothelial cells are key cells in arterial wall functioning, biomechanical research regarding the interaction(s) between shear stress and endothelial functioning became self-evident. Indeed, studies have shown that endothelial cells, both in in-vivo and in-vitro conditions, respond to wall shear stress by inducing protein synthesis, by changes in metabolism and by alterations of their structure and morphology (Cornhill and Roach 1976, Dewey et al. 1981, Flaherty et al. 1972, Nerem et al. 1993). At present, much research is performed to elucidate wall shear stress cell-signalling and transduction pathways at the biomolecular level (Davies 1995, Davies 1991).

The impact of wall shear stress in the circulation is obvious, although the underlying mechanism leading to vessel wall pathology is poorly understood. Several studies clearly point to a role of wall shear stress in vessel wall modifications. For example, a correlation was observed between low wall shear stress and intimal thickness (Friedman et al. 1981), and, between both high and low wall shear stress and intimal hyperplasia (Glagov and Zarins 1989), a proliferation of smooth muscle cells causing obstructive complications for almost every type of vascular intervention like percutaneous transluminal coronary angiography (PTCA), coronary and peripheral arterial bypasses grafting and the construction of arterio-venous fistulas for hemodialysis (Dobrin 1995).

Since wall shear stress has such an impact on the functioning of the arterial vessel wall, the compelling question arises regarding the role of wall shear stress in atherosclerosis related risk factors, such as ageing, smoking and atherosclerosis related diseases such as hypertension, diabetes mellitus, homocysteinemia and chronic renal failure. A basic problem is that wall shear stress is difficult to measure directly and non-invasively due to technical inabilities. However, wall shear stress can be derived from two measurable parameters: wall shear rate, i.e. the velocity gradient at the wall, and local fluid viscosity. The blood flow velocity gradient can be 
estimated from the assumed or measured velocity profile. The estimation of local blood viscosity is based on subjecting a blood sample to a viscometer, hereby taking into account the effect of the observed shear rate.

Several methods are available to determine wall shear rate. The Hot Film Anemometer provides a mean to assess the wall shear rate, but the procedure is highly invasive, while the spatial resolution is limited to $1 \mathrm{~mm}$ (Ling et al. 1968, Rueben et al. 1970). Laser Doppler Anemometry provides an alternative, but this method requires a translucent wall and, hence, can only be applied in model studies (Hayashi et al. 1996, Ku and Giddens 1987). Magnetic Resonance Angiography (MRA) is non-invasive and has a good penetration depth, but its spatial resolution is presently inadequate to estimate the velocity gradient especially under pulsatile conditions near a distending arterial wall (Caro et al. 1992). Until recently the most frequently employed method to estimate wall shear rate is based on assuming the (parabolic) shape of the cross-sectional blood flow velocity distribution (Safar et al. 1981, Simon and Levenson 1990). By assuming the shape of the velocity profile and measuring arterial diameter and centre stream velocity blood flow velocity (recorded with a conventional ultrasound system), wall shear rate can be estimated (chapter 3). However, under pulsatile conditions the shape of the velocity distribution gradually changes during the cardiac cycle, limiting the validity of this method.

Despite the obvious significance of wall shear stress for the functioning of the arterial system and possible pathophysiological consequences, human studies are lacking. Recently in the Cardiovascular Research Institute Maastricht (CARIM) a Shear Rate Estimating System (SRES), based on ultrasound, was developed to assess non-invasively wall shear rate in humans. The system allows the direct assessment of the instantaneous velocity distribution, and hence the velocity gradient (shear rate), close to the wall in human arteries. By taking blood viscosity into account, wall shear stress can be estimated. It was the purpose of the present study to evaluate the performance of this system and to investigate the behaviour of peak and mean wall shear rate and stress in the common carotid artery under physiological and pathophysiological conditions. In a later phase of the study the SRES was also used to assess wall shear rate and stress in the brachial artery under resting conditions. 


\subsection{Aims of the study}

The study is divided into 5 parts:

1. Investigation of the reliability of the Shear Rate Estimation System (SRES) in terms of reproducibility and validity.

2. Values of wall shear stress employed are generally based on model studies; values derived from in vivo studies, especially in humans are scarce. Moreover, its relation to age and sex is unknown. Therefore, wall shear stress in the common carotid artery in humans was assessed to obtain physiological values and its dependence on age and gender, if any.

3. Smoking is a habit, which is known to increase the risk for cardiovascular diseases. It was investigated whether wall shear stress in the common carotid artery is different in smoking and non-smoking male subjects.

4. Chronic renal failure is a risk factor for atherosclerosis. The underlying mechanism, however, is unclear. This renal disease induces remodelling of the arterial system, i.e., enlargement of arterial diameter. It is hypothesised that the increase in diameter results in a low wall shear stress, which could attribute to the early development of atherosclerosis. Therefore, wall shear stress was assessed in patients with end stage renal failure.

5. It is generally accepted that wall shear stress has a more or less constant value along the arterial system and is independent of the type of artery and/or its vascular territory. To test this hypothesis a study was undertaken to compare wall shear stresses in the (elastic) common carotid and the (muscular) brachial artery. 


\subsection{References}

Caro C, Dumoulin C, Graham K, Parker K, Souza S. Secondary flow in the human common carotid artery imaged by MR angiography. J Biomech Eng 1992;114:147149.

Caro CG, Fitzgerald JM, Schroter RC. Atheroma and arterial wall shear: observation, correlation and proposal of a shear dependent mass transfer mechanism for atherogenesis. Proc Roy Soc London 1971;17B:105-159.

Cornhill JF, Roach MR. A quantitative study of the localization of atherosclerotic lesions in the rabbit aorta. Atherosclerosis 1976;23:489-499.

Davies F. Flow-mediated endothelial mechanotransduction. Physiol Rev 1995;75 (3):519-560.

Davies PF. Mechanical sensing mechanisms: shear stress and endothelial cells. J Vasc Surg 1991;13:729-731.

Dewey SL, Eskin SG, Mclntire LV. The dynamic response of vascular endothelial cells to fluid shear stress. J Biomech Eng 1981;103:177-185.

Dobrin PB. Mechanical factors associated with the development of intimal and medial thickening in vein grafts subjected to arterial pressure. Hypertension 1995;26:38-43.

Flaherty JT, Pierce JE, Ferrans VJ, Patel DJ, Tucker WK, Fry DL. Endothelial nuclear patterens in the canine arterial tree with particular reference to hemodynamic events. Circ Res 1972;30:23-33.

Friedman MH, Hutchins GM, Bargeron CB, Deters OJ, Mark FF. Correlation between intimal thickness and fluid shear in human arteries. Atherosclerosis $1981 ; 39: 425-436$. 
Fry DL. Acute vascular endothelial changes associated with increased blood velocity gradients. Circ. Res. 1968;22:165-197.

Furchott RF, Zawadski JV. The obligatory role of endothelial cells in the relaxation of arterial smooth muscle by acetylcholine. Nature 1980;288:373-376.

Glagov S, Zarins CK. Is intimal hyperplasia an adaptive response or a pathologic process? Observations on the nature of nonatherosclerotic intimal thickening. J Vasc Surg 1989;10:571-573.

Hayashi K, Yanai Y, Naiki T. A 3d-LDA study of the relation between wall shear stress and intimal thickness in a human aortic bifurcation. J. Biomech. Eng. 1996;118:273-279.

Kamiya A, Bukhari R, Togawa T. Adaptive regulation of wall shear stress optimizing vascular tree function. Bulletin Math Biol 1984;46:127-137.

Ku D, Giddens D, Zarins C, Glagov S. Pulsatile flow and atherosclerosis in the human carotid bifurcation. Arteriosclerosis 1985;5:293-302.

Ku DN, Giddens DP. Laser doppler anemometer measurements of pulsatile flow in a model carotid bifurcation. J. Biomech. 1987;20:407-421.

Ling S, Atabek H, Fry D, Patel D, Janicki B. Application of heated-film velocity and shear probes to heamodynamic studies. Circ Res 1968;66:1624-1635.

Nerem RM. Vascular fluid mechanics, the arterial wall, and atherogenesis. J Biomech Eng 1992;114:274-282.

Nerem RM. Atherosclerosis and the role of wall shear stress. In: Bevan JA, Kaley G, Rubanyi GM, eds. Flow-dependent regulation of vascular function. New York: Oxford University Press, 1995:300-319. 
Nerem RM, Harrison DG, Taylor WR, Alexander RW. Hemodynamics and vascular endothelial biology. J Cardiovasc Pharmacol 1993;21(Suppl.1):S6-S10.

Rueben SR, Swading JP, de J Lee G. Velocity profiles in the main pulmonary artery of dogs and man, measured with thin-film resistance anemometer. Circ Res 1970;27:995.

Safar M, Peronneau P, Levenson J, Toto-Moukouo J, Simon A. Pulsed doppler: diameter, blood flow velocity and volumic flow of the brachial artery in sustained essential hypertension. Circulation 1981;63:393-400.

Simon AC, Levenson J. Abnormal wall shear conditions in the brachial artery of hypertensive patients. J Hypertension 1990;8:109-114.

Zamir M. Shear forces and blood vessel radii in the cardiovascular system. J Gen Physiolol 1977;69:449-461. 


\section{Wall shear stress in arteries}

Historical, theoretical, functional aspects and assessment

\section{$2.1 \quad$ Historical aspects}

2.2.1 Stationary flow conditions

2.2.2 Pulsatile flow conditions

2.2 Wall shear stress and arterial fluid mechanics

2.3 The viscosity of blood

2.3.1 Influence of plasma viscosity

2.3.2 Influence of temperature

2.3.3 Assessment of blood viscosity

2.4 Wall shear stress related to biochemical factors

2.4.1 Shear stress vasoregulators

2.4.2 Cell-signalling

2.5 Wall shear stress and gene regulation

2.6 Wall shear stress and vessel wall remodelling

2.6.1 Acute remodelling of the vessel wall by shear stress

2.6.2 Wall shear stress and chronic remodelling

$2.7 \quad$ Wall shear stress and vessel wall pathology

2.7.1 Intimal hyperplasia

2.7.2 Atherosclerosis

2.8 Conclusion

2.9 References 


\subsection{Historical aspects}

The first observation, which alluded to the significance of wall shear stress, was as early as in 1761. In that year William Hunter observed a diameter increase of vessels in the microcirculation after the increase of blood volume flow (Hunter 1761). The cause for this phenomenon was not given. It was probably the first observation that volume flow itself or some factor related to volume flow could affect the vessel wall. In 1893, Thoma observed the significance of blood flow in the developing arterial tree of a chicken embryo: vessels with sustained flow continued to grow, while vessels with flow cessation degenerated (Thoma 1893). In 1933 , Schretzenmeyer described acute dilatation in the femoral artery of the cat during work hyperaemia (Schretzenmayr 1933). The mechanism leading to the observed dilatation was not explained. In 1969 Taylor et al. provided evidence that blood volume flow itself was responsible for vasodilatation. They observed that an increase in blood flow, by constructing an arteriovenous connection in the femoral artery of dogs, induced an increase in arterial diameter. The investigators hypothesised that the adaptive response of the diameter was due to a signal from the microcirculation, either via nerves or via the smooth muscle coat of the artery. This hypothesis was rejected in 1970 when Lie and co-workers observed that the flow dependent dilatation persisted in an isolated artery (Lie et al. 1970), leading to the conclusion that a local factor related to flow must be responsible for the diameter increase. In that same year Rodbard proposed that the "hydraulic drag", exerted by the flowing blood on the vessel wall, plays an important role in the dilatation of the artery. He suggested a feedback mechanism via endothelial cells causing an increase of the arterial diameter in order to maintain the drag of the flowing blood at a specific and constant value (Rodbard 1970, Rodbard 1975).

This theory gained support when Zamir et al. calculated wall shear stress in the arterial tree, based on minimum cost principles as developed by Murray et al. (Murray 1926). They arrived at a wall shear stress at every point in the arterial tree at the same constant value of $1.5 \mathrm{~Pa}\left(15\right.$ dyne/cm $\left.{ }^{2}\right) \pm 50 \%$ (Zamir 1977). In 1980 , another support for Rodbard's hypothesis came forward in the study performed by Kamiya et al. (Kamiya and Togawa 1980). They investigated the diameter of the 
common carotid artery of dogs 6 months after the flow was deliberately increased via an AV-fistula. They found a significant diameter increase and hypothesised that the observed dilatation resulted from an attempt to restore the initial wall shear stress to $1.5 \mathrm{~Pa}$. In 1985 this observation and conclusion was confirmed by Guyton et al. who observed that also volume flow restriction inhibits the growth of the diameter of the common carotid artery in juvenile rats (Guyton and Hartley 1985). They also pointed out that age was an important factor in the ability of the vessel to adapt its diameter. In 1986, Langille and O'Donell used the same protocol as Guyton and made similar observations in the common carotid artery of rabbits. They also observed that the vascular wall response was endothelium dependent, again an indication for a direct relationship between blood flow and the endothelium. In 1992, Tohda et al. reported that at the endothelial desquamated portion of a shunted artery arterial dilatation to an increase in volume flow did not occur (Tohda et al. 1992). Today, it is the general view that the drag of the flowing blood, i.e., wall shear stress, is an important hemodynamic parameter that is maintained at $1.5 \mathrm{~Pa}$ under acute and chronic circumstances. This level is regulated via adaptation of the arterial diameter to volume flow changes via interaction with the endothelium (Anayiotos et al. 1994, LaBarbera 1990, Nerem and Girard 1990).

As the importance of wall shear stress was acknowledged, the relationships between wall shear stress and vessel wall pathology was also investigated in a simultaneous manner. In 1966 Fox and Hugh observed that the localisation of atheromas correlated with regions of boundary layer separation (Fox and Hugh 1966). Such locations are focal regions where flow reversal takes place temporarily as a consequence of an instantaneous adverse pressure gradient. It is precisely in those regions where predominantly low mean wall shear stress exists. This theory was called the low shear theory. In contrast, in 1968 a high shear theory was born as in the aorta of dogs atherosclerotic lesions were found predominantly at locations experiencing excessive high mean wall shear stress (35-40 Pa) (Fry 1968). It was thought that such high shear stress could induce mechanical damage to the endothelium resulting in the initiation of atherosclerosis. In 1971, however, Caro et al. found more evidence for the low shear theory when they analysed in detail the influence of hemodynamics in human aortas on atherosclerotic lesions and found 
that areas of low shear stress correlated to the occurrence of plaques (Caro et al. 1971). Moreover, they suggested that atherogenesis might be due to a pathologic shear dependent mass transport mechanism between blood and the endothelium. In 1981, Friedman et al. suggested that not only the level of shear stress could be of importance in atherogenesis, but also the pulse shear rate (difference between maximum and minimum shear rate) (Friedman et al. 1981). They also found a negative correlation between the level of mean wall shear stress and vessel wall thickness. In 1984 Davies et al. observed that mean wall shear stress levels below 1.5 $\mathrm{Pa}$ produced a time and force dependent increased uptake of extracellular fluid via plasmolemmal vesicles. This finding implies that low mean wall shear stress levels can modulate transendothelial transport. In $1985 \mathrm{Ku}$ et al. (Ku et al. 1985) confirmed the observations of Friedman et al. They studied flow in casts of human carotid bifurcation and found that intimal thickening was predilected to regions of low and oscillatory wall shear stress. Whether intimal thickening is related to atherosclerosis is still unclear, although present studies indicate that intimal thickening in the common carotid artery could be indicative of the development of atherosclerosis (Bots et al. 1996). However, some investigators see intimal media thickening as a normal development of the vascular wall within life (O'Rourke 1995, Stary 1997). In 1995 Dobrin et al. found wall shear stress to be related to another form of vascular disease, namely intimal hyperplasia (Dobrin 1995)

An important stimulus in the research on the biologic significance of wall shear stress in the circulatory system came forward in 1980, when Furchott and Zawadski made a startling discovery via experiments in segments of arteries. They found that vasodilatation was directly related to the endothelium (Furchott and Zawadski 1980), the target cells of wall shear stress. As a consequence, the interactions between wall shear stress and endothelium gained further attention. Indeed, it was found that wall shear stress is able to affect the endothelial cell anatomically, functionally and metabolically (see chapter 2.3 for details). For example (figure 2.1), wall shear stress causes the release of endothelium derived relaxing factors (EDRFs), like nitrate oxide (NO) and prostacyclin (Frangos et al. 1985), leading to vasodilatation (Cooke et al. 1990, Koller et al. 1993), or endothelium constricting factors (EDCFs), like endothelin, leading to vasoconstriction (Malek and Izumo 
1994, Sharefkin et al. 1991, Yoshizumi et al. 1989). At present a large number of biomolecular investigations are performed to elucidate shear stress cell-signalling pathways. In 1988 Olesen et al. observed a possible shear stress sensing mechanism via $\mathrm{K}^{+}$channels in the endothelial membrane (Olesen et al. 1988). Other studies indicate that shear stress induces an increase of intracellular $\left[\mathrm{Ca}^{2+}\right]$ (Dull et al. 1991, Olesen et al. 1988). In 1993 indirect evidence of a G-protein involvement in flow related $\mathrm{K}^{+}$channel activity was observed (Ohno et al. 1993). The identification of cellular mechanisms associated with shear stress or flow signal transduction can thus potentially lead to therapeutic interventions in the area of vascular diseases such as vasospasm, hypertension, intimal hyperplasia, intimalmedia thickening and atherogenesis.

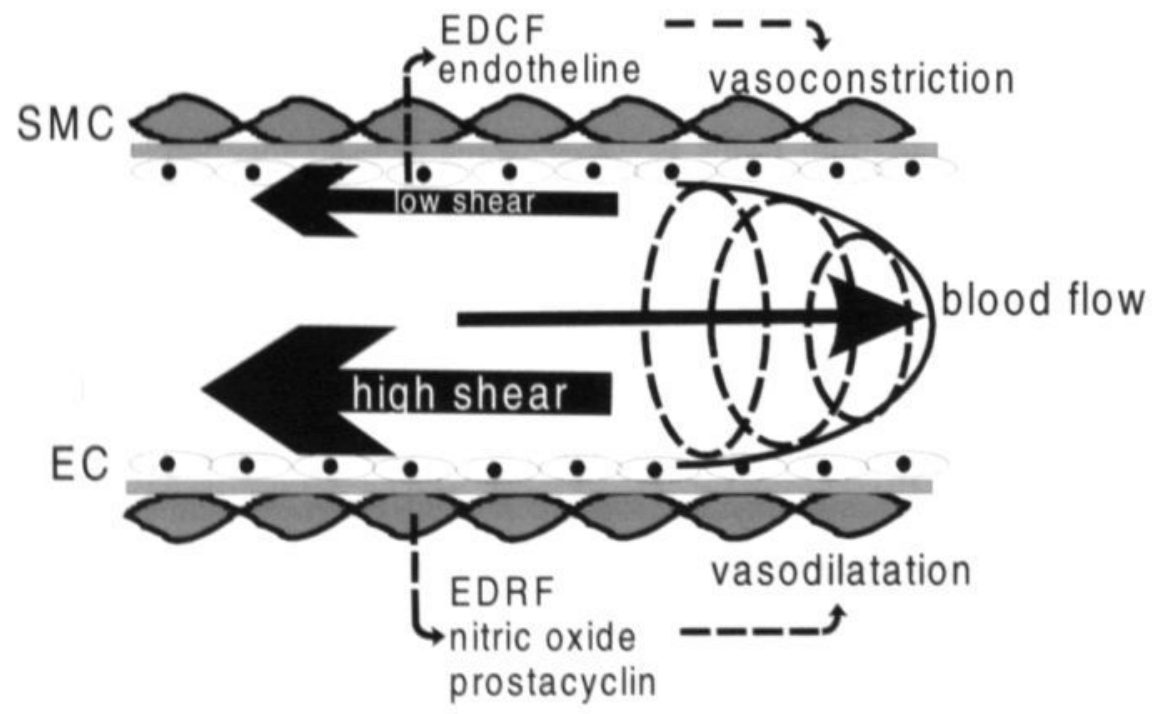

Figure 2.1

High shear stress induces vasodilatation, while low shear stress induces vasoconstriction in order to maintain shear stress at a constant level.

SMC: smooth muscle cell layer; EC: endothelial cell layer; EDCF: endothelial derived constricting factor; EDRF: endothelial derived relaxing factor. 
According to Nerem (Nerem 1995), it can be concluded that in historical perspective the role of wall shear stress or wall shear rate in atherosclerosis has moved forward in a series of "chapters". In the 1960's the debate prevailed regarding the high/low shear stress years. The 1970's can be called shear pattern years, i.e., the correlation of the patterns of the velocity blood flow profile to the pattern of atherosclerosis, including the question whether there is any influence of local hemodynamics on vascular biology. In 1980's the "flow at the heart of cell biology" came forward as cell culture techniques advanced and the effect of shear stress on endothelial layers could be studied. The 1990's can be seen as the "integration years" as knowledge of shear stress behaviour in the arterial system was integrated at the cellular and molecular levels. This resulted in a better understanding of the biologic processes regulating homeostasis of the arterial wall, while simultaneously sensitive measurements systems were developed to measure wall shear stress behaviour in vivo.

\subsection{Wall shear stress and arterial fluid mechanics}

\subsubsection{Stationary flow conditions}

To understand the relationship between wall shear stress and other hemodynamic parameters of the arterial system, it is best to start with flow under stationary flow conditions, such as flow through rigid cylindrical pipes of a constant diameter. Poiseuille's law governs the flow through these systems. This law states that the rate of volume flow is directly proportional to the fourth power of the internal radius and the pressure difference, and inversely proportional to tube length and viscosity:

$$
Q=\frac{\pi\left(P_{1}-P_{2}\right) R^{4}}{8 L \eta}
$$

where $Q \quad$ = volume flow;

$P_{1}-P_{2}=$ pressure drop along a tube segment with length $\mathrm{L}$;

$R \quad=$ internal radius of the tube;

$\eta \quad=\quad$ fluid viscosity 
The basic assumption is that every particle is moving parallel to the axis, and that the particles will be arranged in cylindrical laminae (figure 2.2).

The centre lamina will move at the maximal velocity and the lamina at the wall with zero velocity assuming no slip at the wall. Each outer layer of a lamina is subjected to a constant force field, so that it maintains a constant velocity along the longitudinal axis of the tube. This force field, shear stress, opposes fluid motion. Shear stress is proportional to the local fluid viscosity and local velocity gradient $(\delta v / \delta \eta)$, i.e., the changing velocity that occurs along the radius $(R)$ of the tube. The local velocity gradient is also called the local shear rate $(\gamma)$ :

$$
\gamma(r)=-\frac{\delta v}{\delta r}
$$

Shear stress, $\tau$, is given as:

$$
\tau=-\frac{\delta v}{\delta r}{ }^{\star} \eta
$$

where $\eta$ is the viscosity of the fluid.

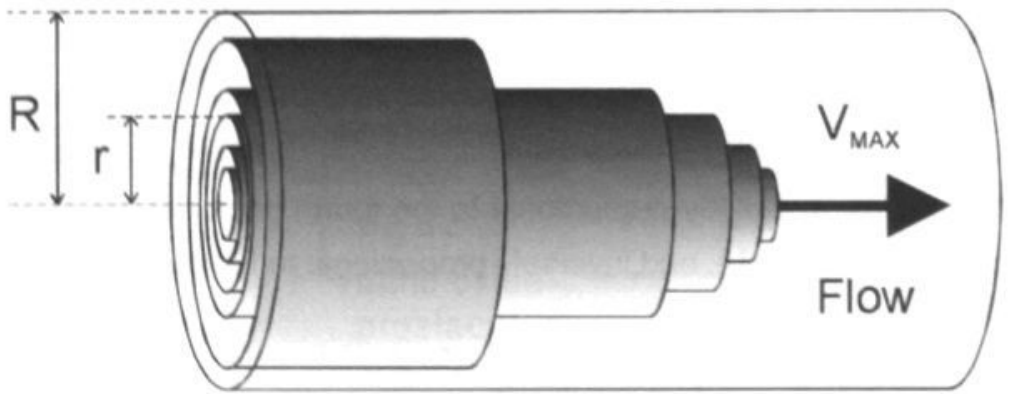

\section{Figure 2.2}

Poiseuille flow of a Newtonian fluid through a rigid cylindrical tube. The motion of the liquid is pictured as the telescopic sliding of cylinders over each other. The layer at the wall is at rest and the velocity in the axial direction increases parabolically, only at sufficient long entrance length, with radial distance $r$, reaching a maximum at the tube axis $\left(V_{\max }\right)$. 
Wall shear stress can be described as function of pressure (Strandness and Sumner 1975):

$$
\tau_{w}=\frac{R\left(P_{1}-P_{2}\right)}{2 L}
$$

Using equation (2-1), expression (2-4) is frequently expressed as function of volume flow $(Q)$ :

$$
\tau_{w}=\frac{4 \eta Q}{\pi R^{3}}=\frac{32 \eta Q}{4 \pi D^{3}}
$$

Thus under steady laminar flow and a constant fluid viscosity wall shear stress is simply determined by volume flow and diameter of the tube.

Assuming constant flow to tissue, it seems likely that the vascular system is able to maintain wall shear stress constant by a diameter adaptive autoregulatory negative feedback mechanism. This hypothesis was fitted in the statistical analyses of vascular branching systems where blood volume flow through a vessel is related to its internal radius (Kamiya et al. 1984).

\subsubsection{Pulsatile flow conditions}

In the above assumptions $\mathrm{Q}$ is considered constant, which does not take into account the time dependent behaviour under pulsatile conditions. Therefore, to assess the time-dependent shear rate, the time dependent velocity distribution must be determined, at least theoretically.

In a circular shaped lumen a symmetric velocity profile can be described as:

$$
v(r)=v_{m}\left[1-\left(\frac{r}{R}\right)^{n}\right]
$$


where $v_{m}$ is the maximal velocity in the centre of the vessel and $n$ the bluntness factor; the higher the bluntness factor the flatter the velocity profile. When the bluntness factor is 2 , the velocity profile will be parabolic (figure 2.2).

Using equation (2-2) wall shear rate $\left(\gamma_{w}\right)$ can then be calculated as

$$
\gamma_{w}=-\left.\frac{\delta v(r)}{\delta r}\right|_{r=A}
$$

where $v(r)$ is the observed or modelled velocity distribution as function of the radial position $r$, and $R$ the internal radius of the vessel. Combining equation (2-6) and (2-7) wall shear rate can be expressed as:

$$
\gamma_{w}=\frac{n v_{m}}{R}
$$

Integration of expression (2-4) over the cross-sectional area of the lumen $\left(A=\pi R^{2}\right)$ gives the mean velocity, $\bar{v}$, as function of the maximal velocity $v_{m}$, radius $R$ and bluntness factor $n$ :

$$
\bar{v}=\frac{n}{n+2} v_{m}
$$

Substitution of expression (2-9) in (2-8) results in:

$$
\gamma_{w}=\frac{(n+2) \bar{v}}{R}
$$

Wall shear rate can then be deduced from mean flow velocity and arterial radius and, hence, from $Q$, as:

$$
Q=v^{*} \pi R^{2}
$$


Combination of expression (2-10) and (2-11) gives:

$$
\gamma_{w}=\frac{(n+2) Q}{\pi R^{3}}
$$

For $n=2$ and taking fluid viscosity into account, the latter equation is the same as expression (2-8) (Poiseuille's law). The latter approach is very sensitive to slight variations in estimated diameter. It is most frequently used in non-invasive (e.g. ultrasound) studies, thereby assuming a constant blood viscosity.

In order to evaluate the time dependent behaviour of wall shear stress or wall shear rate in pulsatile conditions the time dependent velocity profile needs to be determined. It can be expected that velocity profiles in the mammalian arterial tree are not parabolic, because of pulsatile blood flow and changing arterial geometry. In these conditions a different wall shear rate can be expected than under stationary conditions. Measurements in the arterial systems by heated film anemometer, intraluminal Doppler, Laser Doppler (Nichols and O'Rourke 1990) and ultrasound studies have confirmed blunted velocity profiles (Reneman et al. 1985).

The factor that affects the shape of the velocity profiles is given in the nondimensional frequency parameter $\alpha$, as provided by Womersly (Nichols and O'Rourke 1990):

$$
\alpha=R \sqrt{\frac{2 \pi t \rho}{\eta}}
$$

where $R=$ internal radius $[\mathrm{m}]$

$f=$ pulse frequency $\left[\mathrm{s}^{-1}\right]$

$\rho=$ specific gravity of blood $\left[\mathrm{kg} \cdot \mathrm{m}^{-3}\right]$

$\eta=$ viscosity of blood $[\mathrm{Pa} . \mathrm{s}]$

In fact, $\alpha$ represents the ratio between inertial and viscous forces in the flowing blood. When it increases, a flatter velocity profile can be expected because then the inertial forces dominate, resulting in less shear in large arteries. 


\subsection{The viscosity of blood $(\eta)$}

The viscosity of a fluid may be considered as the resistance to flow, as the layers of the fluid exhibit intermolecular attractions that tend to resist deformation. Considering viscosity, a fluid can be Newtonian or non-Newtonian. By definition, the viscosity in a Newtonian fluid is constant at all shear rates, while the viscosity in a non-Newtonian fluid varies with shear rate. A non-Newtonian liquid can be categorised in shear thickening and shear thinning fluids. In shear thickening fluids, the viscosity increases when shear rate increases, e.g., wall paper paste, while shear thinning fluids are fluids where viscosity decreases as shear rate increases. Blood is among the latter.

Rinnd san he saen as a fluid with ecvthrocivtes suspended in olasma (Dintenfass 1976). Therefore, the viscosity of blood is determined by the following parameters:

a) the concentration of red blood cells (hematocrit);

b) the viscosity of plasma;

c) the aggregation capacity of red blood cells;

d) the flexibility of the erythrocyte membrane, which depends on the internal viscosity of the erythrocyte determined by the physical condition of the haemoglobin and the geometry of red blood cells. The flexibility of the erythrocyte membrane plays a minor role in the macrocirculation, but becomes very important in the microcirculation (Nichols and O'Rourke 1990).

The viscosity of blood can be regarded as linearly dependent on cell concentration from zero percent (plasma) to a hematocrit of about $45 \%$ at normal shear rates above $90 \mathrm{~s}^{-1}$ (Nichols and O'Rourke 1990). In literature, blood viscosity is frequently estimated to be about 3.5-4.0 mPa.s at a hematocrit of 45 percent and shear rates greater than $90 \mathrm{~s}^{-1}$ (Nichols and O'Rourke 1990). 


\subsubsection{Influence of plasma viscosity}

Plasma is a suspension of water with electrolytes $(7-7.5 \mathrm{~g} / 100 \mathrm{ml})$ and proteins. Large molecules such as albumin, fibrinogen and globulin mainly determine the viscosity of plasma. A positive linear relationship exists between the concentration of proteins and plasma viscosity (Chien et al. 1966, Dintenfass 1976). Plasma is regarded as being Newtonian (Nichols and O'Rourke 1990). The viscosity of plasma in healthy subjects is on the order of $1.2 \mathrm{mPa}$ at $37^{\circ} \mathrm{C}$. The effect of proteins on blood viscosity is not only via an influence on plasma viscosity perse, but also via red cell aggregation and the effective fluidity of erythrocytes (Dintenfass 1985).

\subsubsection{Influence of temperature}

Blood viscosity depends on parameters such as hematocrit, erythrocyte aggregation, plasma viscosity and internal viscosity of the red cell. Each of these factors responds differently to changes of temperature. It is generally accepted that a decrease or an increase of temperature leads to an increase or decrease of blood viscosity, respectively. The viscosity of blood, however, does not vary with temperature between $15^{\circ} \mathrm{C}-40^{\circ} \mathrm{C}$, especially at high shear rates as under physiological conditions (Dintenfass 1985). Thus, under normal in vivo conditions temperature fluctuations have minimal effects on blood viscosity.

\subsubsection{Assessment of blood viscosity}

Blood viscosity can be measured by rotational viscometers using a plate to plate or a cone to plate viscometer according to 2 principles:

1) "controlled shear stress method" where shear stress is set at a constant value and shear rate is measured 
2) "controlled shear rate method" where shear rate is kept constant and the viscosity can be calculated from the assessed shear stress.

In literature, measurements are frequently performed with a digital Brookfield Viscometer (Nichols and O'Rourke 1990).

In 1969, Weaver, Evans and Walder used a cone to plate viscometer to study the effects of hematocrit and shear rate on whole blood viscosity; their measurements were performed at a temperature of $20^{\circ} \mathrm{C}$. The hematocrits were assessed using a microhematocrit centrifuge. As a result of their thorough investigation they proposed the following expression for calculating whole blood viscosity (WBV) in mPa.s:

$$
\log W B V=\log \eta_{0}+\alpha H t
$$

where $\alpha=0.03-0.0076 \log (\gamma)$

$\eta_{0}=$ plasma viscosity in $\mathrm{mPa} . \mathrm{s}$

$\mathrm{Ht}=$ hematocrit in percentage

$\gamma=$ measured shear rate

This approximation circumvents the practical problems associated with the direct measurement of whole blood viscosity and takes into account the local effect of shear rate. It will be used for the estimation of whole blood viscosity in the studies described in the current thesis.

\subsection{Wall shear stress related to biochemical factors}

Upon exposure to wall shear stress the endothelial cell can secrete vasoactive substances to mediate vasoregulation and expression of adhesion molecules, the latter playing a significant role in inflammation and possibly also in atherosclerosis. Most of the investigations on this interrelation have been performed with cultured endothelial cells from human sources and a variety of animal species. Table 2-1 summarises most of the known responses of endothelial cells to shear stress. These responses have temporal aspects; the fastest response occurs within milliseconds and the slowest response takes several hours to occur. 
The relevance of these data is multipurpose:

1. If wall shear stress can be assessed in vivo, a link can be made between the level of wall shear stress and the cellular events. This could open up new alleys in the investigation of wall shear stress in the regulation of vascular tone, vascular remodelling and focal atherogenesis. For example, if one knows at which level wall shear stress induces the release of platelet growth factor (PDGF, a potent smooth muscle cell growth factor), it could lead to the development of biological techniques for intervention or prevention of intimal hyperplasia.

2. The various intracellular changes can be linked to the different responses to shear stress. For example, mechanisms that are linked to early changes of intracellular calcium quantity are probably related to the activation of nitric oxide synthase (NOS) a calcium dependent enzyme that is responsible for the synthesis of the potent vasodilator nitric oxide (NO) from arginine. Preceding the mobilisation of intracellular calcium is an elevation of inosityl triphospate (IP3), the mobilisation of which in turn is preceded by the activation of membrane receptors by e.g. acetylcholine and ATP. Whether such receptors are sensitive to mechanical forces, ligands, or both is at present unclear.

\subsubsection{Shear stress vasoregulators}

There is good evidence that shear stress induced vasodilatation involves the enhanced release of endothelial derived relaxing factors (EDRF's) with as primary components NO and closely related nitroderivatives (Moncada et al. 1991). NO is an important EDRF in the vasculature. NO is a short-lived molecule (half-life time of a few seconds in a physiological buffer) and can be scavenged by haemoglobin (Buga et al. 1991). NO activates cGMP in endothelial and smooth muscle cells resulting in vasorelaxation (Murad 1986). The elevation of cyclic guanine monophosphate (cGMP) is proportional to the intensity of shear stress up to $4 \mathrm{~Pa}$ 
(40 dyne/cm²). Endothelial NOS (eNOS) is constitutively expressed at basal level and its activity is calcium/calmodulin dependent (Lopez-Jaramillo et al. 1990). Thus the mechanism(s) by which flow induces NO-mediated vasodilatation are focused on the regulation of eNOS activity. eNOS anchors to the plasma membrane, which could facilitate the shear activation of eNOS (Sessa 1994).

Additional shear mediated vasotonic control is provided by prostacyclin (Prostaglandin $\mathrm{I}_{2}, \mathrm{PGI}_{2}$ ) (Frangos et al. 1985, Grabowski et al. 1985). This substance induces vasorelaxation, but with a lower potency than NO. Its half time is longer than that of NO (about 3 minutes). In HUVEC (human umbilical vein endothelial cells), $\mathrm{PGI}_{2}$ synthesis and release is biphasic and after an initial rapid release production declines for several hours before recovering to retain a steady rate (Frangos et al. 1985). If pulsatile shear stress is applied, the steady state level of $\mathrm{PGl}_{2}$ is significantly increased compared to the same average shear stress under steady laminar flow conditions (Grabowski et al. 1985). The interplay between NO and prostacyclin remains unclear. In arterioles of rat muscle, it appears that both substances are involved in endothelial mediation of dilatation after increases in blood flow. However, in hypertensive rats, the NO mediated arteriolar dilation was impaired, whereas the $\mathrm{PGl}_{2}$ component was largely unaffected (Koller and Huang 1994). In other vascular areas, such as the basilar artery (Fujii et al. 1991) and coronary microcirculation (Kuo et al. 1992), NO-mediated effects also appear to be dominant over the role of $\mathrm{PGl}_{2}$.

Another shear stress induced molecule is endothelin-1 (ET-1), which is a 21 aminoacid peptide derived from a 39 amino acid precursor (big endotheline) which is the cleavage product of a 202-aminoacid peptide preproendothelin. It is a potent vasoconstrictor synthesised and released by endothelial cells (Yoshizumi et al. 1989). Several isoforms exist, but only ET-1 is synthesised in the endothelium. ET-1 is also a growth factor for endothelial cells in an autocrine manner (Takagi et al. 1990) and smooth muscle cells (Komuro et al. 1988). Therefore, ET-1 may modify arterial diameter by reorganisation of smooth muscle cells as in intimal hyperplasia. NO inhibits the release of ET-1 in the aorta (Boulanger and Lusher 1990). It has been shown that HUVEC released ET-1 at a low shear stress level of $0.18 \mathrm{~Pa}$, 
whereas shear stress between 0.6-2.5 $\mathrm{Pa}$ for periods of longer than 6 hours inhibited ET-1 release (Kuchan and Frangos 1993). Also down regulation of ET-1 mRNA was seen at shear stress of $1.5 \mathrm{~Pa}$. The decline was evident 1 hour after the onset of flow and completed after 2 hours (Malek and Izumo 1992). It has been hypothesised that shear stress might influence ET-1 synthesis and release via Factin fibres in the endothelial membrane or even via the whole cytoskeleton (Morita et al. 1993)

\subsubsection{Cell-signalling}

It has been stated that the shear stress distribution on the endothelial cell surface depends not only on the velocity profile of adjacent fluid but also on the local threedimensional geometry of the cell surface. The latter could be responsible for the observed heterogeneities in a number of flow induced endothelial biological responses, including oscillations in intracellulair calcium both in vivo and vitro, inhibition of endothelial cells in vitro or the expression of adhesion molecules. This leads to the conclusion that the responses are specifically flow related and very local regulatory mechanisms are responsible for the differences (Davies et al. 1997).

Moreover, flow sensors are linked to the intracellular cytoskeleton that concentrate the stresses into and throughout the cell body (Wang et al. 1993). Davies et al. proposed that some aspects of shear stress mediated signalling in the endothelium could be located at focal adhesion sites, thereby transferring the stress forces through the cytoskeleton (Davies et al. 1997). These sites are regions of anchorage to the extracellular matrix. At these focal adhesion sites, a series of molecules provides direct structural communication between the cytoskeleton and the extracellular matrix through transmembrane proteins of the integrin family, allowing both inside and outside signalling between the cell and its matrices

However, besides the shear stress cytoskeleton relationship, also labile chemicals at the cell boundary layer may activate endothelial flow responses independently of physical displacement of the cell (Davies 1995). 
As has already been stated there is evidence for involvement of $\mathrm{K}^{+}$ion channels in the endothelial membrane, while also indirect evidence for G-protein involvement has been found (Ohno et al. 1993). Both studies indicate the direct involvement of the cell membrane.

\title{
2.5 Wall shear stress and gene regulation
}

Wall shear stress can affect the genetic program of the endothelial cell (table 2-2). For example, shear stress is able to interfere with the physiological cell death signal transduction involving a protease family (Dimmeler et al. 1996).

\author{
Table 2-2 \\ Known effects of shear stress on gene regulation.
}

\begin{tabular}{|c|c|c|c|}
\hline Gene & mRNA levels & Time scale & Ref \\
\hline $\mathrm{TPa}$ & large increase & $24 h$ & (Diamond et al. 1989) \\
\hline \multirow[t]{3}{*}{ ET-1 } & large decrease & $24 \mathrm{~h}$ & (Kuchan and Frangos \\
\hline & & & 1993, Sharefkin et al. \\
\hline & & & 1991) \\
\hline PDGF A & ten fold increase & $2-4 \mathrm{~h}(1.6 \mathrm{~Pa})$ & (Hsieh et al. 1991) \\
\hline PDGF B & two to three fold & $2-4 h(1.6 \mathrm{~Pa})$ & \\
\hline & increase & & \\
\hline ET-1 & increase & $24 \mathrm{~h}(2.5 \mathrm{~Pa})$ & \\
\hline c-fos & large increase & $24 \mathrm{~h}(2.5 \mathrm{~Pa})$ & (Hsieh et al. 1991) \\
\hline
\end{tabular}

\subsection{Wall shear stress and vessel wall remodelling}

The term remodelling is used for a broad spectrum of geometrical and structural alterations of the blood vessel, including flow induced changes in vascular structure 
and restenosis (Dzau and Gibbons 1993). The most obvious vascular remodelling process occurs during embryonal development in vasculogenesis (de novo formation of vessels) and angiogenesis (elaboration of vessels from pre-existing vasculature). After birth, remodelling continues as the diameter of the large and medium vessels in the arterial tree gradually increases with age (Baskett et al. 1990, Kawasaki et al. 1987, Leroyd and Taylor 1966). Although the vascular system is considered as a stable system, there are indications that the circulatory system is able to remodel structures in a surprisingly short time frame, i.e., within seconds (Kaiser et al. 1986), if vasodilatation is also considered as a remodelling process. It is very likely that mean wall shear stress is regulated through arterial diameter changes. (Glagov et al. 1987, Kamiya et al. 1984)

\subsubsection{Acute remodelling of the vessel wall by shear stress}

Acute alterations of wall shear stress affect the endothelial cell at both the cellular and the ultrastructural level and result in rapid remodelling of these cells (Nerem et al. 1993). At the intracellular level F-actin exhibits profound redistribution when shear stress is altered in vivo (Kim et al. 1989) or in vitro (Dewey et al. 1981, Sato et al. 1987). However, in vivo it is not clear which levels of shear stress are responsible for the alteration in F-actin distribution. An intriguing observation is that remodelling of endothelial cells in response to a decreased flow also involves loss of endothelial cells, while an increased flow induces proliferation of these cells (Langille et al. 1989). Whether shear rate or shear stress is responsible is unknown. In accordance, atrophy of the vascular supply to the corpus luteum during luteal regression also results in deletion of endothelial cells, suggesting that shear stress or shear rate might trigger apoptosis of endothelial cells (Azmi and O'Shea 1984). It is thus not clear whether the adaptations of the endothelial cell number precedes or follows diameter changes. It remains obscure whether shear stress and/or shear rate directly stimulates cell deletion or proliferation or whether these changes are secondary to changes in vessel luminal surface area to accommodate altered blood flow. 


\subsubsection{Wall shear stress and chronic remodelling}

The first observation that mature arteries are capable to remodel their diameter was probably made by Kamiya et al. in a dog model (Kamiya and Togawa 1980). In this study increased flow was induced by creating an anastomosis between the carotid artery and jugular vein. After 6 months it was observed that arterial wall shear stress was restored to its initial level of $1.5 \mathrm{~Pa}$ via diameter enlargement. Afterwards many vessel wall adaptations have been described. Zarins et al. reported an $84 \%$ increase in medial cross-sectional area of iliac arteries in cynomolgus monkeys after the flow was increased to tenfold for 6 months. Gired et al. have studied the radial artery in hemodialysis patients and found that at the non-arteriovenous side the internal diameter increased to normalise shear stress (Girerd et al. 1995). Langille et al. observed that when flow is altered, the artery first shows vasomotion, i.e., periodical dilation of the vessel, where after remodelling of the vessel wall media occurs (Langille et al. 1989). In addition, chronic adaptations to a decreased volume flow proceed more rapidly than responses to an increased volume flow (Langille and O'Donnel 1986), although it is unclear which mechanism is responsible for these phenomena.

The vessel wall adaptations are endothelium dependent (Kaiser et al. 1986, Pohl et al. 1986, Smiesko et al. 1985) in which several vasoactive substances are involved. In chronic vasoconstriction as well as chronic vasodilatation fundamental changes in arterial wall thickness, matrix composition, and organisation of the arterial wall occur (Zarins 1989). It is presently still unclear how intimal and medial reorganisation of extracellular matrix and smooth muscle cells (SMC) is mediated by the endothelium. Moreover, changes in tensile stress of the endothelium and SMC can lead to altered synthesis and production of collagen, elastin and connective proteases (Sumpio et al. 1987).

It can be concluded that in acute and chronic arterial remodelling a sequence of events occurs in response to an acute or chronic change of shear stress/flow, confirming a close relation of (local) hemodynamics and arterial wall mechanics and metabolic functions. 


\subsection{Wall shear stress and vessel wall pathology}

\subsubsection{Intimal hyperplasia}

Many investigations have shown that wall shear stress is strongly associated with the development of intimal hyperplasia. This disorder is an uncontrolled proliferation of vascular smooth muscle cells (VSMC's) causing inhibition and eventually obstruction of flow. This frequently occurs in $30-40 \%$ of the cases, after Percutaneous Transluminal Coronair Angiography (PTCA), after coronary bypass grafting (25\% of the cases), in autologous venous as well as in polytetrafluroethane (PTFE) peripheral bypasses (25\% of the cases), and in AV-fistulas created for hemodialysis (50\% of the cases) (Hofstra et al. 1995). Data contradict whether high (Hofstra et al. 1995) or low shear stress (Kraiss et al. 1991, Porter et al. 1996) is associated with the initiation of intimal hyperplasia. Vasoactive substances as NO, PDGF, bFGF, TGF and tPA (Davies 1995) could affect proliferation of SMC. Ohno et al. found that increased laminar shear stress induces the expression and secretion of transforming growth factor- $\beta 1$ (TGF- $\beta 1$ ), which is a growth inhibitor of VSMC's (Ohno et al. 1995). The precise role of wall shear stress in relation to intimal hyperplasia remains unclear.

\subsubsection{Atherosclerosis}

Atherosclerosis is a disease of the vascular vessel wall of large and medium sized arteries, manifested by alterations, like fatty streaks, atheromas or plaques in the intima and media of the arterial wall. Fully developed plaques accumulate smooth muscle cells, macrophages, intra- and extracellular lipids in several physical and chemical states, interstitial macromolecules including collagen and elastin fibres, glycoaminoglygans and fibrin and calcium deposits (Glagov et al. 1992). The disease involves complex cascades of interactions of endothelial and smooth muscle cells, monocytes and platelets and plasma proteins (LDL). A prominent feature of atherosclerosis is that plaque depositions tend to be focal, with predominant localisation at arterial branch points and bifurcations. Arteries such as 
the carotid and coronary arteries and those of the lower extremity are particular prone to plaque formation while others, such as those of the upper extremity, are rarely affected. Both the focal and selective distribution of plaques has been attributed to local differences in hemodynamic conditions, with wall shear stress as the important factor. Indeed research has shown an analogy between spatial variability of shear stress and the focal nature of atherosclerosis (Caro et al. 1971, Friedman et al. 1981, Fry 1968, Fry 1969a, Ling et al. 1968, Zarins et al. 1983).

\subsection{Conclusion}

It is clear that wall shear stress plays an important role in vascular wall homeostasis via its target cell: the endothelial cell. To understand the role of wall shear stress in the natural history of vascular diseases such as intimal hyperplasia and atherosclerosis, including the localisation pattern, the role of wall shear stress has to be studied in vivo without disturbing local hemodynamics and, if possible, supported by biochemical studies. Moreover, it can be of great value to study the level and behaviour of wall shear stress under circumstances highly related to atherosclerosis, such as ageing and smoking and diseases like diabetes, hypertension, hypercystinemia and end stage renal failure.

\section{Abbreviations used in table 2-1}

$B A E C$, bovine aortic endothelial cells; BPAEC, bovine pulmonary aortic endothelial cells; HUVEC, human umbilical endothelial cells; EC, endothelial cells; EDRF, endothelium derived relaxing factor; ICAM-1, intercellular adhesion molecule-1; LDL, low density lipoproteins; NO, nitric oxide; Pa, Pascal; PAl-1, plasminogen activator inhibitor-1; PAEC, porcine endothelial cells; $P D G F_{A}, P D G F_{B}$, platelet derived growth factor $A$ and $B$ chains; $\mathrm{PGI}_{2}$, Prostaglandin $\mathrm{I}_{2}$; SMC, smooth muscle cells; VCAM-1, vascular cellular adhesion molecule-1.

Data are derived from literature until December 2000. 


\begin{tabular}{|c|c|c|c|c|}
\hline Shear stress (Pa) & Effect & Cell type + response time & Signifiance & Reference \\
\hline $\begin{array}{l}0.02-1.65 \\
\text { (laminar) }\end{array}$ & $\mathrm{K}^{+}$channel activation & BAEC; $\mathrm{ms}$ & $\begin{array}{l}\text { fast resonse; related to } \\
\text { vasorelxation }\end{array}$ & (Olesen et al. 1988) \\
\hline $1-12$ & hyperpolarisation & BPAEC; steady state $60 \mathrm{~s}$ & $\begin{array}{l}\text { fast resonse; related to } \\
\text { vasorelxation }\end{array}$ & (Nakache and Gaub 1988) \\
\hline 0.8 & fifty fold increase NO & BAEC; $s$ & flow meliated relaxation & $\begin{array}{l}\text { (Frangos and Kuchan } \\
\text { 1991) }\end{array}$ \\
\hline 1.5 & $\begin{array}{l}\text { two fold increase e NOS } \\
\text { mRNA }\end{array}$ & BAEC & releasevO & (Nishida et al. 1992) \\
\hline $0.05-1.34$ & $\begin{array}{l}\text { release ATP, acetylcholine } \\
\text { \& substance P }\end{array}$ & BAEC & modulaon of ionic balance & (Ziegelstein et al. 1992) \\
\hline 3-6 $\mathrm{Pa}$ & transient elevation of $\mathrm{IP}_{3}$ & $\begin{array}{l}\text { BAEC; HUVEC; biphasic; } \\
\text { major peak at } 5 \text { min; } 15-30 \text { s }\end{array}$ & $\begin{array}{l}\text { phosphinositides and } \mathrm{Ca}^{2+} \\
\text { as secod messengers for } \\
\text { shear s'ess transduction }\end{array}$ & (Geiger et al. 1992) \\
\hline $0.0 .45 \mathrm{~Pa}$ & $\begin{array}{l}\text { intracellular } \mathrm{Ca}^{2+} \text { rise, } \mathrm{Ca}^{2+} \\
\text { oscillations }\end{array}$ & BAEC; $14-40 \mathrm{~s}$ & & (Shen et al. 1992) \\
\hline $1 \mathrm{~Pa}$ (pulsatile) & pulsed $P G l_{2}$ release & HUVEC; $<60 \mathrm{~s}$ & $\begin{array}{l}\mathrm{PGl}_{2} \text { reulation of vascular } \\
\text { tone; arithrombotic } \\
\text { propertis }\end{array}$ & (Frangos et al. 1985) \\
\hline $1 \mathrm{~Pa}$ & $\begin{array}{l}\text { induction of c-myc } \\
\text { expression }\end{array}$ & BAEC; $\min$ & early gowth response & (Hsieh et al. 1991) \\
\hline
\end{tabular}




\begin{tabular}{|c|c|c|c|c|}
\hline Shear stress (Pa) & Effect & Cell type + response time & Significance & Reference \\
\hline $1 \mathrm{~Pa}$ & $\begin{array}{l}\text { direct remodelling of focal } \\
\text { adhesion sites, realignment } \\
\text { with flow }\end{array}$ & BAEC; $\min$ & $\begin{array}{l}\text { cell attachment sites as } \\
\text { transmitters and/or } \\
\text { transducers of stress }\end{array}$ & (Robotewskyj et al. 1991) \\
\hline $0-5.1 \mathrm{~Pa}$ & $\begin{array}{l}\text { tenfold enhancement of } \\
\text { PDGF } F_{A} \text { mRA; } 2-3 \text { fold } \\
\text { increase of PDGF } \\
\text { expression }\end{array}$ & HUVEC; BAEC & $\begin{array}{l}\text { enhanced mitogen } \\
\text { secretio;; regulation of } \\
\text { SMC grswth; identification } \\
\text { of shear stress response } \\
\text { element of PDGF promotor }\end{array}$ & $\begin{array}{l}\text { (Hsieh et al. 1991, Hsieh et } \\
\text { al. 1992, Resnick et al. } \\
\text { 1993) }\end{array}$ \\
\hline $1 \mathrm{~Pa}$ & induction of C-fos & BAEC; $2 \mathrm{~h}$ & growth tэsponse genes & (Hsieh et al. 1991) \\
\hline$>1 \mathrm{~Pa}$ & $\begin{array}{l}\text { induction of protein kinase } \\
\text { C }\end{array}$ & BAEC; $>3 \mathrm{~h}$ & $\begin{array}{l}\text { regulaticn of protein, } \\
\text { phosphçrolysation }\end{array}$ & (Girard and Nerem 1990) \\
\hline 0.0.5 Pa (pulsatile) & $\begin{array}{l}\text { endotheline mRNA and } \\
\text { protein secretion both } \\
\text { stimulated and down } \\
\text { regulated }\end{array}$ & PAEC; peak at 2-4h & $\begin{array}{l}\text { regulaticn of } \\
\text { vasocorstriction }\end{array}$ & (Yoshizumi et al. 1989) \\
\hline $1.5 \& 2.5 \mathrm{~Pa}$ & $\begin{array}{l}\text { tPa mRNA expression and } \\
\text { secretion stimulated and } \\
\text { inhibited }\end{array}$ & HUVEC; $5 \mathrm{~h}$ & $\begin{array}{l}\text { enhancement of fibrinolytic } \\
\text { activity }\end{array}$ & (Diamond et al. 1989) \\
\hline $1.5 \& 2.5 \mathrm{~Pa}$ & $\begin{array}{l}\text { PAI-1 mRNA expression } \\
\text { and secretion elevated }\end{array}$ & HUVEC; ? & antagon $_{\text {ses }} \mathrm{tPa}$ effects & (Diamond et al. 1990) \\
\hline$>0.5 \mathrm{~Pa}$ (in vivo) & $\begin{array}{l}\text { cytoskeleton and fibrectin } \\
\text { rearrangement }\end{array}$ & all types; $>6 \mathrm{~h}$ & $\begin{array}{l}\text { associabd with cell } \\
\text { alignme }_{h t}\end{array}$ & $\begin{array}{l}\text { (Dewey et al. 1981, Franke } \\
\text { et al. 1984) }\end{array}$ \\
\hline
\end{tabular}




\begin{tabular}{|c|c|c|c|c|}
\hline Shear stress (Pa) & Effect & Cell type + response time & Significance & Reference \\
\hline$>0.5 \mathrm{~Pa}$ & $\begin{array}{l}\text { cell alignment in direction } \\
\text { of flow }\end{array}$ & all types; $>6 \mathrm{~h}$ & minimises drag on cell & $\begin{array}{l}\text { (Franke et al. 1984, Nagel } \\
\text { et al. 1994) }\end{array}$ \\
\hline $0.1 \mathrm{~Pa}$ & ICAM-1 upregulation & adhesion of leukocytes & & (Nagel et al. 1994) \\
\hline $0.01-2 \mathrm{~Pa}$ & $\begin{array}{l}\text { increases hydraulic } \\
\text { conductivity }\end{array}$ & BAEC & effect on EC metabolism & (Sill et al. 1995) \\
\hline 0-6.2 Pa; & histamine content and & BAEC; $1.5 \mathrm{~h}$ & modulation of endothelial & \\
\hline $\begin{array}{l}\text { Oscillatory SS: } \\
0.16-0.82 \mathrm{~Pa}\end{array}$ & $\begin{array}{l}\text { histamine decarboxylase } \\
\text { activity stimulated }\end{array}$ & BAEC; $>6 h$ & permeability barrier & $\begin{array}{l}\text { (Rosen et al. 1974, } \\
\text { Skarlatos and Hollis 1987) }\end{array}$ \\
\hline $1-8.5 \mathrm{~Pa}$ & $\begin{array}{l}\text { mechanical stiffness of cell } \\
\text { surface proportional to } \\
\text { realignment to flow }\end{array}$ & BAEC; $24 \mathrm{~h}$ & $\begin{array}{l}\text { decreased deformability of } \\
\text { subplasma membrane } \\
\text { cortical complex }\end{array}$ & (Sato et al. 1987) \\
\hline 3-6 $\mathrm{Pa}$ & LDL metabolism stimulated & BAEC; $24 \mathrm{~h}$ & $\begin{array}{l}\text { endothelial cholesterol } \\
\text { halance }\end{array}$ & (Sprague et al. 1987) \\
\hline $0-2.5 \mathrm{~Pa}$ (pulsatile) & release $\mathrm{PGl}_{2}$ & HUVEC; 0-8h & vasodilatation & (Nollert et al. 1989) \\
\hline $0.09-1.4 \mathrm{~Pa}$ & release $\mathrm{PGl}_{2}$ & HUVEC; 0-20 min & vasodilatation & (Grabowski et al. 1985) \\
\hline $0-2.5 \mathrm{~Pa}$ & release EDRF (NO) & HUVEC; 0-15min & vasodilatation & $\begin{array}{l}\text { (Kuchan and Frangos } \\
1994)\end{array}$ \\
\hline 2.6 Pa & decrease $\|-6$ & HAEC; $0-24 h$ & inflammation & (Jirik et al. 1989) \\
\hline $0.2 \mathrm{~Pa}$ & $\begin{array}{l}\text { VCAM-1 expression via } \\
\text { NF-kappaB }\end{array}$ & HAEC; 6 h & $\begin{array}{l}\text { inducing transcriptional } \\
\text { regulator in inflammation }\end{array}$ & (Mohan et al. 1999) \\
\hline
\end{tabular}




\begin{tabular}{|c|c|c|c|c|}
\hline Shear stress (Pa) & Effect & Cell type + response time & Significance & Reference \\
\hline $\begin{array}{l}0.57 \pm 0.1 \mathrm{~Pa} \text { (in } \\
\text { vivo) } \\
<1.6 \pm 0.1 \mathrm{~Pa}\end{array}$ & $\begin{array}{l}\text { increase of eNOS mRNA } \\
\text { and SOD mRNA } \\
\text { no effect }\end{array}$ & coronary arterioles & $\begin{array}{l}\text { a threshold level for shear } \\
\text { stress is needed to induce } \\
\text { vasodilatation }\end{array}$ & (Woodman et al. 1999) \\
\hline laminar $3 \mathrm{~Pa}$ & $\begin{array}{l}\text { induce expression (GRO) } \\
\text { mRNA and protein } \\
\text { expression }\end{array}$ & BAEC; $4 \mathrm{~h}$ & $\begin{array}{l}\text { enhancement of monocyte } \\
\text { adhesion on EC via the } \\
\text { GRO protein }\end{array}$ & (Hagiwara et al. 1998) \\
\hline $1.5 \mathrm{~Pa}$ & activation of Akt kinase & HUVEC; $1 \mathrm{~h}$ & $\begin{array}{l}\text { inhibition of apoptosis of } \\
\text { endothelial cell }\end{array}$ & (Dimmeler et al. 1998) \\
\hline $0.5 \mathrm{~Pa}$ & Elk-1 activation & HAEC; $3 \mathrm{~h}$ & $\begin{array}{l}\text { activation of Egr-1 } \\
\text { (transcription factor) }\end{array}$ & (Schwachtgen et al. 1998) \\
\hline $1.5 \mathrm{~Pa}$ & $\begin{array}{l}\text { inhibition of } \mathrm{H}_{2} \mathrm{O}_{2} \text {-induced } \\
\text { apoptosis }\end{array}$ & HUVEC; $18 \mathrm{~h}$ & inhibition of apoptosis & (Hermann et al. 1997) \\
\hline $0.2-1.2 \mathrm{~Pa}$ & $\begin{array}{l}\text { modulation of von } \\
\text { Willebrand factor }\end{array}$ & HUVEC; & $\begin{array}{l}\text { modulation of arterial } \\
\text { thrombotic events }\end{array}$ & (Galbusera et al. 1997) \\
\hline $2 \mathrm{~Pa}$ & $\begin{array}{l}\text { long term decreased ACE } \\
\text { short term }(2 h) \text { increased } \\
\text { ACE }\end{array}$ & BPAE; $18 \mathrm{~h}$ & $\begin{array}{l}\text { shear stress may play a } \\
\text { role in hypertension via } \\
\text { suppressing ACE gene and } \\
\text { protein expression }\end{array}$ & (Rieder et al. 1997) \\
\hline $1.2 \mathrm{~Pa}$ & $\begin{array}{l}\text { activation of ERK1/2 } \\
\text { protein kinase }\end{array}$ & HUVEC & $\begin{array}{l}\text { mitogen activation by shear } \\
\text { stress }\end{array}$ & (Takahashi and Berk 1996) \\
\hline $1.5 \mathrm{~Pa}$ & $\begin{array}{l}\text { upregulation of junction } \\
\text { protein complexes }\end{array}$ & PAEC; $0,8.5,24,48 \mathrm{~h}$ & $\begin{array}{l}\text { implications for endothelial } \\
\text { permeability barrier }\end{array}$ & (Noria et al. 1999) \\
\hline
\end{tabular}




\subsection{References}

Anayiotos AS, Jones SA, Giddens DP, Glagov S, Zarins CK. Shear stress at a compliant model of the human carotid bifurcation. J Biomech Eng 1994;116:98-106.

Azmi TI, O'Shea JD. Mechanism of deletion of endothelial cells during regression of the corpus luteum. Lab Invest 1984;51:206-217.

Baskett JJ, Lewis RR, Beasley MG, Gosling RG. Changes in carotid artery compliance with age. Age and Ageing 1990;19:214-246.

Bots ML, Hofman A, de Jong PTVM, D.E. G. Common carotid intima-media thickness as an indicator of atherosclerosis at other sites of the carotid artery. The Rotterdam study. Ann Epidemiol 1996;6:147-153.

Boulanger C, Lusher TF. Release of endothelin from the porcine aorta: inhibition by endothelium-derived nitric oxide. J Clin Invest 1990;85:587-590.

Buga GM, Gold ME, Fukuto JM, Ignarro JL. Shear stress-induced release of niitric oxide from endothelial cells grown on beds. Hypertension Dallas 1991;17:187-1993.

Caro CG, Fitzgerald JM, Schroter RC. Atheroma and arterial wall shear: observation, correlation and proposal of a shear dependent mass transfer mechanism for atherogenesis. Proc Roy Soc London 1971;17B:105-159.

Chien S, Usami S, Taylor M, Lundberg JL, Gregerson MI. Effects of hematocrit and plasma proteins on human blood rheology at low shear rates. J Appl Physiol 1966;21:81-87.

Cooke JP, Stamler JS, Andon N, Davies PR, Loscalzo J. Flow stimulates endothelial cells to release a nitrovasodilator that is potentiated by reduced thiol. Am J Physiol 1990;28. 
Davies F. Flow-mediated endothelial mechanotransduction. Physiol Rev 1995;75 (3):519-560.

Davies PF, Barbee KA, Volin MV, Robotewskyj A, Chen J, Joseph L, Griem ML, Wernick MN, Jacobs, E., Polacek DC, DePaola N, Barakat AI. Spatial relationships in early signaling events of flow-mediated endothelial mechanotransduction. Annu Rev Physiol 1997;59:527-549.

Dewey SL, Eskin SG, Mclntire LV. The dynamic response of vascular endothelial cells to fluid shear stress. J Biomech Eng 1981;103:177-185.

Diamond S, Eskin S, Mclntire L. Fluid flow stimulates tissue plasminogen activator socretion by cultured human ondothelial collo. Ocionco 1000;243:1403-1405.

Diamond SL, Sharefkin JB, Dieffenbach C, Frazier-Scott K, Mclntire LV. Tissue plasminogen activator mRNA levels increase in cultured human endothelial exposed to laminar shear stress. J Cell Physiol 1990;143:364-371.

Dimmeler S, Assmus B, Hermann C, Haendeler J, Zeiher AM. Fluid shear stress stimulates phosphorolysation of Akt in human endothelial cells: involvement in suppression of apoptosis. Circ Res 1998;83(3):334-341.

Dimmeler S, Haendeler J, Rippmann V, Nehls M, Zeiher AM. Shear stress inhibits apoptosis of human endothelial cells. Febs Letters 1996;399:71-4.

Dintenfass L. Rheology of blood in diagnostic and preventive medicine. London: Butterworths, 1976:203-233.

Dintenfass L. Blood viscosity, hyperviscosity and hyperviscosaemia. Boston: MTP Press, 1985. 
Dobrin PB. Mechanical factors associated with the development of intimal and medial thickening in vein grafts subjected to arterial pressure. Hypertension 1995;26:38-43.

Dull RO, Hogan RD, Langille BL, Lelkens P, Segal SS, Vatner SF, Weigelt $H$, Young MA. Flow modulation of agonist (ATP)-response $\left(\mathrm{Ca}^{2+}\right)$ coupling in vascular endothelial cells. Am J Physiol 1991;261:H149-H154.

Dzau VJ, Gibbons GH. Vascular remodeling: mechanisms and implications. J cardiovasc Pharmac 1993;21(suppl. 1):S1-S5.

Fox JA, Hugh AE. Localization of atheroma: a theory based on boundary layer separation. Br Heart J 1966;28:388-399.

Frangos JA, Eskin SG, Mcintire LV. Flow effects on prostacyclin production by cultured human endothelial cells. Science 1985;227:1477-1479.

Frangos JA, Kuchan MJ. Fluid flow activates G-proteins that are coupled to Cadependent EDRF production in cultured endothelial cells. FASEB J 1991;5 (Abstract):A1820.

Franke RP, Grafe M, Schinittler H, Seiffge D, Mittermayer C, Drenckhahn D. Induction of human vascular endothelial stress fibers by fluid shear stress. Nature 1984;307:648.

Friedman MH, Hutchins GM, Bargeron CB, Deters OJ, Mark FF. Correlation between intimal thickness and fluid shear in human arteries. Atherosclerosis 1981;39:425-436.

Fry DL. Acute vascular endothelial changes associated with increased blood velocity gradients. Circ. Res. 1968;22:165-197. 
Fry DL. Certain histological and chemical responses of the vascular interface to acutely induced mechanical stress in the aorta of the dog. Circ. Res. 1969a;24:93108.

Fujii K, Heistad DD, Faraci FM. Flow-mediated dilatation of the basilar artery in vivo. Circ Res 1991;69:697-705.

Furchott RF, Zawadski JV. The obligatory role of endothelial cells in the relaxation of arterial smooth muscle by acetylcholine. Nature 1980;288:373-376.

Galbusera M, Zoja C, Donadelli R, Paris S, Morigi M, Benigni A, Figliuzzi M, Remuzzi G, Remuzzi A. Fluid shear stress modulates von Willebrand factor release from human vascular endothelium. Blood 1997;90(4):1558-1564.

Geiger RV, Berk BC, Alexander RW, Nerem RM. Flow induced calcium transients in single endothelial cells: spatial and temporal analysis. Am $\mathrm{J}$ Physiol 1992;262:C1411-C1417.

Girard PR, Nerem RM. Role of protein kinase C in the transduction of shear stress to alterations of endothelial cell morphology. J Cell Biochem 1990;14E:210.

Girerd X, London G, Boutouyrie P, Mourad J, Safar M, Laurent S. Remodeling of the radial artery in respons to a chronic increase in shear stress. Hypertension 1995;27 [part 2]:799-803.

Glagov S, Vito R, Giddens DP, Zarins CK. Micro-architecture and composition of artery walls: relationship to location, diameter and the distribution of mechanical stress. J Hypertension 1992;10 (suppl 6):S101-S104.

Glagov S, Weisenberg E, Zarins CK, Stankunavicius R, Kolettis G. Compensatory enlargement of human atherosclerotic coronary arteries. $N$ Engl $\mathrm{J}$ Med 1987;316:1371-1375. 
Grabowski EF, Jaffe EA, Weksler BB. Prostacyclin production by cultured endothelial cell monolayers exposed to step increases in shear stress. J Lab Clin Med 1985;105:36-43.

Guyton JR, Hartley CJ. Flow restriction of one carotid artery in juvenile rats inhibits growth of arterial diameter. Am J Physiol 1985;256:H540-H546.

Hagiwara H, Mitsumata M, Yamane T, Jin X, Yoshida Y. Laminar shear stress induced GRO mRNA and protein expression in endothelial cells. Circulation 1998;98 (23):2584-2590.

Hermann C, Zeiher AM, Dimmeler S. Shear stress inhibits H2O2-induced apoptosis of human endothelial cells by modulation of the glutathione redox cycle and nitric oxide synthase. Arterioscler Thromb Vasc Viol 1997;17(12):3588-3592.

Hofstra L, Bergmans D, Leunissen K, Hoeks A, Kitslaar P, Daemen M, Tordoir J. Anastomotic intimal hyperplasia in prosthetic arteriovenous fistulas for hemodialysis is associated with initial high flow velocity and not with mismatch in elastic properties. J Am Soc Nephrol 1995;6:1625-1633.

Hsieh HJ, Li NG, Frangos JA. Pulsatile and steady flows increase protooncogenes c-fos and c-myc mRNA levels in human endothelial cells. FASEB J 1991;5:A1820 (Abstract).

Hsieh HJ, Li NQ, Frangos JA. Shear stress increases endothelial platelet derived growth factor mRNA levels. Am J Physiol 1991;260:H642-H646.

Hsieh HJ, Li NQ, Frangos JA. Shear-induced platelet derived growth factor gene expression in human endothelial cells is mediated by protein kinase C. J Cell Physiol 1992;150:552-558.

Hunter. Diameter dependent increase of flow?? Medical Observations and Inquiries $1761 ; X X X V I$. 
Jirik FR, Podor TJ, Hirano T, Kishimoto T, Loskutoff DJ, Carson DA, Lotz M. Bacterial lipolysaccharide and inflammatory mediators augments II-6 secretion by human endothelial cells. Am J Physiol 1989;260:H1992-H1996.

Kaiser L, Hull SJ, Sparks HVJ. Methylene blue and EDTY block flow dependent dilation in canine femoral artery. Am J Physiol 1986;250:H974-H981.

Kamiya A, Bukhari R, Togawa T. Adaptive regulation of wall shear stress optimizing vascular tree function. Bulletin Math Biol 1984;46:127-137.

Kamiya A, Togawa T. Adaptive regulation of wall shear stress to flow change in the canine carotid artery. Am J Physiol 1980;239:H14-H21.

Kawasaki T, Sasayama S, Yagi S, Asakawa T, Hirai T. Non-invasive assessment of the age related changes in stiffness of major branches of the human arteries. Cardiovasc Res 1987;21:678-687.

Kim D, Gotlieb Al, Langille BL. In vivo modulation of endothelial F-actin microfilaments by experimental alterations in shear stress. Arteriosclerosis 1989;9:439-445.

Koller A, Sun D, Kaley G. Role of shear stress and endothelial prostaglandins in flow- and viscosity-induced dilation of arterioles in vitro. Circ Res 1993;72:12761284.

Koller AS, Huang A. Impaired nitric oxide-mediated flow induced dilation in arterioles of spontaneously hypertensive rats. Circ Res 1994;74:416-421.

Komuro I, Kurihara H, Sugiyama HT, Yoshizumi M, Takaku F, Yazaki Y. Endothelin stimulates c-fos and c-myc expression and proliferation of vascular smooth muscle cells. FEBS Lett 1988;238:249-252. 
Kraiss LW, Kirkman TR, Kohler TR, Zierler B, Clowes AW. Shear stress regulates smooth muscle proliferation and neointimal thickening in porous polytetrafluoroethylene grafts. Arteriosclerosis and thrombosis 1991;11:1844-1852.

Ku D, Giddens D, Zarins C, Glagov S. Pulsatile flow and atherosclerosis in the human carotid bifurcation. Arteriosclerosis 1985;5:293-302.

Kuchan MJ, Frangos JA. Shear stress regulates Endothelin-1 release via Protein Kinase C and cGMP in cultured endothelial cells. Am J Physiol 1993;264:H150H156.

Kuchan MJ, Frangos JA. Role of calcium and calmodulin in flow induced nitric oxide production in endothelial cells. Am J Physiol 1994;266:C628-C636.

Kuo L, Davis MJ, Cannon MS, Chilian WM. Pathophysiological consequences of atherosclerosis extends into the microcirculation. Restoration of endothelium dependent responses by L-arginine. Circ Res 1992;70:465-476.

LaBarbera M. Principles of design of fluid transport systems in zoology. Science 1990;249:992-1000.

Langille BL, Bendeck MP. Keeley FW. Adaptations of carotid arteries of young and mature rabbits to reduced carotid blood flow. Am J Physiol 1989;256:H931-H939.

Langille BL, O'Donnel F. Reductions in arterial diameter produced by chronic decreases in blood flow are endothelium-dependent. Science 1986;231:405-407.

Leroyd BM, Taylor MG. Alterations with age in the viscoelastic properties of human arterial walls. Circ. Res. 1966;18:278-291.

Lie M, Sejersted OM, Kill F. Local regulation of vascular cross section during changes in femoral arterial blood flow in dogs. Circ Res 1970;27:727-737. 
Ling S, Atabek H, Fry D, Patel D, Janicki B. Application of heated-film velocity and shear probes to heamodynamic studies. Circ Res 1968;66:1624-1635.

Lopez-Jaramillo P, Gonzalez MC, Palmer RM, Moncada S. The crucial role of physiological calcium concentrations in the production of endothelial nitric oxide and the control of vascular tone. Br J Pharmacol 1990;101:489-493.

Malek A, Izumo S. Physiogical shear stress causes downregulation of endotheline-1 mRNA in bovine aortic endothelium. Am J Physiol 1992;32:C392-C396.

Malek AM, Izumo S. Molecular aspects of signal transduction of shear stress in the endothelial cell. J Hypert 1994;12:989-999.

Mohan S, Mohan N, Valente AJ, Sprague EA. Regulation of low shear flow-induced HAEC VCAM-1 expression and monocyte adhesion. Am J Physiol 1999;276(5 pt 1):C1100-1107.

Moncada S, Palmer RM, Higgs EA. Nitric oxide: physiology, pathophysiology and pharmacology of nitric oxide. Pharmacol Rev 1991;43:109-142.

Morita T, Kurihara H, Maemura K, Yoshizumi M, Yazaki Y. Disruption of cytoskeletal structures mediates shear stress-induced endothelin-1 gene expression in cultured porcine aortic endothelial cells. J Clin Invest 1993;92:1706-1712.

Murad F. Cyclic guanosine monophosphate as a mediator of vasodilation. $\mathrm{J}$ Clin Invest 1986;78:1-5.

Murray $C D$. The physiological principle of minimum work. 1. The vascular system and the cost of blood volume. Proc Natl Acad Sci USA 1926;12:207-214.

Nagel T, Resnick N, Atkinson WJ, Forbes Dewey C, Gimbrone MA. Shear stress selectively upregulates intercellular adhesion molecule-1 expression in cultured human vascular endothelial cells. J Clin Invest 1994;94. 
Nakache M, Gaub HE. Hydrodynamic hyperpolarisation of endothelial cells. Proc Nat Acad USA 1988;85:1841-1843.

Nerem RM. Atherosclerosis and the role of wall shear stress. In: Bevan JA, Kaley G, Rubanyi GM, eds. Flow-dependent regulation of vascular function. New York: Oxford University Press, 1995:300-319.

Nerem RM, Girard PR. Hemodynamic influences on vascular endothelial biology. Tox Path 1990;18:572-582.

Nerem RM, Harrison DG, Taylor WR, Alexander RW. Hemodynamics and vascular endothelial biology. J Cardiovasc Pharmacol 1993;21(Suppl.1):S6-S10.

Nichols WW, O'Rourke MF. The nature of flow of a fluid. In: Nichols WW, O'Rourke MF, eds. McDonald's blood flow in arteries. London: Edward Arnold, 1990:12-53.

Nishida K, Harrison DG, Navas JP, Fisher AA, Dockery SP, Uematsu M, Nerem RM, Alexander RW, Murphy TJ. Molecular cloning and characterization of the constitutive bovine aortic endothelial cell nitric oxide synthase. J Clin Invest 1992;90:2092-2096.

Nollert MU, Hall ER, Eskin SG, Mclntire LV. The effect of shear stress on the uptake and metabolism of arachidonic acid by human endothelial cells. Biochem Biophys Acta 1989;1005:72-78.

Noria S, Cowan DB, Gotlieb AI, Langille BL. Transient and steady-state effects of shear stress on endothelial cell adherens junctions. Circ Res 1999;856:504-514.

Ohno M, Cooke JP, Dzau VJ, Gibbons GH. Fluid shear stress induces endothelial TGF-beta1 transcription and production: modulation by potassium channel blockade. J Clin Invest 1995; 4. 
Ohno M, Gibbons GH, Dzau V, Cooke JP. Shear stress elevates endothelial cell cGMP: Role of potassium channel and G-protein coupling. Circulation 1993;88:193197.

Olesen S, Clapham DE, Davies PF. Heamodynamic shear stress activates a $\mathrm{K}+$ current in vascular endothelial cells. Nature 1988;331:168-170.

O'Rourke M. Mechanical principles in arterial disease. Hypertension 1995;26:2-9.

Pohl U, Holtz J, Busse R, Bassenge E. Crucial role of endothelium in the vasodilator response to increased flow in vivo. Hypertension 1986;8:38-44.

Porter K, Nydahl S, Dunlop P, Varty K, Thrush A, London N. The development of an in vitro flow model of human saphenous vein graft intimal hyperplasia. Cardiovasc Res 1996;31:607-614.

Reneman RS, Van Merode T, Hick P, Hoeks APG. Flow velocity patterns in and distensibility of the carotid artery bulb in subjects of various ages. Circulation 1985;71:500-509.

Resnick N, Collins T, Atkinson W, Bonthron DT, Dewey CF, Gimbrone MA. Platelet derived growth factor $\mathrm{B}$ chain promoter contains a cis-acting fluid shear stressresponsive element. Proc Natl Acad Sci USA 1993;90:4591-4595.

Rieder MJ, Carmona R, Krieger JE, Pritchard KA, Greene AS. Suppression of angiotensin-converting enzyme expression and activity by shear stress. Circ Res 1997;80(3):312-319.

Robotewskyj A, Dull RO, Griem ML, Davies PF. Dynamics of focal adhesion site remodelling in living endothelial cells in respons to shear stress forces using confocal image analysis. FASEB J 1991;5:A527(Abstract). 
Rodbard S. Negative feedback mechanisms in the architecture and function of the connective and cardiovascular tissues. Perspect Biol Med 1970;13:507-527.

Rodbard S. Vascular Caliber. Cardiology 1975;60:4-49.

Rosen LA, Hollis TM, Sharma MG. Alterations in bovine endothelial histidine decarboxylase activity following exposure to shearing stresses. Exp Mol Pathol 1974;20:329-343.

Sato M, Levesque MJ, Nerem RM. Micropipette aspiration of cultured bovine aortic endothelial cells exposed to shear stress. Arteriosclerosis 1987;7:276-286.

Schretzenmayr A. Uber Kreislaufregulatorische vorgange an den grossen arterien bei der muskelarbeit. Pflugers Archiv Ges Physiol 1933;232:743-748.

Schwachtgen JL, Houston P, Campbell C, Sukatme V, Braddock M. Fluid shear stress activation of egr-1 transcription in cultured human endothelial and epithelial cells is mediated via the extracellular signal related kinase 1/2 mitogen activated protein kinase pathway. J Clin Invest 1998;101(11):2540-2549.

Sessa WC. The nitric oxide synthase family of proteins. J Vasc Res 1994;31:131134.

Sharefkin JB, Diamond SL, Eskin SG, Mcintire LV, Dieffenbach CW. Fluid flow decreases preproendothelin mRNA levels and suppresses endotheline-1 peptide release in cultured human endothelial cells. J Vasc Surg 1991;14:1-9.

Shen J, Luscinskas FW, Conolly A, Dewey CF, Gimbrone MA. Fluid shear stress modulates cytosolic free calcium in vascular endothelial cells. Am J Physiol 1992;262:c384. 
Sill HW, Chang YS, Artman JR, Frangos JA, Hollis TM, Tarbell JM. Shear stress increases hydraulic conductivity of cultured endothelial monolayers. Am J Physiol 1995;268 (2 Pt 2):H535-543.

Skarlatos SI, Hollis TM. Cultured bovine aortic endothelial cells show increased histamine metabolism when exposed to oscillatory shear stress. Atherosclerosis 1987;64:55-61.

Smiesko V, Kozik J, Dolezel S. Role of endothelium in the control of arterial diameter by blood flow. Blood Vessels 1985;22:247-251.

Sprague EA, Steinbach BL, Nerem RM, Schwartz CJ. Influence of a laminar steadystate fluid-imposed wall shear stress on the binding, internalization, and degradation of LDL by cultured arterial endothelium. Circulation 1987;76:648-656.

Stary HC. Natural history of atherosclerosis. In: Touboul PJ, Crouse JR, eds. Intima-media thickness and atherosclerosis: predicting the risk? Lancaster: The Parthenon Publishing Group, 1997:1-17.

Strandness DE, Sumner DS. Using physical concepts. Hemodynamics for surgeons. New York: Grune \& Stratton, Inc., 1975:3-20.

Sumpio BE, Banes AJ, Link GW, Iba T. Alterations in aortic endothelial cell morphology and cytoskeletal protein synthesis during cyclic tensional deformation. J Vasc Surg 1987;7:130-138.

Takagi Y, Fusake S, Takata S, Yoshimi H, Tokunaga O, Fuyita T. Autocrine effects of endothelin on DNA synthesis in human vascular endothelial cells. Biochem. Biophys. Res. commun. 1990;168:537-543.

Takahashi M, Berk BC. Mitogen-activated protein kinase (ERK 1/2) activation by shear stress and adhesion in endothelial cells. Essential role for a herbimycinsensitive kinase. J Clin Invest 1996;98(11):2623-2631. 
Thoma R. Histogenese und Histomechanik des Gefasssystems. Stuttgart: Enke, 1893.

Tohda K, Masuda H, Kawamura K, Shozawa T. Difference in dilatation between endothelium-preserved and -desquamated segments in the flow loaded rat common carotid artery. Arterioscler Thromb 1992;12:519-528.

Wang N, Butler JP, Ingber DE. Mechanotransduction across the cell surface and through the cytoskeleton. Science 1993;260:1124-1127.

Woodman CR, Muller JM, Rush JW, Laughlin MH, Price EM. Flow regulation of ecNOS and $\mathrm{Cu} / \mathrm{Zn}$ SOD mRNA expression in porcine coronary arterioles. Am J Physiol 1999;276 (3 Pt 2):H1058-H1063.

Yoshizumi M, Kurihara T, Sugiyama T, Takaku F, Yanagisawa M, Masaki T. Hemodynamic shear stress stimulates endothelin production by cultured endothelial cells. Biochem Biophys Res Comm 1989;161:859-864.

Zamir M. Shear forces and blood vessel radii in the cardiovascular system. J Gen Physiolol 1977;69:449-461.

Zarins CK. Adaptive responses of arteries. J Vasc Surg 1989;9:382-389.

Zarins CK, D.P. G, Bharavadj BK, Sottiurai VS, Mabon RF, Glagov S. Carotid bifurcation atherosclerosis: quantitive correlation of plaque localisation with flow profiles and wall shear stress. Circ Res 1983;53:502-504.

Ziegelstein RC, Cheng L, Capogrossi MC. Flow dependent cytosolic acidification of vascular endothelial cells. Science 1992;258:656-659. 
Chapter 3

\section{The Shear Rate Estimating System (SRES)}

\subsection{Basic principles of ultrasound}

\subsubsection{Pulsed ultrasound}

3.2 Assessment of blood flow velocity with pulsed ultrasound

3.3 The Shear Rate Estimating System (SRES)

3.3.1 Ultrasound signal acquisition

3.3.2 Off-line signal processing

3.3.3 Validation of the Shear Rate Estimation System

3.4 References 
Basic principles of ultrasound 


\subsection{Basic principles of ultrasound}

Ultrasound waves are pressure perturbations propagating through a medium with frequencies far beyond the hearing level. In transcutaneous medical ultrasound equipment sound waves with frequencies ranging from 2 to $10 \mathrm{MHz}$ are used. Ultrasound pressure waves are generated and received using a piezoelectric ceramic (transducer) that is able to convert electrical energy to mechanical energy and vice versa. The voltage signal generated by a received ultrasound pressure wave is termed the radiofrequency ( $\mathrm{ff})$ signal, because of its frequency $(2-10 \mathrm{MHz})$.

\subsubsection{Pulsed ultrasound}

Since a few decades pulsed ultrasound is applied in vascular investigations (Burns 1987) and is based on repetitive emission of short pulses of ultrasound and the subsequent reception of the reflected echoes originating from acoustic impedance transitions in the body. Processing of these echoes can be used to infer anatomical (qualitative) information, e.g., the presence of atherosclerotic plaques in blood vessels, as well as the assessment of functional (quantitative) information, e.g., blood flow velocity. The attractive feature of medical ultrasound lies in its ability to obtain real-time information non-invasively with little or no discomfort and no known hazard for the subject.

An ultrasound reflection occurs at transitions in acoustic impedance at interfaces larger than a few wavelengths $(\lambda)$. The wavelength is defined as

$$
\lambda=\frac{c}{f_{c}}
$$

where $c\left[\mathrm{~m} \cdot \mathrm{s}^{-1}\right]$ is the ultrasound velocity in the transmission medium and $f_{c}[\mathrm{~Hz}]$ the carrier frequency of the ultrasound waves. In soft biologic tissue, the average ultrasound velocity is $1540 \mathrm{~m} \cdot \mathrm{s}^{-1}$. This implies that for an $f_{c}$ of $6 \mathrm{MHz}$ the wavelength $(\lambda)$ is on the order of $250 \mu \mathrm{m}$. 
The amplitude of the reflected echo depends on the:

- amplitude of the emitted pulse

- type of tissue between the transducer and the reflector

- depth of the reflector with respect to the transducer

- relative change in acoustic impedance

- size of the acoustic layer with respect to the wavelength

- orientation of the boundary with respect to the direction of the ultrasound beam (the echo is maximal if the boundary is perpendicular to the ultrasound beam)

If all tissues between the transducer and the site of reflection have approximately the same ultrasound propagation speed then the time delay $\Delta t[\mathrm{~s}]$ between emission and reception is a measure of the distance $s[\mathrm{~m}]$ between the reflector and the transducer:

$$
s=\frac{c^{*} \Delta t}{2}
$$

The factor two in equation (3-2) is due to the fact that the ultrasound waves travel twice the distance from the transducer to the acoustic interface.

If an object is small compared to the wavelength, ultrasound waves will not be reflected in a single direction but will be scattered in all directions. In that case the amplitude of the recorded ultrasound signal is almost independent of the angle between the ultrasound beam and the scattering object. This is, for example, the case when pressure waves with frequencies in the medical application range encounter erythrocytes that have a diameter of 6 to $8 \mu \mathrm{m}$. The local amplitude together with the time-delay of the reflected or backscattered ultrasound signals give information about the type and position of the anatomic boundaries.

The time sequence of a pulsed ultrasound recording at one position is depicted in figure 3.1. Ultrasound pulses are emitted at a time interval of 1/PRF (figure 3.1b) (PRF stands for pulse repetition frequency). When an emitted pulse encounters the acoustic transitions $R_{1}$ and $R_{2}$ (figure 3.1a), an amplitude rise in the received radiofrequency (rf) signal (figure $3.1 \mathrm{c}$ ) at time delays $t_{1}=\frac{2 d_{1}}{c}$ and $t_{2}=\frac{2 d_{2}}{c}$ will occur. 


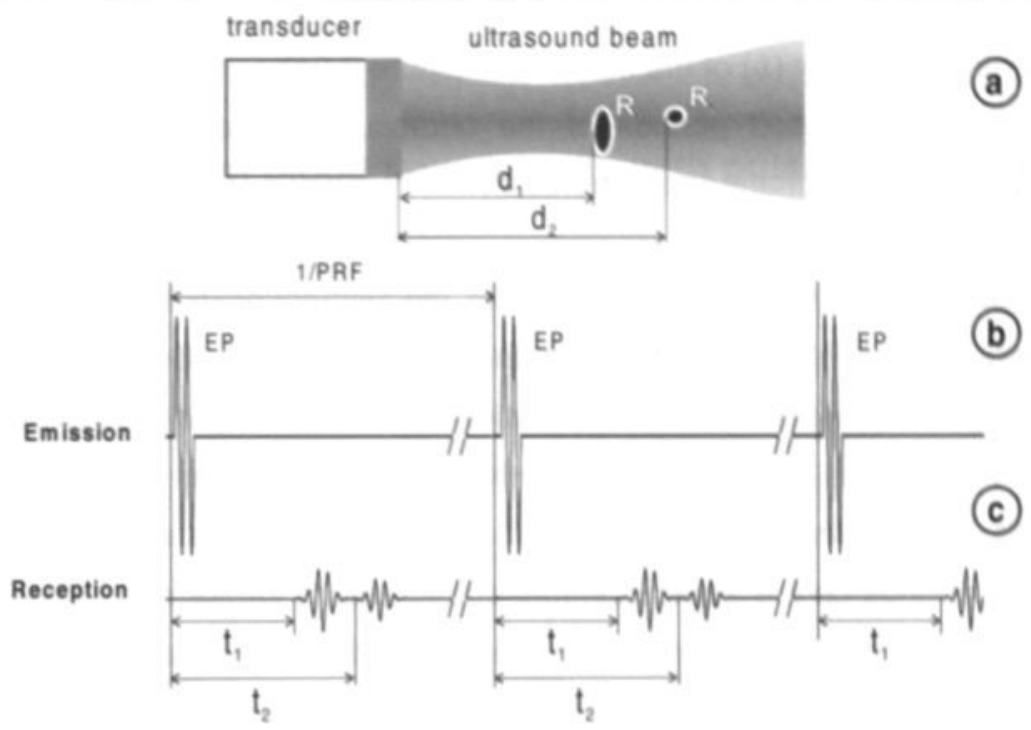

\section{Figure 3.1}

a) shows the reflectors $R_{1}$ and $R_{2}$ in the ultrasound beam of a transducer.

b) shows the time sequence of the emitted pulses (EP); the time between the emitted pulses is equal to 1/PRF.

c) shows the received ultrasound signal. The amplitude rises at $t 1$ and $t 2$ are caused by the reflectors $R$, and $R_{2}$.

To visualize two-dimensional anatomical structures, a Brightness-mode (B-mode) image can be made (figure 3.7). In the B-mode, the ultrasound beam is sequentially moved (mechanically or electrically) within a plane. The amplitude caused by the received echoes is presented in shades of gray. In this way a cross-section of a vessel can be visualized in real-time (for example 25 images per second).

Prerequisites for a good ultrasound system are, among others, a high spatial resolution and a large dynamic range. The spatial resolution is determined by the lateral and axial resolutions. The lateral resolution depends on the local beam width, which is determined by the size of the transducer element and the position of the focal point. If the size of the transducer expressed in wavelengths is constant, then a higher carrier frequency will result in a narrower beam. The length of the emitted pulse determines the axial resolution. The length of the pulse depends on the: 
- carrier frequency $\left(f_{c}\right)$ of the transducer (figure 3.2a)

- number of emitted periods of the ultrasound waves (figure 3.2b). This number can be changed electronically.

The carrier frequency is a characteristic of the ultrasound transducer. A higher carrier frequency results in a better axial and lateral resolution for the same number of emitted periods. However, the attenuation of the ultrasound waves per unit of distance travelled is exponential with their frequency. This means that high ultrasound frequencies have a low depth of penetration. The optimal transducer frequency depends on the application (penetration depth versus resolution). For the investigation of superficial arteries ultrasound transducers with a carrier frequency of 7 to $10 \mathrm{MHz}$ can be used, resulting in a penetration depth of 7 to $5 \mathrm{~cm}$.

(a)
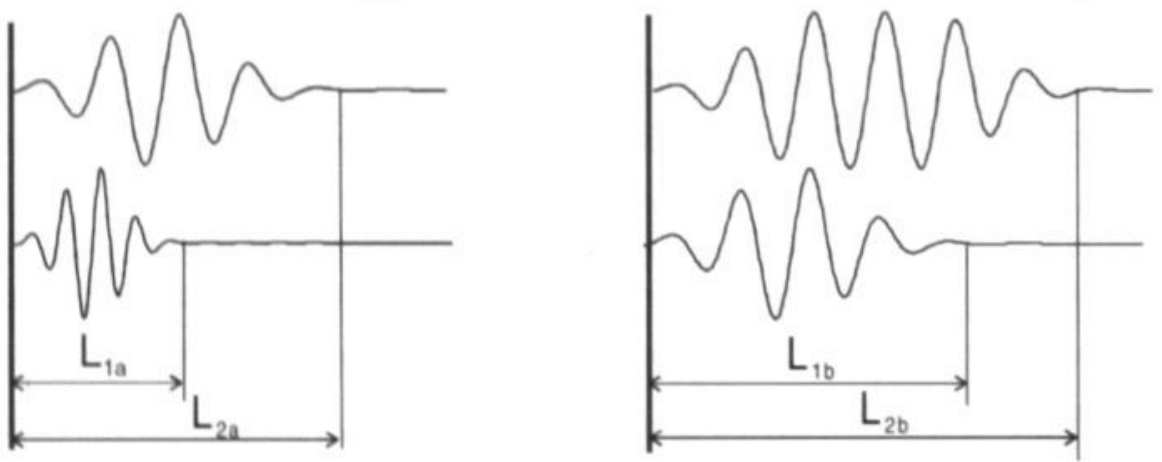

Figure 3.2

a) Difference in length of the emission pulse ( $L_{1 a}$ versus $\left.L_{2 a}\right)$ for transducers with a low (top) and a high (bottom) carrier frequency emitting the same number of periods.

b) Effect on the length of the emission pulse when the number of emission periods is decreased (bottom $L_{b}$ compared to top $L_{2 b}$ ). 


\subsection{Assessment of blood flow velocity with pulsed ultrasound}

Pulsed ultrasound systems transmit and receive intermittently, allowing acquisition of the if signals on a certain depth as function of time. If the emitted ultrasound pulse encounters a moving object, then the reflected or scattered echo shows a depth shift ( $\Delta \mathrm{d}$ in figure 3.3a) with respect to the preious signal. Figure 3.3a shows the reflected pulse from an object moving away from the transducer (located on the left side) for a number of subsequent it-signals. The time between each $\mathrm{r}$-signal is $1 / P R F$ in seconds. Figure 3.3b shows the Doppler signal as function of time at the depth position marked with a dotted line in figure 3.3a. The carrier frequency of this temporal signal $\left(f_{d}\right)$ depends on the velocity of the moving object and on the carrier frequency of the emitted pulse.

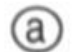

(b)
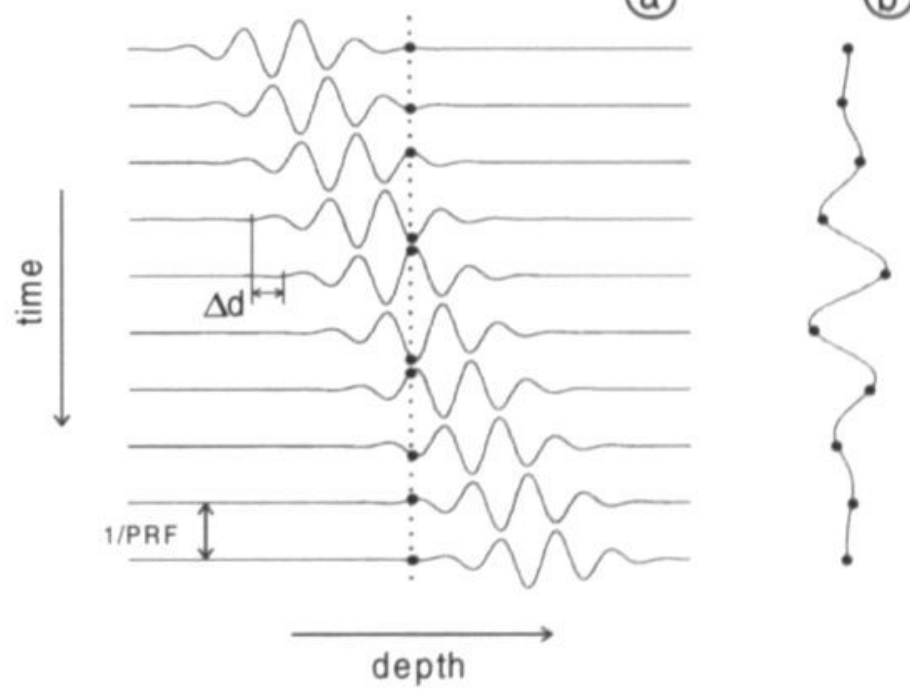

Figure 3.3

(a) shows the reflected pulse from an object moving away from the transducer (located on the left side) for a number of subsequent if signals. The time between each if signal is spaced by 1/PRF seconds.

(b) shows the Doppler signal as function of time at the depth position that is marked with a dotted line in figure 3.3a. 
The relation between the temporal Doppler frequency $f_{d}[\mathrm{~Hz}]$ and the velocity $v$ $\left[\mathrm{m} . \mathrm{s}^{-1}\right]$ of the object is given by:

$$
v=\frac{c f_{d}}{2 f_{c} \cos (\varphi)}
$$

where $\varphi[\mathrm{rad}]$ is the assumed angle between the ultrasound beam and the direction of the moving object, $f_{c}[\mathrm{~Hz}]$ is the carrier frequency of the ultrasound waves and $c$ is the ultrasound velocity in the transmission medium.

In figure 3.4a, the frequency spectrum of the Doppler signal in the center of an artery in the systolic phase is shown. The large peak around zero frequency originates from slowly moving tissue (clutter), in this case the vessel wall. The other (lower) peak originates from the scattering blood. This latter peak has a certain width, because at a given moment not all scatters (erythrocytes) are moving at the same velocity.

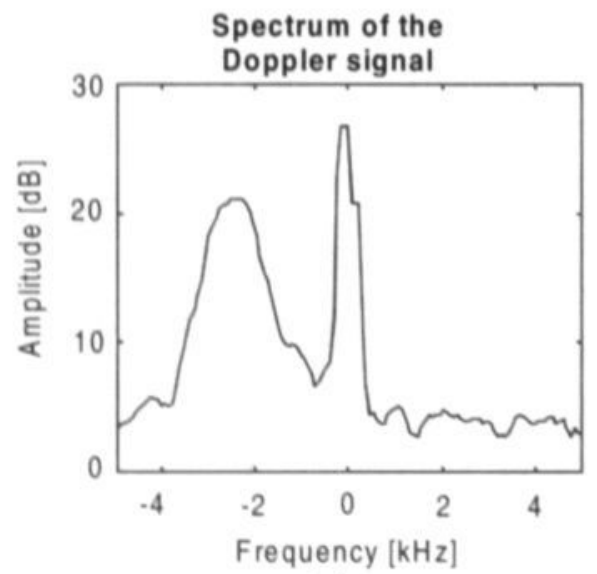

(a)

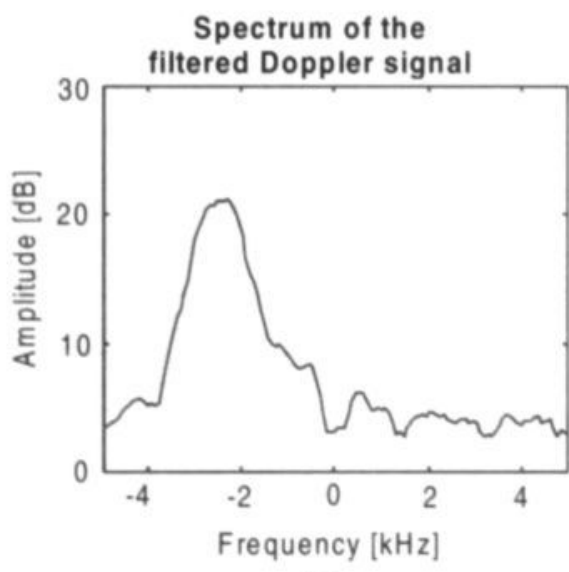

(b)

Figure 3.4

(a) The frequency spectrum of the Doppler signal in the center of an artery. The large peak around zero frequency originates from slowly moving tissue (clutter), in this case the vessel wall. The other (lower) peak originates from the scattering blood.

(b) The frequency spectrum after removal of the large peak using a high pass filter. 
For blood flow velocity measurements, the frequency peak in the Doppler spectrum originating from the slowly moving structures (clutter) has to be removed. This can be done with a high pass filter (figure $3.4 \mathrm{~b}$ ). The cut-off frequency of this high pass filter is somewhere between the Doppler frequency caused by the vessel wall and the Doppler frequency caused by the flowing blood. If the cut-off frequency is chosen too high, then (parts of) the scattering signals will be suppressed as well. If it is chosen too low, then the high amplitudes originating from the vessel wall will dominate the Doppler spectrum. After filtering, the mean velocity at a certain depth can be calculated using equation (3-3).

With pulsed ultrasound it is possible to measure velocities at a certain depth. This can be expanded to more depths simultaneously: multigate pulsed Doppler (Hoeks 1981) (figure 3.5).

With such a system, it is possible to assess the velocity distribution in an artery along a line of observation as function of time. Knowing the velocity distribution along a line of observation, the shear rate can be determined by calculating the first radial derivative of this velocity distribution (equation (2-2), chapter 2).

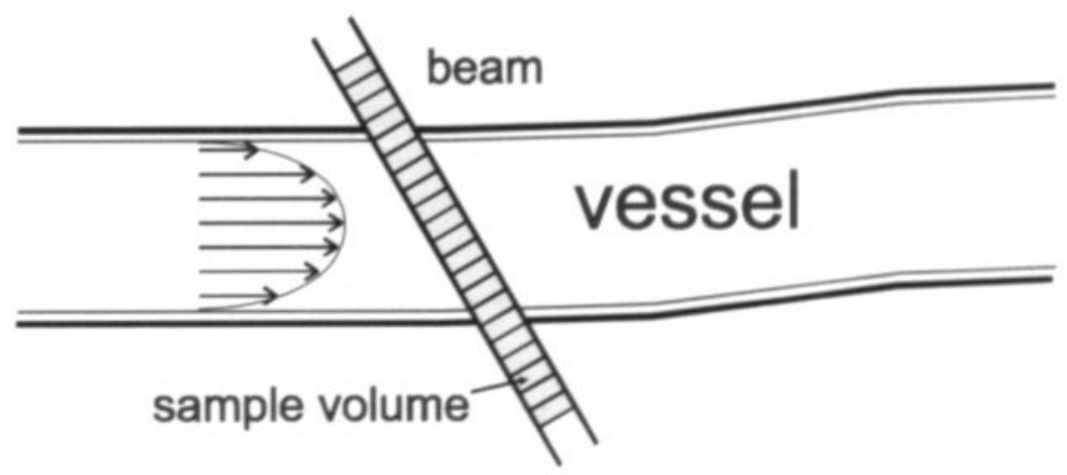

Figure 3.5

Schematic representation for the position of the sample volumes in a multigate pulsed Doppler system. 
To measure velocity near the vessel wall accurately the multigate pulsed Doppler system has to meet certain criteria, namely:

1) a low electrical noise level, because the amplitudes of the scattering erythrocytes are low and will therefore easily be obscured by noise.

2) high spatial and temporal resolutions.

3) a good clutter filter.

\subsection{The Shear Rate Estimating System (SRES)}

The ultrasound group of the Department of Biophysics of CARIM of the Maastricht University has developed a Shear Rate Estimating System (SRES). This system is capable of assessing the wall shear rate distribution by determining at each instant the first radial derivative of the velocity profile near the wall of arteries (Brands et al. 1995, Hoeks et al. 1995). Besides the velocity and the shear rate distribution also the diameter and the diameter change can be determined simultaneously. To achieve a high flexibility in processing, the received if signals are digitised first, stored in a memory and processed off-line. A block diagram of the Shear Rate Estimation System is shown in figure 3.6. The SRES exists of an ultrasound echo system, an A/D (Analog to Digital) converter to digitise if signals, a computer to store the digitised if signals and a software program for (off-line) if signal processing.

computer

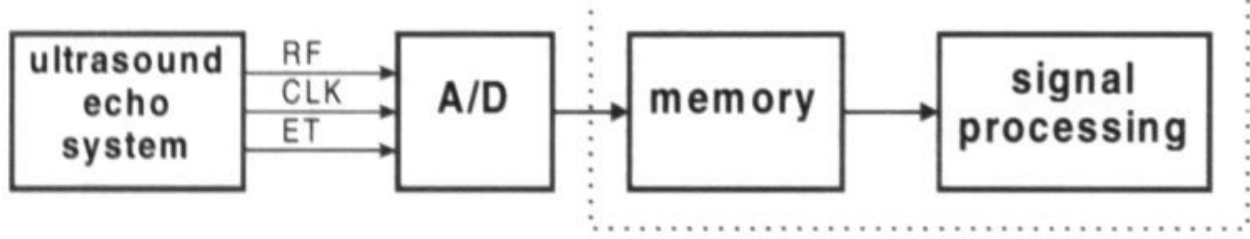

Figure 3.6

Block diagram of the Shear Rate Estimation System. (RF: if signal; CLK: clock, i.e., sample trigger for the $A \sqrt{ }$ converter; $E T$ : emission trigger; $A V D$ : analog to digital converter) 


\subsubsection{Ultrasound signal acquisition}

The received radiofrequency signals are digitised with a sample frequency of 3 to 4 times the carrier frequency of the transducer. For velocity detection the sample frequency should be synchronous with the emission trigger (ET), which is the signal that activates the emission, to ensure synchronous sampling of subsequent If signals at corresponding positions. The digitised data are stored in the memory of a computer. The if signal, the clock synchronous with the ET and the ET are normally not externally available in ultrasound systems. Therefore, these outputs were added to the ultrasound systems used for shear rate measurements.

To be able to measure blood flow velocity, the PRF of the echo system has to be on the order of $10 \mathrm{kHz}$. Because the received if signals should have a high axial resolution, the emission pulse has to be short. In practice this means that conventional ultrasound systems, prior to if signal acquisition, must be set in Doppler mode with a short $(<0.5 \mathrm{~mm}$ ) sample volume in depth or in M-mode (which implies a high resolution) with a high PRF.

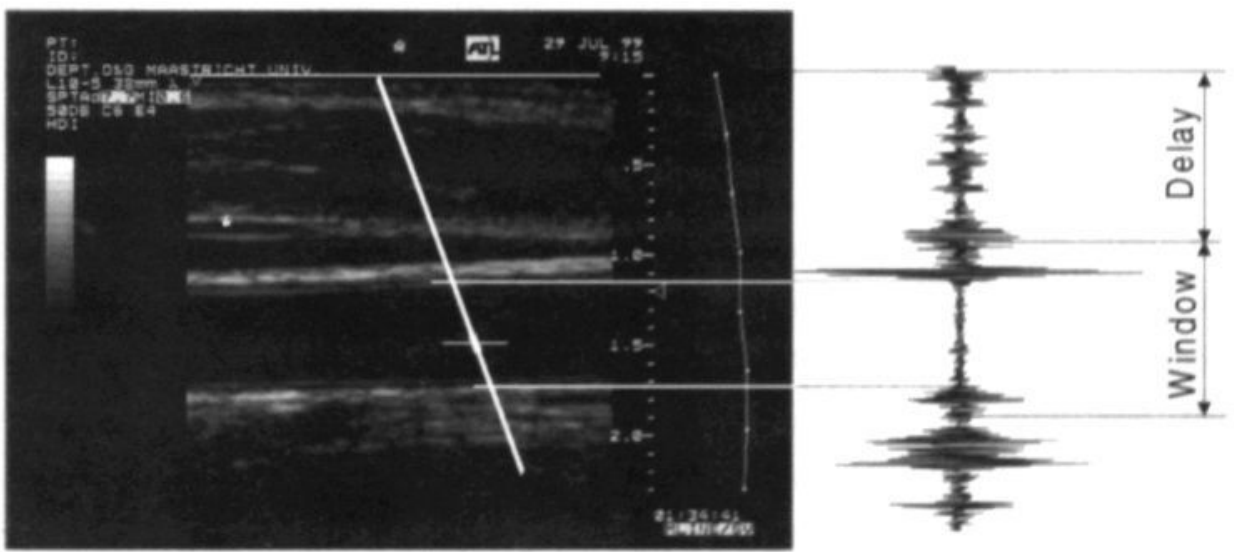

Figure 3.7

B-mode image of a longitudinal cross-section of an artery. The oblique white line in the image represents the line along which the data are acquired. Next to the $B$ mode image, one $i$ line is shown corresponding to the oblique white line. Only the part of the rf signal within the window will be stored in memory. 
Figure 3.7 shows a B-mode image of an artery together with an if signal obtained along the oblique solid white line. After a good longitudinal section was seen on this mode (implying that the artery is seen at the centre of the artery) the measurement procedure was changed to $\mathrm{M}$-mode. To reduce the amount of data only the part of the $i f$ signal that is relevant is acquired and stored in memory. For shear rate measurements in vessels this segment covers the lumen together with the anterior and posterior walls.

After the echosystem is set in Doppler mode with a short sample volume (smaller than $0.5 \mathrm{~mm}$ ) these $\mathrm{r}$ segments are digitised resulting a two-dimensional data matrix (depth and time) in the computer memory (figure 3.8). Because the data is processed off-line, the size of the computer memory limits the total recording time. For one second of data with a PRF of $10 \mathrm{kHz}$ and an acquisition window of $10 \mathrm{~mm}$ a memory of 5 Mega bytes is needed (clock frequency $20 \mathrm{MHz}$ ).

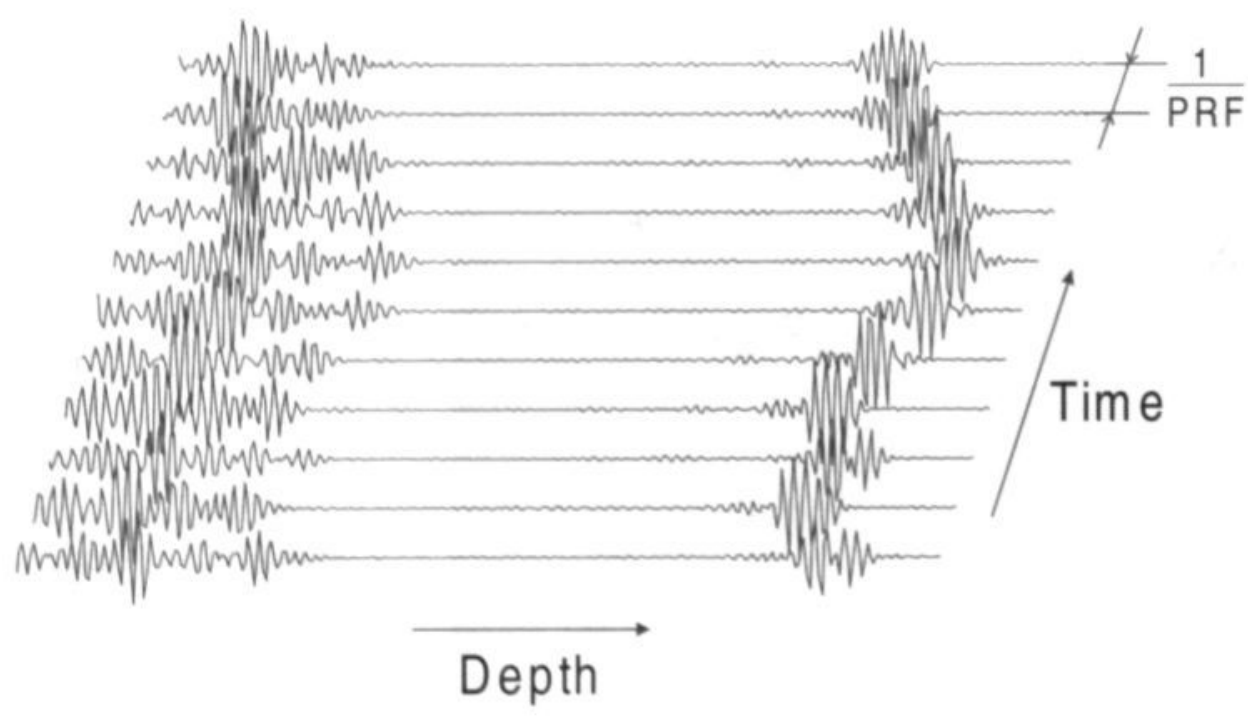

\section{Figure 3.8}

Visualization of the two-dimensional (depth, time) if matrix used for off-line signal processing. The peaks left and right of each if signal represent the echoes resulting from the anterior and posterior vessel wall. 


\subsubsection{Off-line signal processing}

For shear rate measurements, based on the first radial derivative of the velocity distribution, it is essential that the velocity distribution along the artery is measured accurately, especially in the region near the vessel wall.

\subsubsection{The Cross Correlation Model (CCM) frequency estimator}

For short emission pulses the actual carrier frequency of the received if signals gradually decreases due to the attenuation with depth. This means that a fixed value for $f_{c}$ to calculate the velocity (equation (3-3)) will introduce a depth dependent bias (Brands et al. 1995, Hoeks et al. 1994). With the CCM frequency estimator for ultrasound if signals, it is possible to determine accurately both the carrier frequency $\left(f_{c}\right)$ and the frequency of the Doppler signal $\left(f_{d}\right)$. The CCM is employed on a subwindow (few points in time and depth) of the if signal matrix, thereby taking the estimate for the depth dependent $f_{c}$ into account.

\subsubsection{Clutter filter}

The Doppler signals originating from low blood flow velocities near the vessel wall are largely obscured by the high amplitude Doppler signals originating from the vessel wall reflections, which makes a good clutter filter essential. Since the mean frequency of the signals caused by clutter changes with time, the filter characteristics must adapt dynamically to the wall motion. For this purpose a clutter filter has been developed that selectively suppresses the Doppler frequencies within a narrow frequency range centred at the clutter Doppler frequency originating from the vessel walls (Brands et al. 1995, Hoeks et al. 1995). The frequency of the Doppler signal from the vessel wall motion is estimated using the CCM. Since the filter procedure is repeated for all sub-windows within the if matrix clutter suppression is executed according to the local (in depth and in time) signal characteristics. 

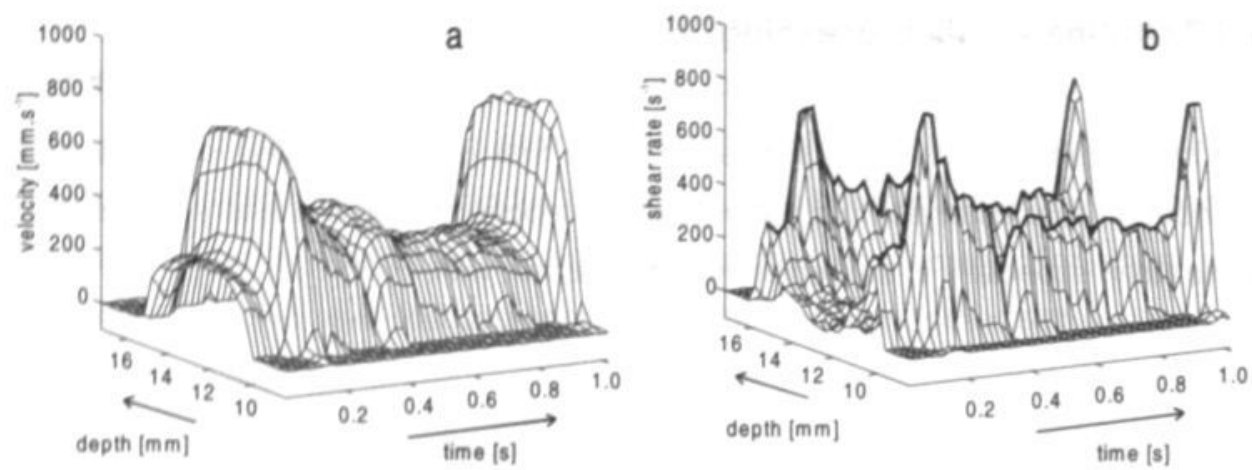

\section{Figure 3.9}

(a) shows an example of a two-dimensional velocity distribution as function of time and depth and its corresponding (b) shear rate distribution. The two thick lines in the shear rate distribution correspond to the instantaneous peak shear rates at the anterior and posterior wall.

\subsubsection{Velocity and shear rate distribution}

After filtering the mean Doppler frequency $\left(f_{d}\right)$ and the carrier frequency $\left(f_{c}\right)$ of each subwindow are estimated with the CCM. The velocity can now be determined by substitution of $f_{d}$ and $f_{c}$ in equation (3-3). This results in a two-dimensional blood velocity distribution as is shown in figure $3.9 \mathrm{a}$.

The spatial resolution of the radial velocity profile is governed by the spatial resolution of the echo used in combination with the number of sample points in depth used for each velocity estimate. For a good estimate 8 sample points in depth and 100 points in time are required. For an if signal sample frequency of $20 \mathrm{MHz}$ and a PRF of $10 \mathrm{kHz}$, this corresponds to a resolution window of $300 \mu \mathrm{m}$ in depth and $10 \mathrm{~ms}$ in time. To obtain a more detailed distribution half-overlapping subwindows are used, providing velocity estimates at increments of $150 \mu \mathrm{m}$ in depth and $5 \mathrm{~ms}$ in time. Once the velocity distribution is known, the shear rate can be determined by calculating the first radial derivative. This results in a shear rate distribution as function of time and depth as is shown in figure $3.9 \mathrm{~b}$. The two thick lines in figure $3.9 \mathrm{~b}$ correspond to the instantaneous peak shear rate at the anterior and posterior vessel wall. Shear rate can be measured as close as $300 \mu \mathrm{m}$ from the vessel wall so that these peak values are not necessarily the real wall shear rate but provide a fair approximation. 


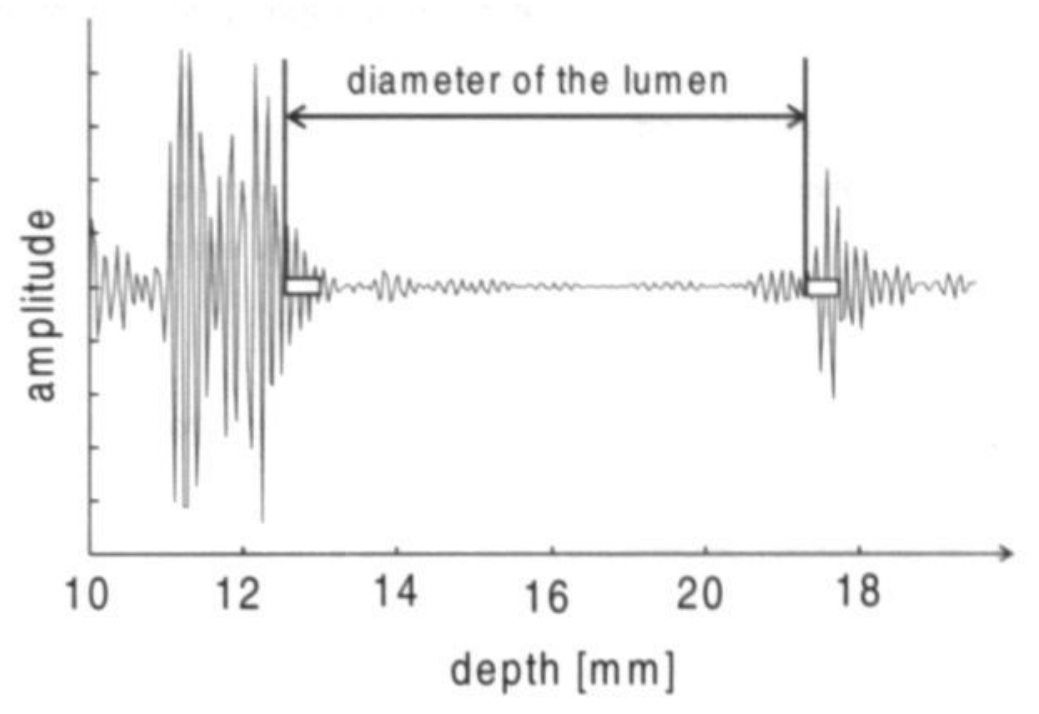

\section{Figure 3.10}

First if signal in the if matrix from a recording of an artery. On the echoes from the anterior wall to lumen and lumen to posterior wall transitions markers (white boxes) are placed. The distance between these markers is the diameter of the lumen.

Besides the velocity and shear rate distribution, also the diameter and diameter change during the cardiac cycle (distension) can be deduced from the signals in the if matrix. The diameter is determined by manually placing markers on echoes originating from the anterior and posterior wall. The distance between these markers is a measure of the diameter of the lumen. Figure 3.10 shows the markers, white boxes, on the echoes from the anterior and posterior wall of the vessel.

The position in depth of the anterior and posterior vessel wall reflections changes during the cardiac cycle. This displacement can be determined by integrating the velocity of each vessel wall over time. The velocity of the vessel wall is determined by employing the CCM on the subwindow positioned at the vessel wall reflection. The diameter change can then be determined by subtracting the displacement of the posterior wall from the anterior wall. Using this method the accuracy and precision of the diameter change is on the order of a few micrometers. 
Finally, one SRES measurement results in three recordings as function of time:

(1) distension,

(2) centre stream velocity and

(3) wall shear rate.

An example of these recordings are shown in figure 3.11 .

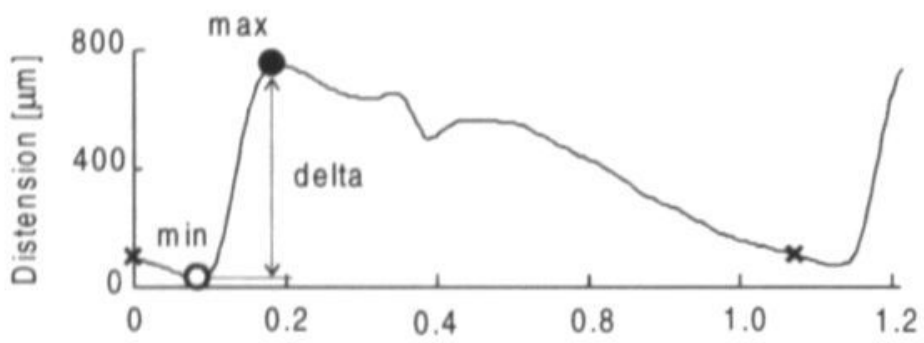

$\max =719 \mu \mathrm{m}$

$\min =0 \mu \mathrm{m}$

delta $=719 \mu \mathrm{m}$

mean $=391 \mu \mathrm{m}$

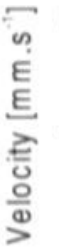

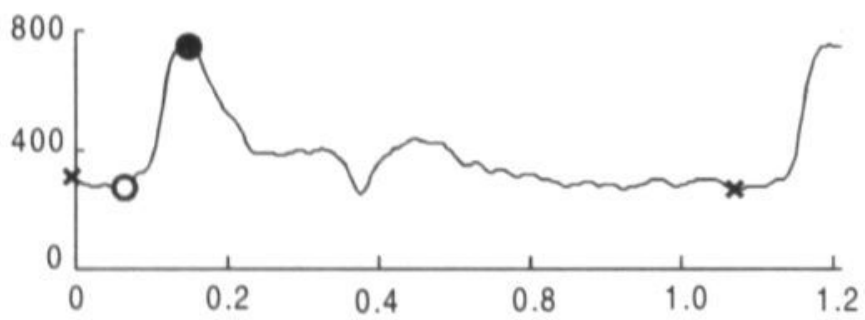

$\max =762 \mathrm{~mm} . \mathrm{s}$

$\min =274 \mathrm{~mm} . \mathrm{s}^{-1}$

delta $=488 \mathrm{~mm} \cdot \mathrm{s}$

mean $=376 \mathrm{~mm} \cdot \mathrm{s}^{-1}$
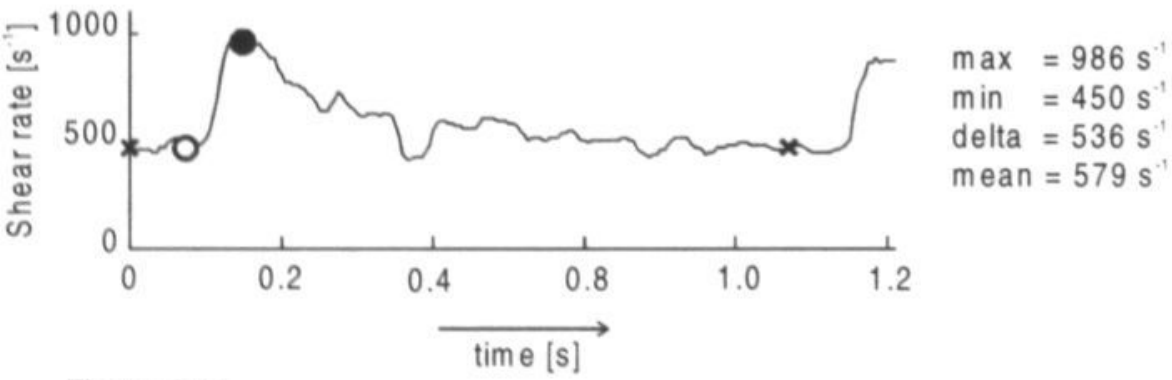

Figure 3.11

An example of the final results of a single SRES measurement in the common carotid artery. The $x$-symbol represents the start and end of the cardiac cycle $(R$ top ECG). The open circle represents the (end-diastolic) minimum and the closed circle represents the maximum of the curve. 
From the time curves in figure 3.11 for each heart beat such signal parameters as mean, minimum (open circle), maximum (closed circle) and delta, which is the maximum value minus the minimum value can be determined. The start of each cardiac cycle, $x$-symbol, is traced from the ECG-recording that is made simultaneously with the ultrasound measurement.

\subsubsection{Validation of the Shear Rate Estimation System}

The SRES was validated in a steady flow bench-model (Gijssen et al. 1998). The shear rate in this model can be regarded to be representative of arteries. The velocity distribution measured with the SRES showed good agreement with the numerically predicted velocity distribution. The values for the wall shear rate found in the bench-model with the SRES were approximately $25 \%$ lower than the expected ones, however. The relative changes in wall shear rate, due to different shapes of the flow, were the same as the predicted values. From this it can be concluded that the absolute shear rate may be underestimated, but it is at least a measure of wall shear rate.

\subsubsection{Limitations of the SRES}

For shear rate measurements the angle between the ultrasound beam and the flowing blood must be known. This means that shear rate can only be measured in relatively straight vessels with a laminar flow. Measurement of shear rate with the SRES in curvatures and bifurcations is therefore not possible yet.

The absolute diameter is determined manually by placing markers on the lumen to wall transition. Therefore two different investigators may obtain different values from the same recordings. These differences, however, were found to be small (Kool et al. 1994). The angle between the ultrasound beam and the artery has to be on the order of $70^{\circ}$, but then the transitions between the lumen and the vessel wall are less distinctive than they would be at an angle of $90^{\circ}$. This complicates the positioning of the markers. 
For shear rate measurements the beam has to go through the centre of the vessel during the recording. This means that the vessel may not move in a lateral direction with respect to the ultrasound beam. Even small changes in lateral direction have a significant effect on the results obtained. This puts high demands on the skills of the investigator using the SRES.

\subsection{References}

Brands PJ, Hoeks APG, Hofstra L, Reneman RS. A noninvasive method to estimate wall shear rate using ultrasound. Ultrasound Med Biol 1995;21:171-185.

Brands PJ, Hoeks APG, Reneman RS. The effect of echo suppression on the mean velocity estimation range of the if cross-correlation model estimator. Ultrasound Med Biol 1995;21:945-959.

Burns PN. The physical principles of Doppler and spectral analysis. J Clin Ultrasound 1987; 15:567-590.

Gijssen FJH, Brands PJ, van de Vosse FN, Janssen JD. Assessment of wall shear rate measurements with ultrasound. J Vasc Invest 1998;4:187-196.

Hoeks APG. A multigate pulsed Doppler system with serial data processing. IEEE Trans Sonics Ultrason 1981;28:242-247.

Hoeks APG, Arts TGJ, Brands PJ, Reneman RS. Processing scheme for velocity estimation using ultrasound RF cross correlation techniques. Eur $\mathrm{J}$ Ultrasound 1994;1:171-182.

Hoeks APG, Samijo SK, Brands PJ, Reneman RS. Noninvasive determination of shear rate distribution across the arterial lumen. Hypertension 1995;26:26-33.

Kool MJF, van Merode T, Reneman RS, Hoeks APG, Struyker Boudier HA, van Bortel LMAB. Evaluation of reproducibility of a vessel wall movement detector system for assessment of large arteries. Cardiovascular Research 1994;28:610614. 


\section{Reproducibility of shear rate and shear stress assessment by means of ultrasound in the common carotid artery of young human males and females}

\begin{tabular}{|c|c|}
\hline 4.1 & Abstract \\
\hline 4.2 & Introduction \\
\hline 4.3 & Materials and methods \\
\hline 4.3.1 & The Shear Rate Estimating System \\
\hline 4.3.2 & Calculated wall shear stress \\
\hline 4.3 .3 & Hemodynamic monitoring \\
\hline 4.3 .4 & Study population \\
\hline 4.3.5 & Study design \\
\hline 4.3 .6 & Procedure \\
\hline 4.3.7 & Analysis \\
\hline 4.4 & Results \\
\hline 4.4.1 & Intrasubject intrasession variability \\
\hline 4.4 .2 & Intersubject intrasession variability \\
\hline 4.4 .3 & Short and medium intersubject intersession variability \\
\hline 4.5 & Discussion \\
\hline 4.6 & References \\
\hline
\end{tabular}

S.K. Samijo, J.M. Willigers, P.J. Brands, R. Barkhuysen, R.S. Reneman, P.J.E.H.M. Kitslaar, A.P.G. Hoeks. 
Reproducibility of wall shear rate and stress 


\subsection{Abstract}

In the present study the reliability of an ultrasonic Shear Rate Estimating System, in terms of intrasubject intrasession, intersubject intrasession and intersubject intersession variability coefficients, in the assessment of wall shear rate (WSR) in the common carotid artery (CCA) was determined in 8 presumed healthy volunteers. Measurements were performed on consecutive days (day 1, day 2, day 7). To investigate whether there are differences in WSR due to gender, dynamic WSR in the CCA was assessed in 11 presumed healthy males (mean age 24 yrs) and 11 presumed healthy females (mean age 25 yrs). Wall shear stress (WSS) was estimated from WSR and calculated whole blood viscosity. The average intrasubject intrasession variability is about $15 \%$ for peak WSR and about $12 \%$ for mean WSR. The intersubject intrasession variability for peak WSR decreased from $19 \%$ on day 1 to $16 \%$ on day 7 and for mean WSR from $17 \%$ on day 1 to $11 \%$ on day 7 . The intersubject intersession variability is on the order of $5 \%$ for peak WSR and about $4 \%$ for mean WSR and no significant differences could be detected between peak and mean WSR values on day 1, day 2 and day 7, indicating good short and medium term intersubject intersession reproducibility. No differences in peak and mean WSR were found between the left and the right CCA in the male as well as in the female group. Mean WSS was similar in males $(1.3 \pm 0.3 \mathrm{~Pa})$ and in females $(1.2 \pm 0.2 \mathrm{~Pa})$, but peak WSS was slightly, but significantly, higher in males $(4.3 \pm$ 1.3 $\mathrm{Pa})$ than in females $(3.3 \pm 0.7 \mathrm{~Pa})$. It can be concluded that peak and mean WSR can be reliably determined non-invasively with the use of ultrasound.

\subsection{Introduction}

Wall shear stress (wall shear rate times whole blood viscosity) is the drag of the flowing blood exerted on the vessel wall. In a variety of studies it has been shown that wall shear stress is an important determinant of endothelial cell function, among others, influencing the production of such vasoactive substances as NO (EDRF) (Rubanyi et al. 1990), prostacycline (Frangos et al. 1985) and endotheline (Sharefkin et al. 1991; Malek and Izumo 1992), and, hence, of vessel wall function. 
The information available on the effect of wall shear stress on artery wall function in vivo is limited mainly because of the lack of techniques to non-invasively assess wall shear rate. Techniques that have been used to assess wall shear rate in vivo are either invasive (Ling et al. 1968, Kamiya and Togawa 1980, White et al. 1994), elaborate (Caro et al. 1992) or assume stationary flow conditions (Binns et al. 1989; Hofstra et al. 1995).

Because mean and pulsatile wall shear stress may differently affect arterial wall function and change differently with age, we developed a non-invasive ultrasound system to estimate dynamic wall shear rate, i.e., the velocity gradient at the wall during the cardiac cycle (Brands et al. 1995; Hoeks et al. 1995). The aim of the present study was to assess the reliability of this Shear Rate Estimating System in terms of reproducibility. To this end repeated measurements were performed in both common carotid arteries of young presumed healthy male volunteers on 3 occasions (day 1, day 2 and day 7), and the intrasubject intrasession (variations within one subject within one day), the intersubject intrasession (variations between subjects within one day) and the intersubject intersession (variations between subjects between days) variability were calculated. It was also investigated whether in a young population there are differences in wall shear rate and calculated wall shear stress (wall shear rate times whole blood viscosity) between males and females and between the right and left common carotid arteries.

\subsection{Materials and methods}

\subsubsection{The Shear Rate Estimating System (SRES)}

The ultrasonic SRES has been described in detail elsewhere (Hoeks et al. 1994; Brands et al. 1995). In short, the system consists of three parts: a modified ultrasound echo system (Ultramark 4 plus, Advanced Technology Laboratories, Bellevue, WA, USA) with a short focus mechanical sector probe operating at $5 \mathrm{MHz}$, a Data Acquisition System (DAS) and a computer (486DX2/66) (figure 4.1). The system is able to measure the blood flow velocity distribution along a selected line 
of observation across the centre of the vessel with a spatial resolution of $300 \mu \mathrm{m}$ and a temporal resolution of $10 \mathrm{~ms}$. To obtain a more detailed velocity distribution for both the temporal and radial direction intermediate values were calculated based on half-overlapping data segments.

A recording is started synchronously with a trigger derived from the R-top of the ECG, which facilitates the detection of the maximum (systolic) and minimum (diastolic) velocity as well as the initial arterial diameter. The captured radio frequent (rf) signals (reflected and scattered ultrasound signals) are digitised and stored temporarily in the memory of the data acquisition system (DAS). Due to the limited size of this memory a recording time of only $1.2 \mathrm{~s}$ is available, normally sufficient for capturing one complete heart beat. Subsequently, the data is transferred from the DAS to the computer for processing.

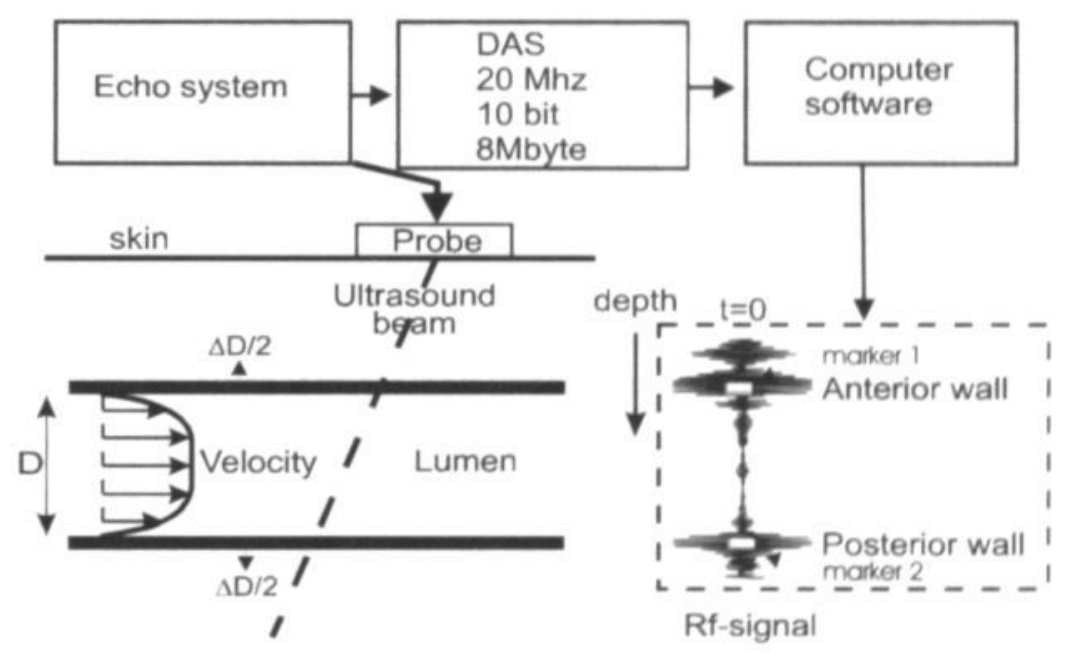

Figure 4.1

Schematic drawing of the shear rate estimating system. The bottom right shows the first radiofrequency line used for identification of the vessel walls (see marker 1 and 2). $D$ is the internal end-diastolic diameter. 

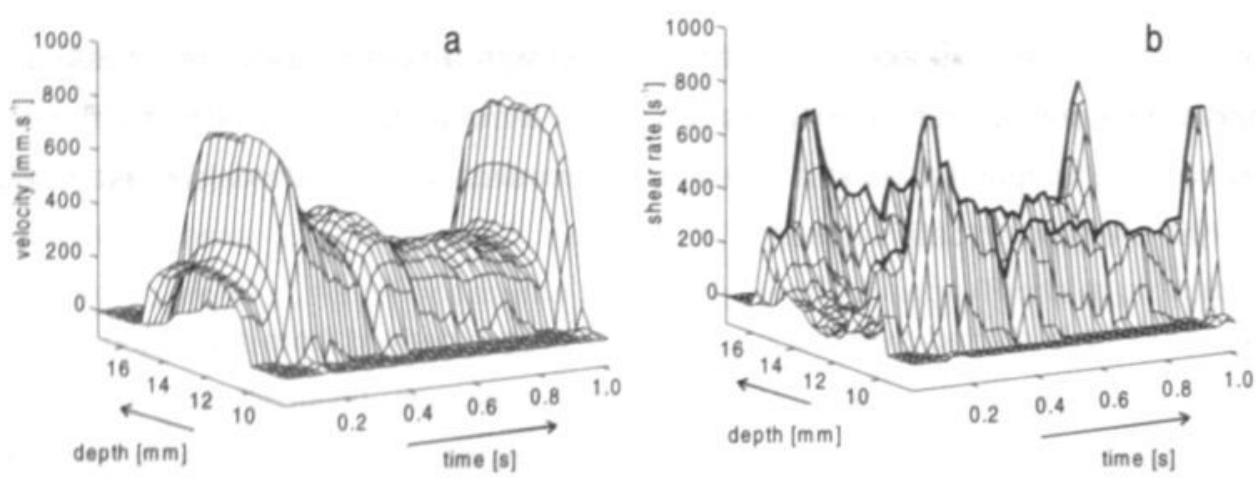

Figure 4.2

(a) The velocity distribution over time in the common carotid artery of a presumed healthy male volunteer.

(b) The shear rate distribution over time in the common carotid artery of the same volunteer.

The signal as function of depth of the first digitised $\mathrm{f}$ line is displayed on the computer screen. From the shape and the position in depth of the reflections, the wall lumen interfaces on both sides are identified manually by placing sample volumes, indicated by markers, on the reflections of the anterior and posterior vessel walls (figure 4.1).

The distance between both markers, corrected for the angle of observation, is considered as the initial (end-diastolic) diameter of the vessel. Processing of the if data within the sample volumes as function of time results in the time dependent change of the arterial wall position (displacement waveform). The difference between the displacement curves of both walls reflects the change in diameter over time, i.e., the distension as function of time.

The signal as function of depth of the first digitised $r f$ line is displayed on the computer screen. From the shape and the position in depth of the reflections, the wall lumen interfaces on both sides are identified manually by placing sample volumes, indicated by markers, on the reflections of the anterior and posterior vessel walls (figure 4.1). 
The distance between both markers, corrected for the angle of observation, is considered as the initial (end-diastolic) diameter of the vessel. Processing of the If data within the sample volumes as function of time results in the time dependent change of the arterial wall position (displacement waveform). The difference between the displacement curves of both walls reflects the change in diameter over time, i.e., the distension as function of time.

To obtain the time-dependent blood flow velocity distribution, a modelled crosscorrelation function is employed to the if data between the markers to estimate the mean velocity over time segments of $10 \mathrm{~ms}$ spaced at $5 \mathrm{~ms}$ ( $50 \%$ overlap) time intervals. The length of the $\mathrm{rf}$ segments in depth corresponds to $300 \mu \mathrm{m}$ spacing at $150 \mu \mathrm{m}$ intervals (50\% overlap) (Hoeks et al. 1994; Brands et al. 1995). Calculating the mean velocity of all if segments results in a time-dependent velocity profile. Such a velocity profile as recorded in the common carotid artery is depicted in figure 4.2a.

The shear rate distribution follows from the radial derivative of the velocity profile at each time instant. A typical recording of a shear rate distribution in the common carotid artery is shown in figure $4.2 \mathrm{~b}$.

The average peak values of the derivatives at the anterior and posterior walls of the vessel is considered as the estimate of the instantaneous longitudinal wall shear rate. This averaging procedure is performed to minimise possible effects induced by secondary flows. From the velocity profile and shear rate distribution such parameters as peak systolic velocity ( $P S V$ in $\left.\mathrm{mm} \cdot \mathrm{s}^{-1}\right)$, mean velocity $\left(M V\right.$ in $\left.\mathrm{mm} \cdot \mathrm{s}^{-1}\right)$ in the centre of the lumen averaged over one heart cycle (figure 4.3b), peak wall shear rate ( $P W S R$ in $\left.\mathrm{s}^{-1}\right)$ at peak systole and mean wall shear rate (MWSR in $\left.\mathrm{s}^{-1}\right)$, which is the time averaged shear rate over one cardiac cycle (figure $4.3 \mathrm{c}$ ), can be determined. Simultaneously with shear rate the diastolic diameter ( $D$ in $\mu \mathrm{m})$ and the displacement of the anterior and posterior wall (distension in $\mu \mathrm{m}$ ) can be determined (figure 4.3a). 


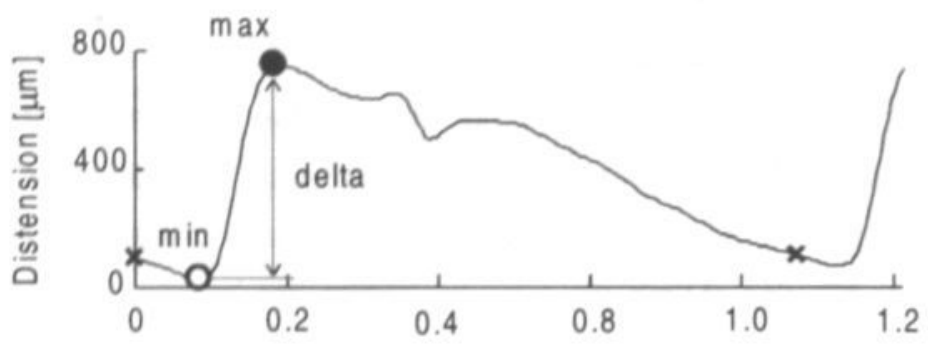

$$
\begin{aligned}
& \max =719 \mu \mathrm{m} \\
& \min =0 \mu \mathrm{m} \\
& \text { delta }=719 \mu \mathrm{m} \\
& \text { mean }=391 \mu \mathrm{m}
\end{aligned}
$$

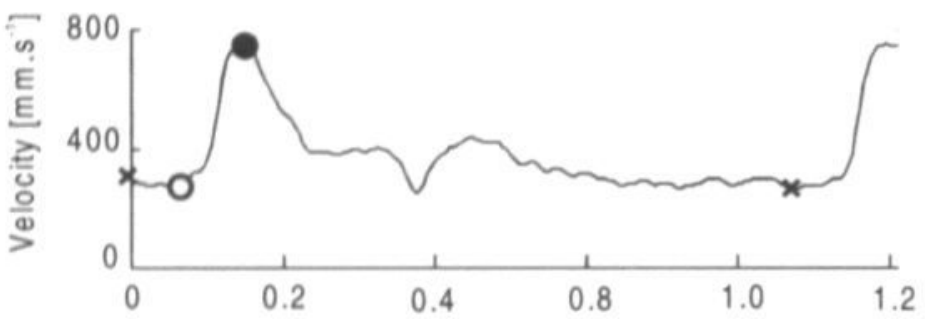

$$
\begin{aligned}
\max & =762 \mathrm{~mm} . \mathrm{s}^{-1} \\
\min & =274 \mathrm{~mm} . \mathrm{s}^{-1} \\
\text { delta } & =488 \mathrm{~mm} . \mathrm{s}^{-1} \\
\text { mean } & =376 \mathrm{~mm} . \mathrm{s}^{-1}
\end{aligned}
$$
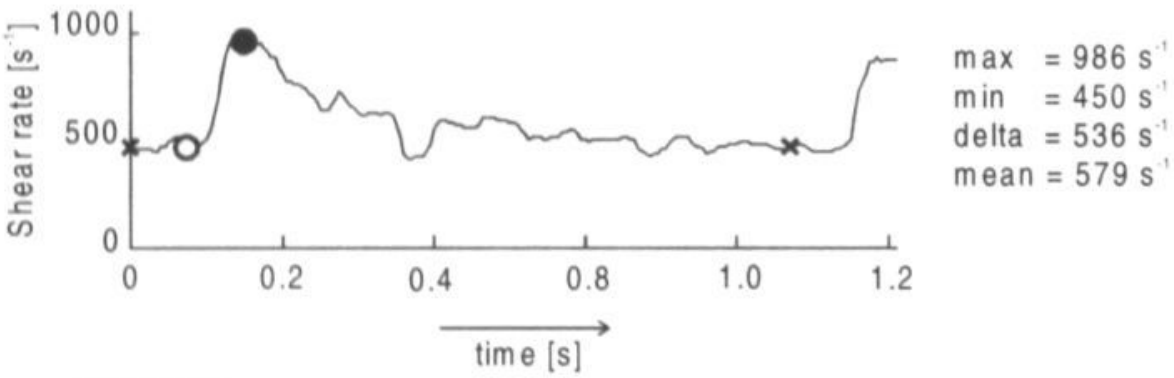

Figure 4.3

Simultaneous readings as function of time of (a) Distension, (b) Centre stream velocity, and (c) Shear rate averaged for the anterior and posterior wall.

\subsubsection{Calculated Wall Shear Stress}

From plasma viscosity, hematocrit and mean wall shear rate whole blood viscosity (WBV can be estimated using the approximation proposed by Weaver (Weaver et al. 1969):

$$
\log W B V=\log \eta_{0}+\alpha \cdot H t
$$

with

$$
\alpha=0.030-0.0076 \log (M W S R)
$$


where $W B V$ is whole blood viscosity in $\mathrm{mPa} . \mathrm{s}, \eta_{0}$ plasma viscosity in $\mathrm{mPa} . \mathrm{s}, \mathrm{Ht}$ hematocrit in percentage and MWSR mean wall shear rate in $\mathrm{s}^{-1}$. This approximation circumvents the practical problems associated with the direct measurement of whole blood viscosity, while the individual dependent factors such as hematocrit and plasma viscosity, which are important determinants of an individual WBV, are taken into account. To assess wall shear stress (WSS), wall shear rate (WSR) is multiplied by whole blood viscosity, employing the relationship:

$$
W S S=W B V W S R
$$

\subsubsection{Hemodynamic monitoring}

Blood pressure, in terms of systolic (SBP), diastolic (DBP), mean (MAP) and pulse $(P P)$ pressure were determined non-invasively on the upperarm by means of a semi-automated oscillometric device (Dinamap; Critikon, Tampa, Florida, USA).

\subsubsection{Study population}

Eleven presumed healthy male and 11 presumed healthy female volunteers participated in the study. Eight of the male subjects participated in the reproducibility study. Measurements were performed in the left and right common carotid arteries. The male volunteers had an average age of 24 years (range 20-36 years), an average weight of $76 \mathrm{~kg}$ (range $58-88 \mathrm{~kg}$ ) and a mean height of $179 \mathrm{~cm}$ (range 167 $192 \mathrm{~cm}$ ). The female volunteers had an average age of 25 years (range 19-32 years), an average weight of $61 \mathrm{~kg}$ (range 53-72 kg) and a mean height of $167 \mathrm{~cm}$ (range 160-180 cm). All participants were non-smokers and clinically free of cardiovascular or other diseases. None of them used medication. All subjects had given written informed consent. The study was approved by the joint medical ethical committee of the Academic Hospital Maastricht and the Maastricht University. 


\subsubsection{Study design}

To determine short and medium term variability, wall shear rate was assessed in 8 of the 11 male subjects using the same procedure on 3 occasions: day 1, day 2 and day 7 . The other 3 males and the female group were measured only on day 1 . To determine possible differences between males and females and as a consequence of side both common carotid arteries were studied and measured in a random order in the male $(n=11)$ as well as female $(n=11)$ study populations.

\subsubsection{Procedure}

The measurements were always performed in the morning starting at $8.30 \mathrm{a} . \mathrm{m}$. The subjects were examined in the supine position in a climatized room with a temperature of $22^{\circ} \mathrm{C}-24^{\circ} \mathrm{C}$. After an acclimatisation period of $10-15$ minutes, the measurements were started. The blood pressure oscillometer was set to take a recording every 5 minutes. An ultrasound echo system (Ultramark 4 plus) in B-mode was employed to verify that the common, internal and external carotid arteries were free of plaques. A line of observation was selected crossing the common carotid artery (CCA) 2 to $4 \mathrm{~cm}$ proximal to the tip of the flow divider at an angle of $70^{\circ}$ with the longitudinal axis of the artery. Then by pressing a foot switch a recording of the received radiofrequent ultrasound signals ( $\mathrm{rf}$ signals) was made for $1.2 \mathrm{~s}$ and stored on the hard disk of the computer, while the first if line was shown on the computer screen. The walls of the vessel were identified by the operator by placing markers. Subsequently the spectral composition of the Doppler signal, originating from the midstream sample, was considered to appreciate the spectral signal to noise ratio (SNR). Recordings with a peak spectral SNR less than $10 \mathrm{~dB}$ were discarded and these measurements were repeated. The measurement procedure was repeated 18 to 20 times for both carotid arteries with a time interval of 3 to 4 minutes. The whole procedure took about 2.5 hours per subject. Hereafter, the SRES was set to calculate the velocity distribution, wall shear rate and distension waveform for all recordings, taking about 6 minutes per measurement. From the 18 or 20 independent measurements performed on each side, the velocity profiles with an axial asymmetry, due to a bad signal to noise ratio, were excluded. 
On day 1 , height and weight of the subjects were measured to calculate body mass index (weight divided by the square of the length, BMI). Hereafter, blood was collected from the antecubital vein for determining hematocrit $(\mathrm{Ht})$, and plasma viscosity.

\subsubsection{Analysis}

As a measure of variability, the variation coefficient (VC) of the parameters was calculated using the following equation:

$$
V C=100 \cdot \text { Standard Deviation } / \text { Mean }[\%]
$$

\section{- The intrasubject intrasession variability}

The intrasubject intrasession variability is the mean variability within 1 subject within one day. This was determined by assessing the standard deviation $\left(\sigma_{l}\right)$ of subject $I$ for each day, and computing the average standard deviation for the group, corrected for the number of beats $n_{i}\left(\sqrt{\frac{\Sigma\left(n_{i} \cdot \sigma^{2}\right)}{\Sigma n_{i}}}\right)$, and likewise the corresponding mean value.

- The intersubject intrasession variability

The intersubject intrasession variability is the variability between the subjects within 1 day. This was determined by calculating separately the $V C$ within the group $(n=8)$ on that day (day 1 , day 2 and day 7 ).

- The short and the medium intersubject intersession variability

The short term variability is defined as the intersubject intersession variability between day 1 and day 2 . The medium term variability is defined as the intersubject intersession variability between day 1 and day 7 . To investigate whether there was a possible influence of day a multi-analysis of variance was performed. 
The paired Student's t-test was applied to check for possible differences between the left and the right CCA, while the unpaired Student's t-test was employed to detect possible differences in the parameters measured by the SRES between the male and the female group. The level of statistical significance was selected at $p<0.05$. All statistical analyses were performed with the SPSS statistical software for Windows, release 6.0 .

\subsection{Results}

The peak and mean wall shear rate data of the subgroup of 8 male subjects are presented in table 4.1. For both the left and right common carotid arteries PWSR ranged from $811 \mathrm{~s}^{-1}$ to $1584 \mathrm{~s}^{-1}$ and MWSR ranged from $282 \mathrm{~s}^{-1}$ to $535 \mathrm{~s}^{-1}$.

\subsubsection{Intrasubject intrasession variability (table 4.1)}

The intrasubject intrasession variability ranged from $10 \%$ to $22 \%$ for PWSR and $5 \%$ to $17 \%$ for MWSR. In the left common carotid artery the average intrasubject intrasession VC on day 1 , day 2 , day 7 was $15 \%, 15 \%$ and $13 \%$, respectively, for PWSR, and $10 \%, 12 \%$ and $12 \%$, respectively, for MWSR. In the right common carotid artery the average intrasubject intrasession $V C$ on day 1, day 2 and day 7 was the same (15\%) on all three days for PWSR and was $13 \%, 11 \%$ and $15 \%$, respectively, for MWSR.

\subsubsection{Intersubject intrasession variability (table 4.2)}

In the left common carotid artery the average intersubject intrasession VC on day 1 , day 2 and day 7 was $19 \%, 16 \%, 16 \%$, respectively, for PWSR, and $17 \%, 16 \%$ and $11 \%$, respectively, for $M W S R$. In the right common carotid artery, the average intersubject intrasession $V C$ on day 1 , day 2 , day 7 was $20 \%, 17 \%$ and $18 \%$, respectively, for PWSR and $19 \%, 12 \%$ and $6 \%$, respectively, for MWSR. These data show a moderate variability with a decrease from day 1 to day 7 for both PWSR and MWSR on both sides. 


\section{Table 4.1}

Average values \pm standard deviations of peak wall shear rate (PWSR) and mean wall shear rate (MWSR) per subject per day of the subpopulation of 8 male subjects. The bottom line gives the mean values and within parentheses, the mean intrasubject intrasession coefficient of variation, corrected for number of beats at each side per day.

\section{PWSR}

\section{LEFT}

\section{DAY 1}

\section{DAY 2}

DAY 7

\section{RIGHT}

\section{DAY 1}

\section{DAY 7}

$\begin{array}{lllll}\text { PP1 } & 1436 \pm 217 \quad 1327 \pm 137 \quad 1396 \pm 182 \quad 1180 \pm 204 & 1053 \pm 150 \quad 1434 \pm 214\end{array}$

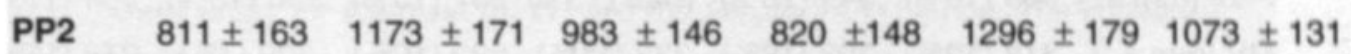

$\begin{array}{lllll}\text { PP3 } & 1197 \pm 209 & 1584 \pm 192 \quad 1322 \pm 178 \quad 1055 \pm 178 \quad 1433 \pm 164 \quad 1009 \pm 137\end{array}$

PP4 $1304 \pm 134 \quad 1038 \pm 179 \quad 948 \pm 154 \quad 1239 \pm 188 \quad 1117 \pm 192 \quad 1008 \pm 130$

$\begin{array}{llllllllll}\text { PP5 } 1312 \pm 218 & 1324 \pm 241 & 1257 & \pm 172 & 1424 & \pm 128 & 1249 & \pm 158 & 1460 & \pm 228\end{array}$

PP6 $1256 \pm 144 \quad 1402 \pm 223 \quad 1048 \pm 118 \quad 1472 \pm 199 \quad 1302 \pm 204 \quad 1278 \pm 177$

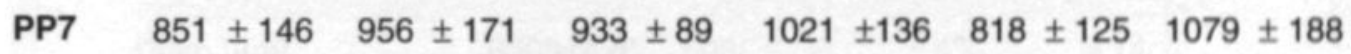

PP8 $\quad 1198 \pm 162 \quad 1271 \pm 172 \quad 1118 \pm 162 \quad 909 \pm 151 \quad 1053 \pm 163 \quad 909 \pm 152$ Mean $1161(15 \%) \quad 1241(15 \%) \quad 1104(13 \%) \quad 1132(15 \%) \quad 1189(15 \%) \quad 1150(15 \%)$

\section{MWSR}

\section{LEFT}

\section{DAY 1}

PP1

PP2

PP3

PP4

PP5

PP6

PP7

PP8

mean

$407 \pm 43$

$298 \pm 30$

$388 \pm 40$

$510 \pm 47$

$398 \pm 34$

$399 \pm 43$

$311 \pm 31$

$380 \pm 36$

\section{DAY 2}

DAY 7

$388 \pm 37$

$388 \pm 67$

$343 \pm 39$

$322 \pm 29$

$535 \pm 29$

$430 \pm 54$

$371 \pm 47$

$375 \pm 65$

$396 \pm 67$

$360 \pm 27$

$394 \pm 56$

$317 \pm 33$

$334 \pm 42$

$324 \pm 37$

$389 \pm 31$

$381 \pm 36$

$388(12 \%)$
356 (12\%)

\section{RIGHT}

DAY 1

DAY 2

DAY 7

$370 \pm 38 \quad 348 \pm 41 \quad 348 \pm 41$

$282 \pm 35 \quad 316 \pm 15 \quad 364 \pm 63$

$330 \pm 29 \quad 431 \pm 34$

$363 \pm 51$

$512 \pm 58$

$418 \pm 48$

$398 \pm 58$

$408 \pm 56$

$335 \pm 26$

$369 \pm 50$

$411 \pm 65$

$351 \pm 50$

$348 \pm 50$

$364 \pm 45$

$333 \pm 61$

$389 \pm 67$

$324 \pm 45$

$347 \pm 33$

$331 \pm 35$

$372(13 \%)$

$360(11 \%) \quad 365(15 \%)$ 


\section{Table 4.2}

Average values for peak systolic velocity (PSV), mean velocity (MV), peak wall shear rate (PWSR) and mean wall shear rate (MWSR) per day of the subpopulation of 8 males. Within parentheses, the mean intersubject intrasession coefficient of variation for left and right common carotid artery on day 1, day 2, and day 7 is given.

\begin{tabular}{lccccc}
\multicolumn{2}{c}{ Day 1} & \multicolumn{2}{c}{ Day 2 } & \multicolumn{2}{c}{ Day 7} \\
Left & Right & Left & Right & Left & Right \\
\hline $5(10 \%)$ & $944(16 \%)$ & $1028(13 \%)$ & $957(15 \%)$ & $936(13 \%)$ & $904(17 \%)$ \\
$8(12 \%)$ & $302(18 \%)$ & $333(11 \%)$ & $292(10 \%)$ & $309(7 \%)$ & $278(15 \%)$ \\
$71(19 \%)$ & $1140(20 \%)$ & $1259(16 \%)$ & $1165(17 \%)$ & $1126(16 \%)$ & $1156(18 \%)$ \\
$6(17 \%)$ & $375(19 \%)$ & $396(16 \%)$ & $360(12 \%)$ & $362(11 \%)$ & $364(6 \%)$
\end{tabular}

\subsubsection{Short and medium intersubject intersession variability (table 4.3)}

No significant differences in the measured parameters and their variabilities were found between the days ( $P W S R \mathrm{p}=0.82$, MWSR $\mathrm{p}=0.87$ ) indicating good short term and medium term reproducibility. In the left common carotid artery the variability over the days was $6 \%$ for PWSR (mean: $1168 \mathrm{~s}^{-1}$ ) and $5 \%$ for MWSR (mean: $375 \mathrm{~s}^{-1}$ ). In the right common carotid artery the variability over the days is $3 \%$ for the PWSR (mean: $1157 \mathrm{~s}^{-1}$ ) and $2 \%$ for MWSR (mean: $365 \mathrm{~s}^{-1}$ ).

In this group on day 1 , day 2 , and day 7 , blood pressure and heart rate values were in the normal range and did not vary significantly over the days.

In the male $(n=11)$ and female $(n=11)$ groups no significant differences in the measured parameters could be detected between the left and right common carotid arteries. Therefore, in both groups the data recorded on the left and right sides were pooled for comparison between the genders. 
PSV, MV, peak WSS (PWSS), PP and Ht were higher in the male than in the female group (table 4.3). PWSR and BMI were higher in males than in females, but these differences just did not reach the level of significance (table 4.3). MWSR, mean WSS (MWSS), SBP, DBP, MAP and plasma and calculated whole blood viscosity were not significantly different between both groups.

\section{Table 4.3}

Average values \pm standard deviations, pooled for the left and right common carotid artery for the male $(n=11)$ and the female $(n=11)$ group. The difference between males and females are given in percentage of the male values. $P$-value is the significance level of the difference. "denotes significant difference $(p<0.05)$ between the groups.

\begin{tabular}{|c|c|c|c|c|}
\hline & male & female & difference & p-value \\
\hline Diam $[\mu \mathrm{m}]$ & $6309 \pm 426$ & $6086 \pm 220$ & $4 \%$ & 0.14 \\
\hline $\mathrm{PSV}\left[\mathrm{mm} \cdot \mathrm{s}^{-1}\right]$ & $1045 \pm 214$ & $817 \pm 134$ & $22 \%$ & $0.00^{*}$ \\
\hline $\mathrm{MV}\left[\mathrm{mm} \cdot \mathrm{s}^{-1}\right]$ & $320 \pm 44$ & $267 \pm 56$ & $17 \%$ & $0.02^{*}$ \\
\hline PWSR $\left[s^{-1}\right]$ & $1338 \pm 376$ & $1074 \pm 244$ & $20 \%$ & 0.07 \\
\hline MWSR $\left[s^{-1}\right]$ & $414 \pm 82$ & $379 \pm 53$ & $8 \%$ & 0.25 \\
\hline PWSS [Pa] & $4.3 \pm 1.3$ & $3.3 \pm 0.68$ & $23 \%$ & $0.03^{*}$ \\
\hline MWSS [Pa] & $1.3 \pm 0.27$ & $1.2 \pm 0.18$ & $12 \%$ & 0.13 \\
\hline SBP [mmHg] & $118 \pm 7$ & $116 \pm 10$ & $3 \%$ & 0.51 \\
\hline DBP [mmHg] & $63 \pm 5$ & $68 \pm 8$ & $-6 \%$ & 0.17 \\
\hline $\mathrm{PP}[\mathrm{mmHg}]$ & $55 \pm 8$ & $48 \pm 5$ & $13 \%$ & $0.03^{*}$ \\
\hline $\mathrm{MAP}$ [mmHg] & $84 \pm 4$ & $85 \pm 8$ & $-1 \%$ & 0.73 \\
\hline $\mathrm{Ht}$ & $0.45 \pm 0.03$ & $0.40 \pm 0.03$ & $11 \%$ & $0.00^{*}$ \\
\hline Plasma Visc. [mPa.s] & $1.11 \pm 0.07$ & $1.11 \pm 0.05$ & $0 \%$ & 0.97 \\
\hline WBV [mPa.s] & $3.20 \pm 0.29$ & $3.09 \pm 0.29$ & $3 \%$ & 0.39 \\
\hline BMI $\left[\mathrm{kg} \cdot \mathrm{m}^{-2}\right]$ & 23.6 & 21.8 & $7 \%$ & 0.06 \\
\hline
\end{tabular}




\subsection{Discussion}

The findings in the present study show that peak and mean wall shear rate can be determined with the Shear Rate Estimating System with moderate variability. Wall shear stress was estimated from measured wall shear rate and calculated whole blood viscosity. The mean wall shear stress found is the same (on the order of 1.2 $\mathrm{Pa}$ ) in young males and females, but peak wall shear stress is higher in young males.

The wall shear rate values found in the present study are in agreement with those in a previous study on a different set of subjects (Hoeks et al. 1995). The values of mean wall shear stress as found in the present study are similar to those found by other investigators (Rodbard 1970; Kamiya and Togawa 1980; Zarins et al. 1987).

The intersubject intrasession variability exceeds the intrasubject intrasession variability for peak wall shear rate, but these variabilities are the same for mean wall shear rate.

For both the peak wall shear rate and the mean wall shear rate in the left and right common carotid arteries, the intersubject intrasession variability declines over the days, indicating regression to the mean after the first day of measurement. This reduced variability over the days could result from diminished biological variability because of acquaintance of the volunteers with the procedure, despite the fact that on all three days the measurements did not start before hemodynamic stability was attained. Although the intersubject intrasession variability declined, the mean values of peak and mean wall shear rate were not significantly different over the days. Therefore, in future studies one session will be enough to assess the shear rate in a given subject, but probably with a slightly larger variability. The standard error of the estimate can be reduced by increasing the number of measurements within a relatively short period of time to minimise the effect of physiological variations. 
In subject 3 and 4 peak wall shear rate and mean wall shear rate were significantly different on day 1 and day 2 (table 4.1). This can be explained by differences in hemodynamic conditions as indicated by the differences in peak systolic and mean centre stream velocity, and heart rate (data not shown) on those two days. If these subjects are excluded, the mean intersubject intrasession variability is reduced from $12 \%$ to about $8 \%$ for mean wall shear rate, but it remains the same for peak wall shear rate $(15 \%)$. These variations in hemodynamics are likely to be cardiac in origin, because peak and mean wall shear rate were similar in the right and left common carotid arteries. The absence of a difference in hemodynamics between the left and the right common carotid artery in both sexes is in agreement with previous findings (Fujishiro and Yoshimura 1982; Taylor 1988).

The hematocrit and plasma viscosity, for the calculation of whole blood viscosity, were assessed only on day 1 , because the variation in these parameters over the days will be small (Maes et al. 1995). Henceforth, the intra- and intersubject variability as well as the short term and long term variation of the calculated wall shear stress will be similar to those of the measured wall shear rate (see equation $(4-2))$.

In earlier studies using ultrasound (Kamiya and Togawa 1980; Hofstra et al. 1995; Hoeks et al. 1995) whole blood viscosity was assumed to be constant for the conversion from wall shear rate to wall shear stress. In the present study a more realistic individual estimation of wall shear stress was made based on hematocrit and plasma viscosity, which both depend on personal lifestyle as well as gender and age.

It is interesting to note that by taking into consideration calculated whole blood viscosity the nearly significant difference in peak wall shear rate between males and females shifts to a significant difference in peak wall shear stress. Although mean wall shear stress is the same in both groups, peak wall shear stress is lower in females than in males. Thus, whole blood viscosity has to be considered in interpreting the influence of shear on arterial wall function. 
Caro et al. found in the common carotid artery peak wall shear stresses of the same order. He suggested that oscillation of shear stress observed in the carotid bulb, rather than the unidirectional peak wall shear stress, coincides with the localisation of plaques. The physiological interaction of a higher peak wall shear stress on endothelial cells is yet unknown.

The moderate variability in the assessment of peak and mean wall shear rate as observed in this study is partly due to the limitation of measuring shear rate only over one cardiac cycle. Because of trade-offs between memory size, velocity range and range in depth, the recording time for a single observation is presently limited to 1.2 seconds. The data analysis is based on measurements over one single heart beat spaced in time, which results in a higher variance of the measurements than if the registrations were averaged over several consecutive heart beats.

In the Shear Rate Estimating System a high spatial resolution is obtained by the use of a high resolution ultrasound system in echo-mode (short pulse, narrow beam width) in combination with processing of the radio-frequent signal with a length of the sample window set at $0.30 \mathrm{~mm}$ (2 wavelengths), spaced at $0.15 \mathrm{~mm}$ (overlap $50 \%$ ) (Hoeks et al. 1994). An advantage of the Shear Rate Estimating System is that the time dependent changes in velocity distribution, and hence, in wall shear rate can be determined. This is not the case in studies in which wall shear rate is estimated by means of the Hagen-Poiseuille approximation requiring the measurement of the centre stream velocity with conventional pulsed Doppler systems and of vessel diameter (Binns et al. 1989; Hofstra et al. 1995).

The Shear Rate Estimating System allows the simultaneous assessment of wall shear rate, vessel diameter and distensibility (figure 4.3) making it possible to study the relationship between artery wall function and wall shear rate or stress.

The Shear Rate Estimating System described can only be employed in straight vessel segments, like the common carotid artery, where a symmetric velocity profile can be expected. The Shear Rate Estimating System measures blood flow velocity based on the Doppler principle (velocity vector projection) and therefore, secondary flows will interfere with the determination of the axial vector in the blood vessel (Brands et al. 1995). 
In the present Shear Rate Estimating System the maximal centre stream velocity that can be determined is limited to $1800 \mathrm{~mm} \cdot \mathrm{s}^{-1}$ by velocity aliasing. This limitation depends on the pulse repetition frequency, the ultrasound carrier frequency $(5 \mathrm{MHz})$ and the angle of interrogation $\left(70^{\circ}\right)$ of the vessel. A higher pulse repetition frequency permits detection of higher blood flow velocities, but limits the depth of interrogation. In both groups, however, none of the subjects exhibited peak blood flow velocities exceeding $1800 \mathrm{~mm} \cdot \mathrm{s}^{-1}$ and nobody had to be excluded from the study because of suspected velocity aliasing.

In conclusion, it is shown that with the wall Shear Rate Estimating System, as described in this study, wall shear rate can be assessed in the common carotid artery with a moderate variability. Despite a difference in peak and mean centre stream velocity between the male and female groups, the peak and mean wall shear rates are not significantly different. Peak wall shear stress, however, is slightly higher in males than in females, but mean wall shear stress is the same in both sexes.

\subsection{References}

Binns RL, Ku DN, Stewart MT, Ansley JP, Coyle KA. Optimal graft diameter: effect of wall shear stress on vascular healing. J Vasc Surg 1989;10:326-37.

Brands PJ, Hoeks APG, Hofstra L, Reneman RS. A noninvasive method to estimate wall shear rate using ultrasound. Ultrasound Med Biol 1995;21:171-185.

Caro CG, Dumoulin CL, Graham KH, Parker KH, Souza SP. Secondary flow in the human common carotid artery imaged by MR angiography. J Biomech Eng 1992;114:147-149.

Frangos JA, Eskin SG, Mctire LV. Flow effects on prostacyclin production by cultured human endothelial cells. Science 1985;227:1477-1479. 
Fujishiro K, Yoshimura S. Haemodynamic changes in carotid blood flow with age. Study on non-invasive measurements of changes with age in blood flow velocity, vessel diameter and blood flow volume in common carotid artery. Jikeika Med J 1982;29:125-138.

Hoeks APG, Arts TGJ, Brands PJ, Reneman RS. Processing scheme for velocity estimation using ultrasound RF cross correlation techniques. Eur $\mathrm{J}$ Ultrasound 1994;1:171-182.

Hoeks APG, Samijo SK, Brands PJ, Reneman RS. Assessment of wall shear rate in humans: an ultrasound study. J Vasc Invest 1995;1:108-117.

Hofstra L, Bergmans DCJJ, Leunissen KML, Hoeks APG, Kitslaar PJEHM, Daemen MJAP, Tordoir JHM. Anastomotic intimal hyperplasia in prosthetic arteriovenous fistulas for hemodialysis is associated with initial high flow velocity and not with mismatch in elastic properties. J Am Soc Nephrol 1995;6:1625-1633.

Kamiya A, Togawa T. Adaptive regulation of wall shear stress to flow change in the canine carotid artery. Am J Physiol 1980;239:H14-H21.

Ling SC, Atabek HB, Fry DL, Patel DJ, Janicki BS. Application of heated-film velocity and shear probes to heamodynamic studies. Circ Res 1968;66:1624-1635.

Maes M, Scharpe S, Cooreman W, Wauters A, Neels H, Verkerk R, De Meyer F, D'Hondt P, Peeters D, Cosyns P. Components of biological, including seasonal, variation in hematological measurements and plasma fibrinogen concentrations in normal humans. Experientia 1995;51:141-9.

Malek A, Izumo S. Physiogical shear stress causes downregulation of endotheline-1 mRNA in bovine aortic endothelium. Am J Physiol 1992;32:C392-C396.

Rodbard S. Negative feedback mechanisms in the architecture and function of the connective and cardiovascular tissues. Perspect Biol Med 1970;13:507-527. 
Rubanyi GM, Freay AD, Kauser K, Johns A, Harder DA. Mechanoreception by the endothelium: mediators and mechanisms of pressure and flow induced vascular responses. Blood Vessels 1990;27:246-257.

Sharefkin JB, Diamond SL, Eskin SG, Mcintire LV, Dieffenbach CW. Fluid flow decreases preproendothelin mRNA levels and suppresses endotheline-1 peptide release in cultured human endothelial cells. J Vasc Surg 1991:14:1-9.

Taylor KJW. Clinical applications of carotid doppler ultrasound. In: Clinical applications of Doppler ultrasound, K Taylor, P Burns, P Wells (ed). New York: Raven Press, 1988: 120-161.

Weaver JPA, Evans A, Walder DN. The effect of increased fibrinogen content of the viscosity of blood. Clin Sci 1969;36:1-10.

White KC, Kavanaugh JF, Wang DM, Tarbell JM. Hemodynamics and wall shear rate in the abdominal aorta of dogs. Circ Res 1994;75:637-649.

Zarins CK, Zatina MA, Giddens DP, Ku DN, Glagov S. Shear stress regulation of artery lumen diameter in experimental atherogenesis. J Vasc Surg 1987;5:413-420. 
Reproducibility of wall shear rate and stress 


\section{Wall shear stress in the common carotid artery as function of age and gender}

\begin{tabular}{|c|c|}
\hline 5.1 & Abstract \\
\hline 5.2 & Introduction \\
\hline 5.3 & Materials and methods \\
\hline 5.3 .1 & Subjects \\
\hline 5.3 .2 & Wall shear rate assessment: \\
\hline & The Shear Rate Estimating System \\
\hline 5.3 .3 & Hemodynamic monitoring \\
\hline 5.3 .4 & Assessment of compliance \\
\hline 5.3 .5 & Biochemical analysis \\
\hline 5.3 .6 & Wall shear stress assessment \\
\hline 5.3 .7 & Measurement procedure \\
\hline 5.3 .8 & Statistical analysis \\
\hline 5.4 & Results \\
\hline 5.4 .1 & Wall shear stress as function of age \\
\hline 5.4 .2 & $\begin{array}{l}\text { Wall shear rate and blood flow velocity } \\
\text { as function of age }\end{array}$ \\
\hline 5.4 .3 & WBV as function of age \\
\hline 5.4 .4 & Diameter and compliance as function of age \\
\hline 5.5 & Discussion \\
\hline & References \\
\hline
\end{tabular}

S.K. Samijo, J.M. Willigers, R. Barkhuysen, P.J.E.H.M. Kitslaar, R.S. Reneman, P.J. Brands, A.P.G. Hoeks.

Published in: Cardiovascular Research, 39:515-522, 1998. 
Wall shear stress as function of age and gender 


\subsection{Abstract}

Wall shear stress (wall shear rate multiplied by whole blood viscosity) was assessed in the right common carotid artery (CCA) of 111 presumed healthy male $(n=56)$ and female $(n=55)$ volunteers, varying in age between 10 and 60 years. Wall shear rate was measured with a high resolution ultrasound system. Whole blood viscosity was calculated from hematocrit, plasma viscosity and shear rate. Simultaneously, arterial diameter and compliance were determined. From the second to the sixth age decade peak wall shear stress was significantly higher in males than in females and decreased linearly from 4.3 $\mathrm{Pa}$ to $2.6 \mathrm{~Pa}(r=-0.56, p<0.001)$ in males and from 3.3 $\mathrm{Pa}$ to $2.5 \mathrm{~Pa}(r=-0.54, p<0.001)$ in females. Mean wall shear stress tended to decrease from 1.5 $\mathrm{Pa}$ to $1.2 \mathrm{~Pa}(r=-0.26, p=0.057)$ in males and decreased significantly from 1.3 $\mathrm{Pa}$ to $1.1 \mathrm{~Pa}(r=-0.30, p=0.021)$ in females. No significant difference in mean wall shear stress was found between males and females in any age decade. The diameter of the CCA increased significantly in both males $(r=0.26$, $p<0.05)$ and females $(r=0.40, p<0.003)$. Compliance decreased significantly in both sexes (males: $r=-0.48, p<0.001$; females: $r=-0.69, p<0.001$ ). It is proposed that the reduction in mean wall shear stress with age results from the concomitant increase in diameter in an attempt to limit the reduction in compliance of the artery with increasing age.

\subsection{Introduction}

Wall shear stress is the drag exerted by flowing blood on the vessel wall. This stress is thought to play an important role in adaptational processes of the vascular wall by inducing the production by endothelial cells of substances such as nitricoxide (Joannides et al. 1995, Rubanyi et al. 1990), prostacyclin (Frangos et al. 1985), and endothelin (Sharefkin et al. 1991).

Based on the assumption that the arterial tree is an optimally designed conduit system mean wall shear stress can be expected to be the same for all vessels to achieve minimal expenditure of energy for flowing blood (minimum work model) 
(Murray 1926, Rodbard 1970). Under physiological circumstances this value was estimated to be on the order of $1.5 \mathrm{~Pa}\left(15 \mathrm{dyne} / \mathrm{cm}^{2}\right)$, irrespective of calibre and function of the vessel (Kamiya and Togawa 1980, LaBarbera 1990). Indeed, in the monkey iliac artery Zarins et al. found mean wall shear stress to be regulated around this value through diameter adaptations (Zarins et al. 1987). Similar observations were made by Langille and O' Donnell in the rabbit common carotid artery (Langille et al. 1989). These investigators also showed the diameter adaptation response to be age dependent, i.e. less efficacy at older age. These studies indicate that mean wall shear stress is regulated around a certain constant value by adapting the internal diameter of the vessel to the quantity of blood flowing through it.

Studies in humans showed an increase of luminal diameter and stiffening of the vessel wall with advancing age (Baskett et al. 1990, Fujishiro and Yoshimura 1982, Hansen et al. 1995, Laogun and Gosling 1982, Reneman et al. 1985, Reneman et al. 1986). The diameter increase throughout life may be attributed to an effort to limit the reduction of compliance with increasing age (Reneman et al. 1986). Assuming that the blood flow per unit of tissue is independent of age, estimated mean wall shear stress would decrease with age due to the age-dependent increase in diameter (Duncan et al. 1990, Nichols and O'Rourke 1990, Perktold et al. 1994). This, however, would be at variance with the hypothesis that wall shear stress is maintained at the same level through diameter adaptations.

It was the aim of the present study to investigate the age and sex dependent changes in wall shear stress, if any, in the common carotid artery of presumed healthy male and female volunteers varying in age between 10 and 60 years. The diameter and the compliance of this artery were assessed as well. Wall shear stress was calculated from wall shear rate and whole blood viscosity. Wall shear rate was determined with a specially designed ultrasonic Shear Rate Estimation System developed at our institute (Brands et al. 1995, Hoeks et al. 1995). This system also allows the simultaneous assessment of arterial diameter and compliance using a wall tracking algorithm (Hoeks et al. 1990). Whole blood viscosity was estimated from hematocrit, plasma viscosity and mean wall shear rate. 


\subsection{Materials and methods}

\subsubsection{Subjects}

Two hundred (100 males and 100 females) subjects, varying in age between 10 and 60 years and living in the Maastricht city and environment, were contacted between September 1995 and August 1996. Their names and addresses were randomly selected from the population register of Maastricht. Respondents who smoked and/or used medication were excluded, leaving 129 subjects for further analysis. From these subjects 18 had to be excluded from the study: eleven subjects because of diagnosed hypertension (>140 mmHg systolic and/or $>90 \mathrm{mmHg}$ diastolic blood pressure) and/or cholesterol levels higher than $6.4 \mathrm{mmol} / \mathrm{L}, 2$ subjects because of elevated glucose levels (>10 mmol/l) and 5 subjects because of detected plaques in the carotid artery bifurcation, leaving 111 subjects (55 females and 56 males) for further analysis. None of these participants had a history of cardiopulmonary or other major diseases and all were clinically free of cardiovascular symptoms. All subjects had normal levels of haemoglobin, hematocrit, glucose, cholesterol, HDL, LDL, triglycerides and plasma viscosity. According to institutional guidelines, all subjects, including the parents of the subjects younger than 18 years, were aware of the investigational nature of the study and gave written informed consent. The study was approved by the joint medical ethical committee of the Academic Hospital Maastricht and Maastricht University.

\subsubsection{Wall shear rate assessment: The Shear Rate Estimation System}

The ultrasonic system to measure wall shear rate has been described in detail before (Brands et al. 1995, Hoeks et al. 1995, Samijo et al. 1997). In short, for the present study the Shear Rate Estimation System (SRES) consisted of an Ultramark 9 plus (Advanced Technology Laboratories, Bellevue, WA, USA) with a broadband (5-9 $\mathrm{MHz}$ ) curved array transducer and an ultrasonic processing system in a personal computer (figure 5.1). The received raw digitised $(20 \mathrm{MHz})$ radio-frequent 
(rf) signals were transferred to the personal computer $(486 \mathrm{DX} 4 / 100)$ through an interface configuration consisting of an internal card in the ATL-system in combination with a custom built plug-in card for the PC. The latter card makes it possible to selectively capture segments of the if signals starting at a preselected depth and with a preselected width. To assess the instantaneous blood velocity distribution along a selected line of observation (in B-mode) with a high axial resolution, the echo system was switched to a wide band pulsed Doppler mode with short transducer activation.

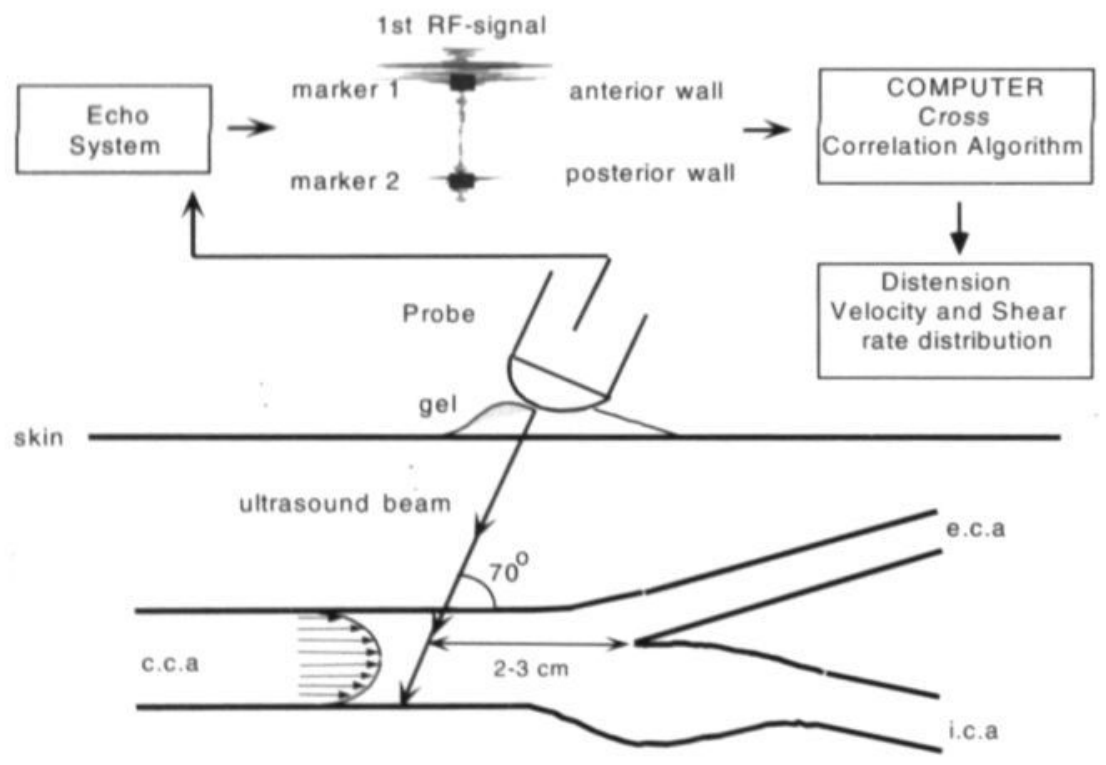

Figure 5.1

Schematic representation of the shear rate measurement procedure. After a measurement is recalled the end-diastolic lumen boundaries are manually identified with markers, whereupon calculation of distension waveform, velocity and shear rate distribution is started. c.c.a= common carotid artery; e.c.a. =external carotid artery; i.c.a. $=$ internal carotid artery. 
The returned acoustic signals have an effective pulse length of 3 periods at $5.3 \mathrm{MHz}$ equivalent to a spatial resolution of $375 \mu \mathrm{m}$. Each velocity estimate is based on overlapping data segments of $300 \mu \mathrm{m}$ in depth and $10 \mathrm{~ms}$ in time and is obtained using a modelled cross correlation function for the if signal (Brands et al. 1995). Data acquisition is initiated synchronously with a trigger derived from the top of the R-wave of the ECG, facilitating the detection of the maximum (systolic), mean and minimum (diastolic) velocity (in $\mathrm{mm}^{-1} \mathrm{~s}^{-1}$ ) as well as the initial (diastolic) arterial diameter. The available PC memory presently limits the recording time to 1.2 seconds, which is sufficient to capture data of one heartbeat. Processing of the received $\mathrm{r}$ signals as function of time provides both the time dependent change of arterial diameter (distension waveform) (Hoeks et al. 1990) and the velocity distribution as function of depth (figure 5.2a) (Brands et al. 1995).
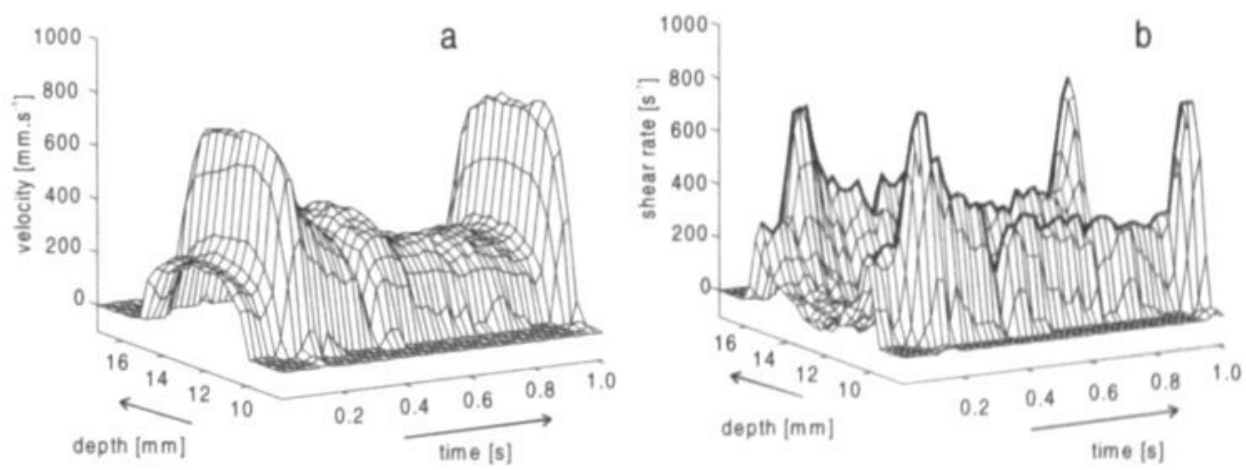

Figure 5.2

(a) The velocity distribution across the diameter as function of time in the common carotid artery of a presumed healthy male volunteer. The velocity profile is a flattened parabola.

(b) The instantaneous shear rate distribution as function of time in the common carotid artery of the same volunteer showing the highest values near the vessel walls with the peak values in systole. 
The peak value of the distension waveform gives the distension $(\Delta D)$. The velocity waveform as recorded in the centre of the lumen provides peak systolic velocity ( $P S V$ in mm. $\left.\mathrm{s}^{-1}\right)$ and mean velocity $\left(M V\right.$ in $\left.\mathrm{mm} \cdot \mathrm{s}^{-1}\right)$. The latter is comparable with the mean of the spatial envelope of the Doppler signal received with conventional pulsed Doppler systems in the centre of the lumen.

The instantaneous shear rate distribution follows from the radial derivative of the velocity profile at each time instant. A typical recording of a shear rate distribution is shown in figure $5.2 \mathrm{~b}$. The maximum value of the derivative, averaged for the anterior and posterior wall of the vessel, is considered as an estimate of wall shear rate. The averaging procedure is performed to minimise possible effects induced by secondary flows (Brands et al. 1995). The peak wall shear rate in systole (PWSR in $\mathrm{s}^{-1}$ ) and shear rate averaged over one cardiac cycle, i.e., mean wall shear rate (MWSR in $\mathrm{s}^{-1}$ ), are used for further analysis.

\subsubsection{Hemodynamic monitoring}

Brachial artery blood pressure and heart rate were determined with a semiautomated oscillometric device (Dinamap; Critikon, Tampa, Florida, USA), which was set to take a recording every 5 minutes.

\subsubsection{Assessment of compliance}

To investigate the relationship between wall shear stress and the elastic behaviour of the vessel wall, if any, the compliance coefficient (CC) of the common carotid artery was calculated from the measured diameter, distension and blood pressure data:

$$
C C=\pi \frac{\Delta D^{*} D}{2 \Delta P} \quad\left[\mathrm{~mm}^{2} / \mathrm{kPa}\right]
$$


where $D$ is end-diastolic diameter in $\mathrm{mm}$ and $\Delta P$ is pulse pressure (systolic minus diastolic pressure) in $\mathrm{kPa}$ as measured at the brachial artery in the upper arm. The latter is an estimate of the pulse pressure in the common carotid artery (Reneman et al. 1986). This coefficient can be regarded as a parameter for the storage capacity of an arterial segment for blood.

\subsubsection{Biochemical analysis}

Blood samples were obtained without stasis from an antecubital vein for determination of hematocrit, haemoglobin, glucose, high density lipoprotein (HDL), low density lipoprotein (LDL), triglycerides and cholesterol using standard autoanalysing techniques. Plasma viscosity was determined using an Ostwald microviscometer (Schott Gerate GMBH, Hofheim, Germany).

\subsubsection{Wall shear stress assessment}

From plasma viscosity, hematocrit and mean wall shear rate whole blood viscosity (WBV) can be estimated using the approximation proposed by Weaver (Weaver et al. 1969):

$$
\log W B V=\log \eta_{0}+\alpha \cdot H t
$$

with

$$
\alpha=0.030-0.0076 \log (\text { MWSR }
$$

where $W B V$ is whole blood viscosity in $\mathrm{mPa} . \mathrm{s}, \eta_{0}$ plasma viscosity in $\mathrm{mPa} . \mathrm{s}, \mathrm{Ht}$ hematocrit in percentage, and MWSR mean wall shear rate in $\mathrm{s}^{-1}$. This approximation circumvents the practical problems associated with the direct measurement of whole blood viscosity.

To asses wall shear stress (WSS), wall shear rate (WSR) was multiplied by the estimated whole blood viscosity, employing the relationship:

$$
W S S=W B V^{*} W S R
$$




\subsubsection{Measurement Procedure}

The measurements were always performed in the morning. The subjects were examined in supine position in a climatised room with a temperature of $22^{\circ} \mathrm{C}-24^{\circ} \mathrm{C}$. A history on symptoms related to atherosclerosis was taken, after which a physical examination was performed. Blood was collected and after an acclimatisation period of at least 10 minutes the blood pressure and ultrasound measurements started. The echosystem was switched to B-mode to verify if both common, internal and external carotid arteries were free of plaques and to select the site of measurement. Wall shear rate measurements were performed only in the right common carotid artery as preliminary studies have shown that there are no differences in hemodynamics between the left and right common carotid arteries (Fujishiro and Yoshimura 1982, Olson 1974, Samijo et al. 1997, Taylor 1988). A line of observation was selected crossing the right common carotid artery (CCA) 2 to $3 \mathrm{~cm}$ proximal to the tip of the flow divider at an angle of 70 degrees with the longitudinal axis of the artery (figure 5.2). Hereafter a recording during 1.2 seconds of the received if signals was made and stored on the hard disk of the computer. The measurement procedure was repeated 20 times with a time interval of 2 to 3 minutes. After these measurements, each recording was recalled where after the vessel walls were manually identified by placing sample volumes, indicated by markers, on the reflections of the anterior and posterior vessel wall (figure 5.2). The distance between both markers, corrected for the angle of observation, is considered as the initial (end-diastolic) diameter ( $D$ in $\mu \mathrm{m}$ ) of the vessel.

At the end of the measurement session the SRES was set to calculate artery wall distension, and the velocity and wall shear rate distributions in the artery, taking about 2 minutes per measurement with the computer employed. From the 20 independent measurements per subject only recordings with an axial symmetrical velocity profile were included. Within each session on the average 1 to 2 recordings had to be excluded, because they did not meet the criteria. 


\subsubsection{Statistical analysis}

Data are expressed as mean \pm standard deviation (SD). The unpaired Student's t-test was employed to explore whether differences in the parameters measured with the SRES were statistically significant between males and females. To investigate age dependency linear regression was performed. Regression coefficients (slope) are expressed with their standard error ( $r c \pm s e$ ). The significance level was set at $p<0.05$. All statistical analyses were performed with the statistical software package SPSS for Windows, release 6.0.

\subsection{Results}

\subsubsection{Wall shear stress as function of age}

Between 10 and 60 years of age PWSS and MWSS decreased in both the female and the male group (tables 5.1 and 5.2; figures 5.3 and 5.4).

In the female group PWSS decreased by $26 \%$ ( 3.33 to $2.48 \mathrm{~Pa}, \mathrm{rc}=-0.024 \pm 0.005$ ) and MWSS by $19 \%(1.29$ to $1.05 \mathrm{~Pa}, \mathrm{rc}=-0.005 \pm 0.002)$. In the male group these parameters decreased by $40 \%(4.27$ to $2.56 \mathrm{~Pa}, \mathrm{rc}=-0.035 \pm 0.007)$ and $18 \%(1.45$ to $1.19 \mathrm{~Pa}, \mathrm{rc}=-0.005 \pm 0.002)$, respectively. PWSS was significantly higher in males than in females, until the sixth age decade. The regression coefficients for this parameter were similar for both groups (figure 5.3). MWSS decreased slightly but significantly in the female group and was similar to the male group, although the latter descent just did not reach the level of significance (figure 5.4). 


\section{Table 5.1}

Peak (PSV) and mean (MV) blood flow velocity, peak (PWSR) and mean (MWSR) wall shear rate, and peak (PWSS) and mean (MWSS) wall shear stress as function of age per decade in the right common carotid artery in the female group $(n=55)$. * denotes significant difference compared to the male group (table 5.2).

\section{Females}

$\begin{array}{cccccccc}\text { age } & \mathbf{n} & \begin{array}{c}\text { PSV } \\ {\left[\mathrm{mm} \cdot \mathbf{s}^{-1}\right]}\end{array} & \begin{array}{c}\text { MV } \\ {\left[\mathrm{mm} \cdot \mathbf{s}^{-1}\right]}\end{array} & \begin{array}{c}\text { PWSR } \\ {\left[\mathbf{s}^{-1}\right]}\end{array} & \begin{array}{c}\text { MWSR } \\ {\left[\mathbf{s}^{-1}\right]}\end{array} & \begin{array}{c}\text { PWSS } \\ {[\mathrm{Pa}]}\end{array} & \begin{array}{c}\text { MWSS } \\ {[\mathrm{Pa}]}\end{array} \\ 10-19 \text { y } & 10 & 848 \pm 149 & 315 \pm 59 & 1150 \pm 191 & 450 \pm 85 & 3.33 \pm 0.62^{*} & 1.29 \pm 0.16 \\ 20-29 \text { y } & 12 & 762 \pm 136 & 267 \pm 40 & 965 \pm 182 & 375 \pm 52 & 2.87 \pm 0.49^{*} & 1.12 \pm 0.18 \\ 30-39 \text { y } & 15 & 706 \pm 133 & 289 \pm 43 & 906 \pm 152 & 379 \pm 80 & 2.75 \pm 0.57^{*} & 1.14 \pm 0.24 \\ 40-49 \text { y } & 10 & 592 \pm 76 & 266 \pm 55 & 748 \pm 138 & 357 \pm 111 & 2.36 \pm 0.25^{*} & 1.11 \pm 0.23 \\ 50-59 \text { y } & 8 & 621 \pm 88 & 282 \pm 52 & 793 \pm 136 & 341 \pm 99 & 2.48 \pm 0.38 & 1.05 \pm 0.23\end{array}$

\section{Table 5.2}

Peak (PSV) and mean (MV) blood flow velocity, peak (PWSR) and mean (MWSR) wall shear rate, and peak (PWSS) and mean (MWSS) wall shear stress as function of age per decade in the right common carotid artery in the male group $(n=56)$.

\section{Males}

\begin{tabular}{|c|c|c|c|c|c|c|c|}
\hline & 1 & PS & MV & $\begin{array}{c}\text { PWSR } \\
{\left[\mathrm{s}^{-1}\right]}\end{array}$ & $\begin{array}{c}\text { MWSR } \\
{\left[\mathrm{s}^{-1}\right]}\end{array}$ & $\begin{array}{c}\text { PWSS } \\
\text { [Pa] }\end{array}$ & $\begin{array}{c}\text { MWSS } \\
{[\mathrm{Pa}]}\end{array}$ \\
\hline & 8 & & $347 \pm 37$ & 9 & 8 & 78 & 45 \\
\hline & 12 & 4 & $9+47$ & 1050 & 408 . & 3.59 & 1.39 \\
\hline & 18 & 8. & $27+4$ & $983 \pm 188$ & $375 \pm 74$ & 8 & $1.24 \pm 0.21$ \\
\hline & 11 & & & & 10 & $7 \pm 0.44$ & 122 \\
\hline & & & & $08 \pm 114$ & $57=$ & $56 \pm 0.31$ & .19 \\
\hline
\end{tabular}




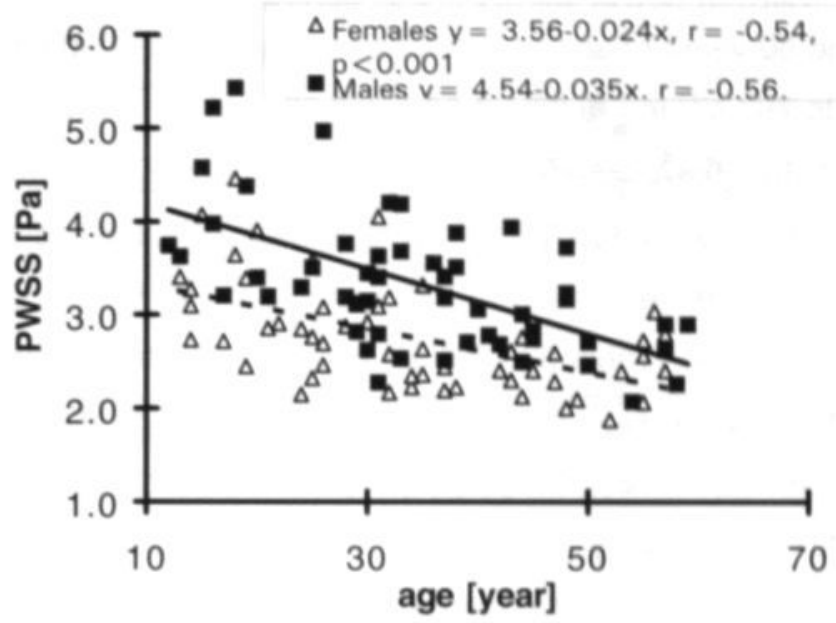

Figure $\mathbf{5 . 3}$

Peak wall shear stress (PWSS) in the right common carotid artery as function of age in the female and male groups.

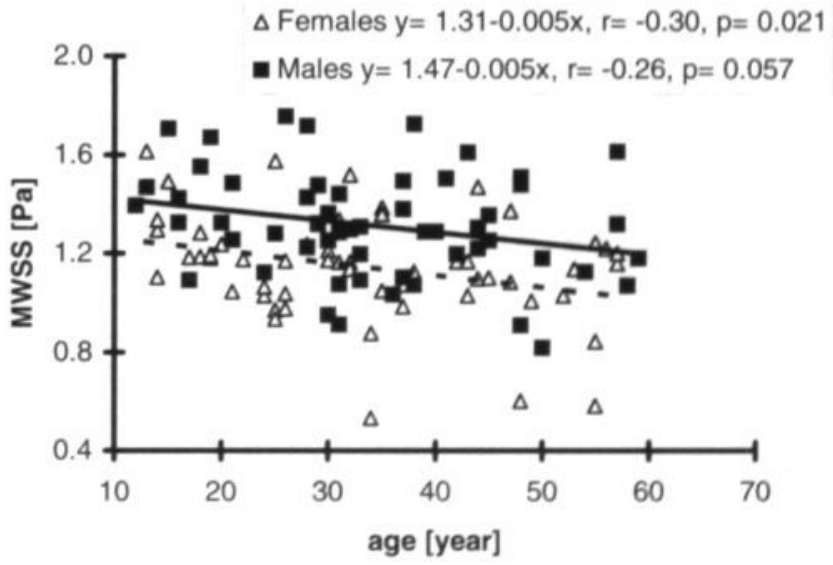

Figure 5.4

Mean wall shear stress (MWSS) in the right common carotid artery as function of age in the female and male groups. 


\subsubsection{Wall shear rate and blood flow velocity as function of age}

Between 10 and 60 years of age in the female group PWSR (table 5.1) decreased by $31 \%\left(1150\right.$ to $\left.793 \mathrm{~s}^{-1}, \mathrm{rc}=-9.82 \pm 1.68, \mathrm{r}=-0.63, \mathrm{p}<0.001\right)$, MWSR by $24 \%(450$ to $\left.341 \mathrm{~s}^{-1}, \mathrm{rc}=-2.40 \pm 0.87, \mathrm{r}=-0.35, \mathrm{p}<0.008\right)$ and PSV by $27 \%\left(848\right.$ to $621 \mathrm{~mm} . \mathrm{s}^{-1}$, $r c=-6.74 \pm 1.23, r=-0.60, p<0.001) . M V$ decreased by $10 \%$, but this descent did not reach the level of significance $\left(315\right.$ to $282 \mathrm{~mm} \cdot \mathrm{s}^{-1}, \mathrm{rc}=-0.72 \pm 0.52, \mathrm{r}=-0.19, \mathrm{p}=$ 0.17). In the male group (Table 5.2) PWSR decreased with age by $45 \%$ (1389 to $\left.767 \mathrm{~s}^{-1}, \mathrm{rc}=-11.79 \pm 2.41, \mathrm{r}=-0.55, \mathrm{p}<0.001\right)$, MWSR by $25 \%\left(475\right.$ to $357 \mathrm{~s}^{-1}, \mathrm{rc}=-$ $1.79 \pm 0.88, r=-0.30, p<0.025)$, PSV by $32 \%\left(976\right.$ to $667 \mathrm{~mm} . \mathrm{s}^{-1}, \mathrm{rc}=-7.08 \pm 1.41$, $r=-0.56, p<0.001)$, and MV by $13 \%$ (347 to $301 \mathrm{~mm} . \mathrm{s}^{-1}, r \mathrm{r}=-0.94 \pm 0.58, r=-0.27$, $p<0.111)$. The regression coefficients for either of these parameters were not significantly different between the male and the female group.

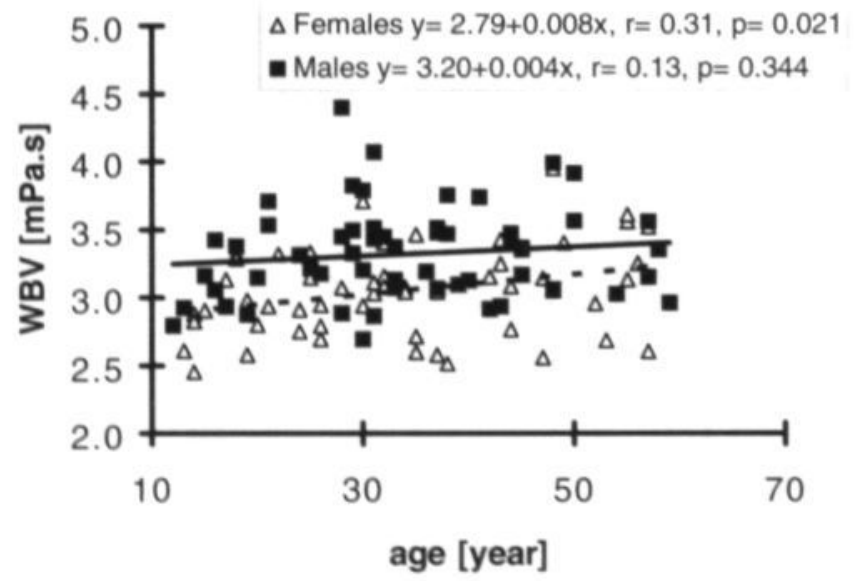

Figure 5.5

Whole blood viscosity (WBV) as function of age in the female and male groups. 


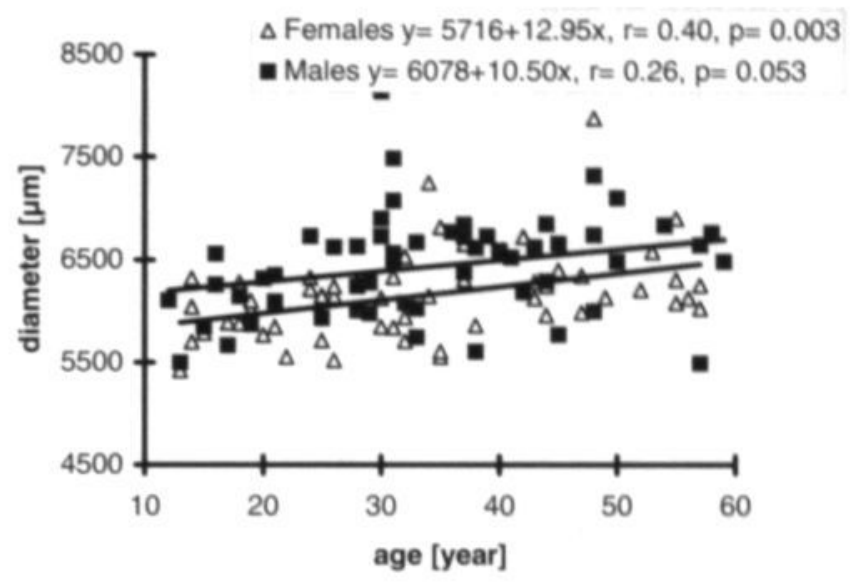

Figure 5.6

Internal diameter of the right common carotid artery (CCA) as function of age in the female and male groups.

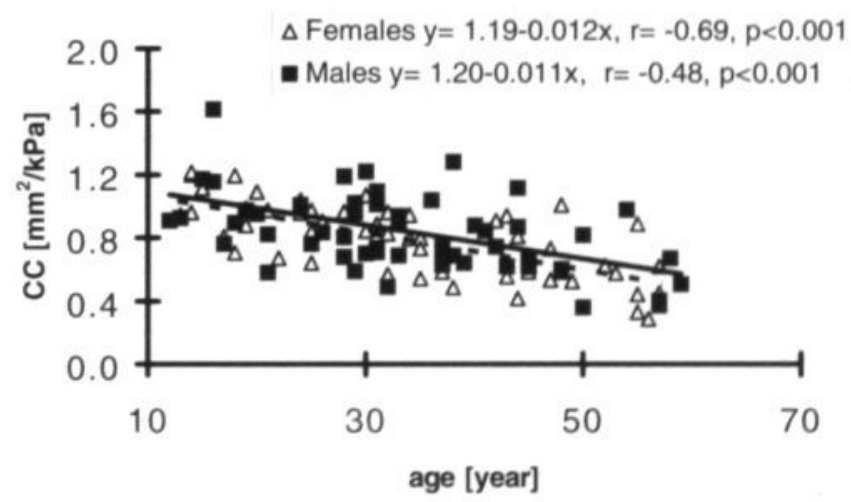

Figure 5.7

The compliance coefficient of the right common carotid (CCA) artery in the female and male groups as function of age. 


\subsubsection{WBV as function of age}

In the female group WBV showed a significant increase of $10 \%$ (2.89 to $3.18 \mathrm{mPa} . \mathrm{s}$, $r c=0.008 \pm 0.003, r=0.31, p<0.021$ ) between 10 and 60 years of age. In the male group WBV tended to increase about $6 \%$ (from 3.03 to $3.22 \mathrm{mPa} . \mathrm{s}, \mathrm{rc}=0.004 \pm$ $0.004, r=0.13, p=0.34)$, but this change did not reach the level of significance (figure 5.5).

\subsubsection{Diameter and compliance as function of age}

In both sexes the diameter of the CCA increased significantly about $7 \%$ (females from 5.92 to $6.31 \mathrm{~mm}$ and males from 6.02 to $6.44 \mathrm{~mm}$ ) from the second to the sixth age decade. The diameter increase (figure 5.6) with age was similar for both sexes (females: $r c=12.9 \pm 4.1, r=0.40, p=0.003$; males: $r c=10.5 \pm 5.3, r=0.26, p=0.05$ ). CC decreased significantly by $48 \%\left(1.01\right.$ to $0.53 \mathrm{~mm}^{2} / \mathrm{kPa}, \mathrm{rC}=-0.012 \pm 0.002, \mathrm{r}=$ $-0.69, \mathrm{p}<0.001)$ in the female group and by $46 \%\left(1.05\right.$ to $0.59 \mathrm{~mm}^{2} / \mathrm{kPa}, \mathrm{rc}=-0.011$ $\pm 0.003, r=-0.48, p<0.001$ ) in the male group (figure 5.7 ). It is of interest to note that in this population the decrease in $C C$ is not due to an increase of $\triangle \mathrm{P}$. From the second to the sixth age decade $\Delta P$ decreased significantly in males $(\mathrm{rC}=-0.37 \pm$ $0.07, r=-0.54, p<0.001)$ and did not change in the females $(r c=0.10 \pm 0.08, r=0.17$, $p=0.21$ ). Therefore the observed decrease in compliance with increasing age can only be attributed to a loss of elasticity of the arterial wall.

\subsection{Discussion}

In this study peak and mean wall shear stress in the right common carotid artery of humans, varying in age between 10 and 60 years were determined with a noninvasive system based on ultrasound technology. In both sexes peak and mean wall shear stress decreased linearly with age. The decrease in peak wall shear stress is more pronounced in males than in females up to the sixth age decade. No significant difference in mean wall shear stress could be found between males and females. 
For both sexes the decrease in peak wall shear stress with age can be explained by the descent of peak wall shear rate due to a decrease in peak systolic blood flow velocity. The latter is in agreement with previous studies in which blood flow velocity was also found to decrease with age (Fujishiro and Yoshimura 1982, Taylor 1988). The higher peak wall shear stress in males than in females can be attributed to the higher peak wall shear rates (although not significantly different per decade) combined with the higher whole blood viscosities in males. The higher blood viscosity in males than in females as observed in the present study is in agreement with observations of de Simone et al. (de Simone et al. 1990). The physiological implication of a difference in peak wall shear stress due to gender for the vessel wall is as yet unknown and needs further investigation.

The descent of mean wall shear stress with age in both sexes was surprising, because we expected this parameter to be regulated around the same value. This hypothesis was based on the minimum work theory, proposing a constant value of mean wall shear stress irrespective of diameter (LaBarbera 1990, Murray 1926, Rodbard 1970). On the other hand, assuming no change in volume flow with age, the increase in diameter with increasing age, which is in agreement with earlier observations (Baskett et al. 1990, Fujishiro and Yoshimura 1982, Kawasaki et al. 1987, Reneman et al. 1985) will result in a reduction of mean wall shear rate and, hence, a decrease of mean wall shear stress when the increase in blood viscosity with age is limited as is the case in the present study. Despite the decrease of mean wall stress with increasing age the measured values still remain in the range compatible with the minimum work theory according to Kamiya et al. (Kamiya et al. 1984). These investigators concluded that mean wall shear stress in the arterial tree should be within the range of 0.75 to $2.25 \mathrm{~Pa}$. The individual mean wall shear stress values found in the present study varied between $0.53 \mathrm{~Pa}$ and $1.61 \mathrm{~Pa}$ in females and between $0.82 \mathrm{~Pa}$ and $1.76 \mathrm{~Pa}$ in males between the second and sixth decade.

In a recent study, Gnasso et al. found a more pronounced decrease of mean wall shear stress with age than in the present study (Gnasso et al. 1996). In their study the subjects at older age appeared to be overweighed $\left(\mathrm{BMI}>25 \mathrm{~kg} / \mathrm{m}^{2}\right)$, which was not the case in the younger population. It is known that in obese subjects blood flow 
velocities are underestimated as compared to lean subjects, explaining partly the lower range of mean wall shear stress values at older age and, thereby, confounding the correlation between wall shear stress and age. Moreover, wall shear stress was estimated indirectly based on the Poiseuille's equation, assuming a steady parabolic velocity profile. The shape of the velocity profile, however, varies with the phase of the cardiac cycle (figure 5.1) and has a flattened rather than a parabolic profile (Reneman et al. 1985, Samijo et al. 1997). Thus the time dependent change of the velocity gradient in the spatial direction is not taken into account in their study. In a former study of our group it has been shown that the approximation of wall shear stress based upon Poiseuille results in an underestimation, especially at higher blood flow velocities (Hoeks et al. 1995). This will affect the outcome of age dependency studies because blood flow velocities decreases with age.

Although in both sexes mean wall stress remains within the physiological range, as far as the minimum work theory is concerned, it can not be excluded that the lower wall shear stress at older age negatively influences endothelial cell function and, hence, the properties of the arterial wall. Low wall shear stress, after all, has been associated with the initiation of atherosclerosis (Caro et al. 1971) and arterial wall thickening (Friedman et al. 1981, Zarins et al. 1983). It may quite well be that the impaired endothelial cell function at older age (Egashira et al. 1993, Hongo et al. 1988, Lusher et al. 1993, Taddei et al. 1995, Zeiher et al. 1993) is related to the reduced wall shear stress.

To tentatively investigate the relations between wall shear stress, age and vessel wall structure (diameter) and function (distension and compliance), if any, a multiple stepwise forward regression analysis was performed. In the female as well as in the male group an association was found between peak wall shear stress and distension (females $r=0.66, p<0.0001$; males $r=0.69, p<0.0001$ ), independent of the other variables indicating dominance over age and compliance. The significant positive correlation between peak wall shear stress and distension is at variance with findings in in vitro model studies (Anayiotos et al. 1994, Duncan et al. 1990). In the latter studies wall shear stress in a rigid tube was compared to wall shear stress 
in an elastic tube of the same diameter. In the present study, however, the elasticity of the common carotid artery is inversely coupled to the arterial diameter with a variable flow, which probably explains the discrepancy between our findings and the results of the in vitro studies.

The stepwise forward regression analysis also indicates a strong negative correlation between mean wall shear stress and diameter (females $r=-0.62$, $p<0.0001$; males $r=-0.55, p<0.0001)$, dominating the contribution of age or compliance. This suggests that the decrease of mean wall shear stress as function of age can be attributed to an increase of vessel diameter. The latter induces a decrease of mean wall shear rate, which in combination with a relatively small increase in whole blood viscosity results in a decrease of mean wall shear stress. The increase of vessel diameter can be seen as an attempt to limit the decrease in compliance with increasing age (Reneman et al. 1986) suggesting that (pulsatile) volume flow is the regulated parameter with age. This could also be explained from the minimum work theory. Incorporation of compliance in this theory will reveal that at a lower distension a shift to a larger diameter is necessary to attain minimum cost. The latter concept needs theoretical exploration.

Our results show that with increasing age regulation of mean wall shear stress is not fully attained via adjustments of lumen diameter. Studies which do show direct interaction between wall shear stress and diameter pertain to experiments in which wall shear stress is changed acutely by alterating flow (Langille et al. 1989, Zarins et al. 1987). These and our findings indicate that mean wall shear stress is adjusted by vessel diameter in case of acute and subacute changes in volume flow, but that in chronic processes, such as ageing, other factors are involved.

In conclusion, the present investigation indicates that in the common carotid artery of human males and females peak and mean wall shear stress decrease linearly with age. The decrease of peak wall shear stress results from a decrease in peak wall shear rate with increasing age. The decrease of mean wall shear stress results from the age dependent change in diameter of the artery in an attempt to limit the loss of compliance under these circumstances. 


\subsection{References}

Anayiotos AS, Jones SA, Giddens DP, Glagov S, Zarins CK. Shear stress at a compliant model of the human carotid bifurcation. J Biomech Eng 1994;116:98-106.

Baskett JJ, Lewis RR, Beasley MG, Gosling RG. Changes in carotid artery compliance with age. Age and Ageing 1990;19:214-246.

Brands PJ, Hoeks APG, Hofstra L, Reneman RS. A noninvasive method to estimate wall shear rate using ultrasound. Ultrasound Med Biol 1995;21:171-185.

Brands PJ, Hoeks APG, Reneman RS. The effect of echo suppression on the mean velocity estimation range of the $i f$ cross-correlation model estimator. Ultrasound Med Biol 1995;21:945-959.

Caro CG, Fitzgerald JM, Schroter RC. Atheroma and arterial wall shear: observation, correlation and proposal of a shear dependent mass transfer mechanism for atherogenesis. Proc Roy Soc London 1971;17B:105-159.

de Simone G, Devereux RB, Chien S, Alderman MH, Atlas SA, Laragh JH. Relation of blood viscosity to demographic and physiologic variables and to cardiovascular risk factors in apparently normal adults. Circulation 1990;81:107-117.

Duncan DD, Bargeron CB, Borchardt SE, Deters OJ, Gearhardt SA, Mark FF, Friedman $\mathrm{MH}$. The effect of compliance on wall shear in casts of a human aortic bifurcation. J Biomech Eng 1990;112:183-188.

Egashira K, Tetsuzi I, Hirooka Y, Kai H, Sugimachi M, Suzuki S, Kuga T, Urabe Y, Takeshita A. Effects of age on endothelium dependent vasodilation of resistance coronary artery by acetylcholine in humans. Circulation 1993;88:77-81.

Frangos JA, Eskin SG, Mcintire LV. Flow effects on prostacyclin production by cultured human endothelial cells. Science 1985;227:1477-1479. 
Friedman MH, Hutchins GM, Bargeron CB, Deters OJ, Mark FF. Correlation between intimal thickness and fluid shear in human arteries. Atherosclerosis $1981 ; 39: 425-436$.

Fujishiro K, Yoshimura S. Haemodynamic changes in carotid blood flow with age. Study on non-invasive measurements of changes with age in blood flow velocity, vessel diameter and blood flow volume in common carotid artery. Jikeika Med J 1982;29:125-138.

Gnasso A, Carallo C, Irace C, Spagnuolo V, De Novara G, Mattioli PL, Pujia A. Association between intima-media thickness and wall shear stress in common carotid arteries in healthy male subjects. Circulation 1996;94:3257-3262.

Hansen F, Mangell P, Sonesson B, Lănne T. Diameter and compliance in the human common carotid artery - Variations with age and sex. Ultrasound Med Biol 1995;21:1-9.

Hoeks APG, Brands APG, Smeets FAM, Reneman RS. Assessment of distensibility of superficial arteries. Ultrasound Med Biol 1990;16:121-128.

Hoeks APG, Samijo SK, Brands PJ, Reneman RS. Assessment of wall shear rate in humans: an ultrasound study. J Vasc Invest 1995;1:108-117.

Hoeks APG, Samijo SK, Brands PJ, Reneman RS. Noninvasive determination of shear rate distribution across the arterial lumen. Hypertension 1995;26:26-33.

Hongo K, Nakagomi T, Kassel NF, Sasaki T, Lehman M, Vollmer DG, Tsukara T, Ogawa $\mathrm{H}$, Torner J. Effects of aging and hypertension on endothelium-dependent vascular relaxation in rat carotid artery. Stroke 1988;19:892-897.

Joannides R, Haefeli WE, Linder L, Richard V, Bakkali EH, Thuillez C, Lusher TF. Nitric oxide is responsible for flow dependent dilatation of human peripheral conduit arteries in vivo. Circulation 1995;91:1314-1319. 
Kamiya A, Bukhari R, Togawa T. Adaptive regulation of wall shear stress optimizing vascular tree function. Bulletin Math Biol 1984;46:127-137.

Kamiya A, Togawa T. Adaptive regulation of wall shear stress to flow change in the canine carotid artery. Am J Physiol 1980;239:H14-H21.

Kawasaki T, Sasayama S, Yagi S, Asakawa T, Hirai T. Non-invasive assessment of the age related changes in stiffness of major branches of the human arteries. Cardiovasc Res 1987;21:678-687.

LaBarbera M. Principles of design of fluid transport systems in zoology. Science 1990;249:992-1000.

Langille BL, Bendeck MP, Keeley FW. Adaptations of carotid arteries of young and mature rabbits to reduced carotid blood flow. Am J Physiol 1989;256:H931-H939.

Laogun AA, Gosling RG. In vivo arterial compliance in man. Clin Phys Physiol Meas 1982;3:201-212.

Lusher TF, Boulanger CM, Yang Z, Noll G, Dohi Y. Interactions between endothelium-derived relaxing and contracting factors in health and cardiovascular disease. Circulation 1993;87[suppl V]:V36-V44.

Murray CD. The physiological principle of minimum work. 1. The vascular system and the cost of blood volume. Proc Natl Acad Sci USA 1926;12:207-214.

Nichols WW, O'Rourke MF. Aging, high blood pressure and disease in humans. In: Nichols WW, O'Rourke MF, eds. Mc Donald's Blood Flow in Arteries. London: Edward Arnold, 1990:398-420.

Olson RM. Human carotid artery wall thickness, diameter, and blood flow by a noninvasive technique. J Appl Phys 1974;37:955-960. 
Perktold K, Thurner E, Kenner T. Flow and stress characteristics in rigid walled and compliant carotid artery bifurcation models. Med Biol Eng Comput 1994;32:19-26.

Reneman RS, Van Merode T, Hick P, Hoeks APG. Flow velocity patterns in and distensibility of the carotid artery bulb in subjects of various ages. Circulation 1985;71:500-509.

Reneman RS, van Merode T, Hick P, Muytjens AMM, Hoeks APG. Age-related changes in carotid artery wall properties in men. Ultrasound Med Biol 1986;12:465471.

Rodbard S. Negative feedback mechanisms in the architecture and function of the connective and cardiovascular tissues. Perspect Biol Med 1970;13:507-527.

Rubanyi GM, Freay AD, Kauser K, Johns A, Harder DA. Mechanoreception by the endothelium: mediators and mechanisms of pressure and flow induced vascular responses. Blood Vessels 1990;27:246-257.

Samijo SK, Willigers JM, Brands PJ, Barkhuysen R, Reneman RS, Kitslaar PJEHM, Hoeks APG. Reproducibility of shear rate and shear stress assessment by means of ultrasound in the common carotid artery of young human males and females. Ultrasound Med Biol 1997;23:583-590.

Sharefkin JB, Diamond SL, Eskin SG, Mcintire LV, Dieffenbach CW. Fluid flow decreases preproendothelin mRNA levels and suppresses endotheline-1 peptide release in cultured human endothelial cells. J Vasc Surg 1991;14:1-9.

Taddei S, Virdis A, Mattei P, Ghiadoni L, Gennari A, Fasolo CB, Sudano I, Salvetti A. Aging and endothelial function in normotensive subjects and patients with essential hypertension. Circulation 1995;91:1981-1987. 
Taylor KJW. Clinical applications of carotid Doppler ultrasound. In: Taylor KJW, Burns PN, Wells PNT, eds. Clinical applications of Doppler ultrasound. New York: Raven Press, 1988:120-161.

Weaver JPA, Evans A, Walder DN. The effect of increased fibrinogen content on the viscosity of blood. Clin Sci 1969;36:1-10.

Zarins CK, D.P. G, Bharavadj BK, Sottiurai VS, Mabon RF, Glagov S. Carotid bifurcation atherosclerosis: quantitive correlation of plaque localisation with flow profiles and wall shear stress. Circ Res 1983;53:502-504.

Zarins CK, Zatina MA, Giddens DP, Ku DN, Glagov S. Shear stress regulation of artery lumen diameter in experimental atherogenesis. J Vasc Surg 1987;5:413-420.

Zeiher AM, Drexler H, Saurbier B, Just H. Endothelium-mediated coronary blood flow modulation in humans. J Clin Invest 1993;92:652-662. 
Chapter 6

\section{Chronic smoking does not affect the basal level of wall shear stress}

\begin{aligned} 6.1 & Abstract \\ 6.2 & Introduction \\ 6.3 & Materials and methods \\ 6.3 .1 & Subjects \\ 6.3.2 & Wall shear rate assessment \\ \hline 6.3 .3 & Hemodynamic monitoring \\ 6.3.4 & Assessment of strain \\ 6.3.5 & Biochemical analysis \\ 6.3.6 & Whole blood viscosity assessment \\ 6.3.7 & Wall shear stress assessment \\ \hline 6.3 .8 & Measurement procedure \\ \hline 6.3 .9 & Statistical analysis \\ \hline 6.4 & Results \\ \hline 6.5 & Discussion \\ 6.6 & References \end{aligned}

S.K. Samijo, R. Barkhuysen, J.M. Willigers, R.S. Reneman, P.J.E.H.M. Kitslaar, A.P.G. Hoeks. 
Chronic smoking and wall shear stress 


\subsection{Abstract}

It is generally accepted that cigarette smoking accelerates atherogenesis, probably via endothelial injury. Endothelial cell and function are affected by wall shear stress (wall shear rate times blood viscosity). This hemodynamic factor is also found to be of importance in atherogenesis. Whether cigarette smoking affects the basal level of wall shear stress is unknown. In the present study, peak and mean wall shear rate were non-invasively measured in the common carotid artery of 20 presumably healthy smoking and lifetime non-smoking male subjects, using a shear rate estimating system based on ultrasound. The equipment also allows the measurement of arterial diameter and arterial wall characteristics, like distension $(\Delta D)$ and strain $(S)$. Blood viscosity was determined where after peak and mean wall shear stresses were calculated. Between the smoking and non-smoking males no significant difference in peak ( $3.2 \pm 0.8 \mathrm{~Pa}$ vs. $3.3 \pm 0.8 \mathrm{~Pa}$ ) and mean (on the order of $1.3 \mathrm{~Pa}$ ) wall shear stress, diameter $(6.7 \pm 0.5 \mathrm{~mm}$ vs. $6.5 \pm 0.4 \mathrm{~mm})$ and vessel wall characteristics could be found. It is concluded that chronic smoking does not affect the basal level of wall shear stress in the common carotid artery of men.

\subsection{Introduction}

Cigarette smoking is a major risk factor for the development of atherosclerosis. Although the underlying mechanism is not precisely known, there are indications that repetitive injury of endothelial cells via smoke constituents plays a role in atherogenesis due to smoking (Bierman 1987). Long term cigarette smoking has morphological effects on the endothelium (Davis et al. 1989) and it has been observed that blood plasma of smokers contains more cotinine and thiocyanate compared to non-smokers, products that are cytotoxic to endothelial cells (Blann and McCollum 1993). Moreover, cigarettes smoke products causes impairment of endothelial cell prostacyclin production (Reinders et al. 1986), which may lead to impaired vasodilating properties. Indeed, acute smoking induces a significant decrease in endothelium dependent dilatation in the brachial artery (Lekakis et al. 
1997), while the basal nitric oxide-mediated vasodilation may be impaired (McVeigh et al. 1996). Endothelium dependent vasodilation is related to wall shear stress (Davies 1991, Rubanyi et al. 1986), which is the drag exerted on the vessel wall, i.e., the endothelium, by the flowing blood. Changes in wall shear stress induce alterations in the production of nitric oxide (Cooke et al. 1990), prostacyclin (Frangos et al. 1985), and endothelin (Yoshizumi et al. 1989) and alterations in vasodilation or vasoconstriction, respectively (Davies 1991). In addition, atherosclerosis preferably develops in areas of low wall shear stress (Gibson et al. 1993, Nerem 1995).

Thus, both smoking and wall shear stress affect endothelial cell function and are thought to play a role in atherogenesis. However, whether chronic smoking influences wall shear stress is as yet unknown.

Therefore, it was the aim of the present study to investigate whether smoking influenced peak and mean wall shear stress (wall shear rate times blood viscosity) in the common carotid artery. The study was performed on smoking and lifetime non-smoking male subjects. Wall shear rate was assessed non-invasively by means of an especially designed system (Brands et al. 1995) and wall shear stress was calculated by multiplying the assessed wall shear rate by local whole blood viscosity. The ultrasound system also allows the assessment of arterial luminal diameter and changes in diameter during the cardiac cycle (distension), allowing the calculation of strain.

\subsection{Material and methods}

\subsubsection{Subjects}

The study was performed on 20 smoking and 20 age-matched, lifetime nonsmoking males. Both groups had an average age of $39 \pm 10$ years. The duration of smoking was on the average of $19.4 \pm 6.5$ years (range 8 to 35 years). The number of cigarettes smoked per day was on the average $19.5 \pm 6.4$ (range 15 to 30 
cigarettes). None of the subjects had a history of coronary heart disease, cerebrovascular accidents, peripheral arterial disease, diabetes or hyperlipidemia. They used no medication, had normal glucose levels, hematocrits, lipid profiles and blood pressures (systolic blood pressure $\leq 140 \mathrm{~mm} \mathrm{Hg}$; diastolic blood pressure $\leq$ $90 \mathrm{~mm} \mathrm{Hg}$ ). All subjects were aware of the investigational nature of the study and had given written informed consent. The study was approved by the joint medical ethical committee of the Academic Hospital Maastricht and the Maastricht University.

\subsubsection{Wall shear rate assessment}

Wall shear rate was measured only in the right common carotid artery, because preliminary studies have shown that there are no differences in hemodynamics between the left and the right common carotid artery (Samijo et al. 1997). The system used to measure wall shear rate, the Shear Rate Estimating System (SRES), has been described in detail before (Brands et al. 1995, Hoeks et al. 1995). Briefly, an echosystem (Ultramark 9 plus, Advanced Technology Laboratories, Bellevue, WA, USA) with a broadband (5-9 MHz) curved array transducer was used to receive reflected and backscattered ultrasound signals. The received wide-band digitised $(20 \mathrm{MHz})$ radio-frequency $(\mathrm{r} f)$ signals were transferred to a computer $(486 \mathrm{DX} 4 / 100)$ through an interface configuration, consisting of an internal card in the ATL-system in combination with a custom build plug-in card for the personal computer. The latter card allows the selective capture of segments of the if signal starting at a preselected depth and with a preselected width. At present the available PC memory limits the recording to 1.2 seconds, which is sufficient to capture data of one complete heartbeat.

To assess the instantaneous blood velocity distribution along a line of observation (selected in B-mode) with a high axial resolution, the echosystem was switched to a wide band pulsed Doppler mode with short transducer activation. The returned acoustic signals have an effective pulse length of about 3 periods at $5.3 \mathrm{MHz}$, equivalent to a spatial resolution of $375 \mu \mathrm{m}$. Each velocity estimate is based on half 
overlapping if data segments of 300 micrometers in depth and $10 \mathrm{~ms}$ in time and is obtained by means of a modelled cross correlation algorithm for the if signals (Brands et al. 1995).

Data acquisition is initiated synchronously with a trigger derived from the top of the R-wave of an ECG signal, facilitating the detection of the end-diastolic diameter $(D)$, the diameter change over time and the cross- sectional time dependent velocity distribution. The peak value of the diameter change during the cardiac cycle (distension waveform) gives the distension $(\Delta D)$.

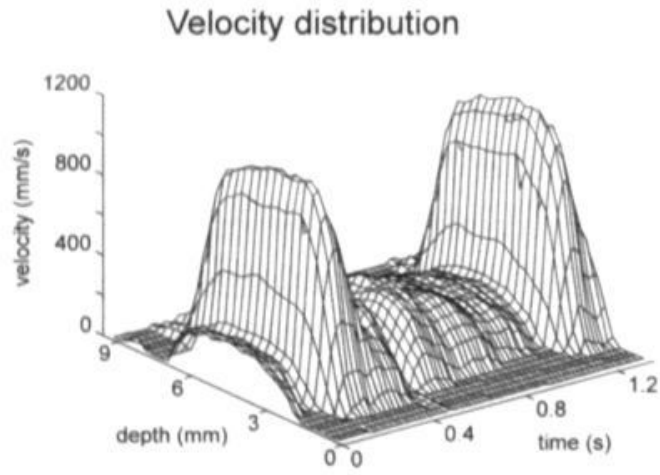

Shear rate distribution

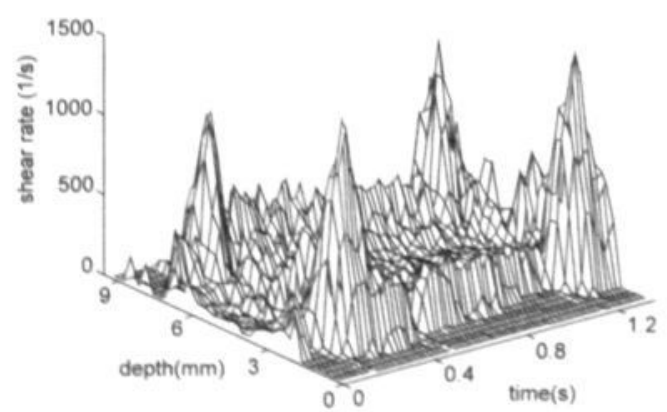

Figure 6.1

Velocity and shear rate distribution in the CCA of a male smoking subject. 
Based on the same if signals the time-dependent velocity distribution was calculated. A typical velocity distribution in the common carotid artery of a smoking subject is given in figure 6.1a. The velocity distribution provides peak systolic blood velocity $\left(P S V\right.$ in $\left.m m . s^{-1}\right)$ and the time averaged mean velocity $\left(M V\right.$ in $\left.\mathrm{mm} . \mathrm{s}^{-1}\right)$, both in the centre of the lumen. The latter is comparable with the time-averaged mean frequency of a Doppler signal received with conventional pulsed Doppler systems from the centre of the lumen.

The instantaneous shear rate distribution follows from the radial derivative of the velocity profile at each site and at each time instant, as is shown in figure $6.1 \mathrm{~b}$. The average of the maximum values of the shear rates at the anterior and posterior vessel wall is considered as an estimate of the instantaneous wall shear rate. The spatial averaging procedure is performed to minimise possible effects induced by secondary flows (Brands et al. 1995). The values of the spatial maximum (peak) wall shear rate at peak systole ( $P W S R$ in $\mathrm{s}^{-1}$ ) and wall shear rate averaged over one cardiac cycle (the mean wall shear rate, MWSR in $\mathrm{s}^{-1}$ ) were used for further analysis.

\subsubsection{Hemodynamic monitoring}

Blood pressure and heart rate were determined with a semi-automated oscillometric device (Dinamap; Critikon, Tampa, Florida, USA) on the contralateral upper arm relative to the site of ultrasound measurement (left brachial artery). The device was set to take a recording every 5 minutes. The average of the values for the systolic and diastolic blood pressure (SBP and $D B P$ ), mean arterial blood pressure (MAP), pulse pressure $(P P)$ and heart rate $(H R)$ over the session was noted as the subject's reading.

\subsubsection{Assessment of strain (S)}

The strain is calculated as:

$$
S=(\Delta D / D) * 100 \%
$$




\subsubsection{Biochemical analysis}

Blood samples were obtained without stasis from an antecubital vein for determination of hematocrit, hemoglobin, high-density lipoprotein (HDL) cholesterol, triglycerides and total cholesterol using standard auto-analysing techniques. Plasma viscosity was determined using an Ostwald micro-viscometer (Schott Gerate GmbH, Hofheim, Germany).

\subsubsection{Whole blood viscosity assessment}

From plasma viscosity, hematocrit and mean wall shear rate, whole blood viscosity can be estimated using the approximation proposed by Weaver (Weaver et al. 1969):

$$
\log W B V=\log \eta_{0}+\alpha \cdot H t
$$

with

$$
\alpha=0.030-0.0076 \log (M W S R)
$$

where $W B V$ is whole blood viscosity in $\mathrm{mPa} . \mathrm{s}, \eta_{0}$ plasma viscosity in $\mathrm{mPa} . \mathrm{s}, \mathrm{Ht}$ hematocrit in percentage, and MWSR mean wall shear rate in $\mathrm{s}^{-1}$. The approximation circumvents the practical problems associated with the direct measurement of whole blood viscosity and incorporates the correction for local shear rate conditions.

\subsubsection{Wall shear stress assessment}

To assess wall shear stress (WSS), wall shear rate (WSR) was multiplied by the estimated whole blood viscosity (WBV), employing the relationship:

$$
W S S=W B V^{*} W S R
$$




\subsubsection{Measurement Procedure}

All the measurements were performed in the morning. The smoking subjects did not smoke for at least one hour prior to the measurements. The subjects were examined in the supine position in a climatised room with a temperature of $22^{\circ} \mathrm{C}$. $24^{\circ} \mathrm{C}$. A history on symptoms related to atherosclerosis was taken, after which a physical examination was performed. Blood was collected and after an acclimatisation period of at least 10 minutes the blood pressure and ultrasound measurements started. First, on both sides, the common, internal and external carotid arteries were visualised in B-mode to screen for possible existence of plaques and to select the site of measurement. A line of observation was selected crossing the right common carotid artery (CCA) 2 to $3 \mathrm{~cm}$ proximal to the tip of the flow divider at an angle of 70 degrees with the longitudinal axis of the artery. Hereafter a recording of the received if signals was made during 1.2 seconds and stored on the hard disk of the computer. The measurement procedure was repeated 20 times with a time interval of 2 to 3 minutes and the average of these measurements was taken as the subject's reading. After these measurements, each recording was recalled where after the vessel walls were manually identified by placing sample volumes, indicated by markers, on the reflections of the anterior and posterior vessel wall. The distance between both markers, corrected for the angle of observation, is considered as the initial (end-diastolic) diameter ( $D$ in $\mu \mathrm{m}$ ) of the vessel.

At the end of the measurement session the SRES was set to calculate arterial wall distension simultaneously with the velocity and wall shear rate distributions in the same artery segment, which took about 2 minutes per measurement with the computer employed. From the 20 independent measurements per subject only those recordings with a symmetrical velocity profile were included. Within each session on the average 1 to 2 recordings had to be excluded because they did not meet the criteria.

An earlier study showed that in the CCA of a young population the assessment of peak WSS and mean WSS had an intrasession intrasubject variation per 
measurement, in terms of coefficient of variation, of on the order of $15 \%$ and $12 \%$, respectively (Samijo et al. 1997). The intersession variability was on the same order (Samijo et al. 1997). Therefore, the average of 20 measurements, which will reduce the variability substantially, was used for further analysis.

\subsubsection{Statistical analysis}

Data are expressed as mean \pm standard deviation (SD). The unpaired Student's t-test was employed to explore whether differences in the parameters measured with the SRES were statistically significant between the smoking and non-smoking population. The significance level was set at $p<0.05$. All statistical analyses were performed with the statistical software package SPSS for Windows, release 6.0.

\subsection{Results}

The findings in the present study are presented in table 6.1. No significant difference was observed in PWSS (on the order of $3.4 \pm 0.8 \mathrm{~Pa}$ ) between the smoking and non-smoking subjects. Also no significant difference in mean wall shear stress (MWSS) could be detected between the smoking and non-smoking group (about $1.3 \pm 0.2 \mathrm{~Pa}$ ).

Also PWSR was not significantly different between the smoking and non-smoking group $\left(905 \pm 260 \mathrm{~s}^{-1}\right.$ vs. $\left.1038 \pm 264 \mathrm{~s}^{-1}\right)$, neither was $M W S R\left(363 \pm 85 \mathrm{~s}^{-1}\right.$ vs. $407 \pm$ $\left.75 \mathrm{~s}^{-1}\right)$.

Whole blood viscosity was significantly higher in the smoking than in the nonsmoking group (3.57 $\pm 0.52 \mathrm{mPa} . \mathrm{s}$ vs. $3.27 \pm 0.27 \mathrm{mPa} . \mathrm{s} ; \mathrm{p}=0.03)$.

Compared to the non-smoking group no significant differences in diameter $(6.7 \pm$ $0.5 \mathrm{~mm}$ vs. $6.5 \pm 0.4 \mathrm{~mm})$ and in vessel wall properties $(\Delta D .540 \pm 168$ vs. $529 \pm$ $155 \mu \mathrm{m}$; S: $8 \pm 2.6 \%$ vs. $8.2 \pm 2.5 \%$ ) could be observed. Hemodynamic parameters such as blood pressure and heart rate were similar for both groups. 
The smoking subjects had a significant lower body mass index ( $B M I)$ than the nonsmoking subjects $\left(23.9 \pm 2.7 \mathrm{~kg} / \mathrm{m}^{2}\right.$ vs. $\left.25.9 \pm 3.0 \mathrm{~kg} / \mathrm{m}^{2} ; \mathrm{p}=0.04\right)$. This difference was due to the difference in weight $(84.6 \pm 10.9 \mathrm{~kg}$ vs. $74.3 \pm 8.7 \mathrm{~kg} ; \mathrm{p}=0.003)$ rather than the difference in height between the smokers and non-smokers $(1.81 \pm$ $0.07 \mathrm{~m}$ vs. $1.77 \pm 0.06 \mathrm{~m} ; \mathrm{p}=0.05$ ).

\section{Table 6.1}

Mean \pm standard deviation and p-value. For abbreviations see text.

\begin{tabular}{|c|c|c|c|c|c|}
\hline \multirow[b]{2}{*}{ PWSS [Pa] } & \multicolumn{2}{|c|}{ Smoking } & \multicolumn{2}{|c|}{ Non-smoking } & \multirow{2}{*}{$\begin{array}{l}\text { P value } \\
0.50\end{array}$} \\
\hline & 3.2 & \pm 0.8 & 3.4 & \pm 0.8 & \\
\hline MWSS [Pa] & 1.3 & \pm 0.2 & 1.3 & \pm 0.2 & 0.51 \\
\hline PWSR [s $\left.{ }^{-1}\right]$ & 905 & \pm 260 & 1038 & \pm 264 & 0.12 \\
\hline MWSR $\left[\mathrm{s}^{-1}\right]$ & 363 & \pm 85 & 407 & \pm 75 & 0.09 \\
\hline WBV [Pa.s] & 3.57 & \pm 0.52 & 3.27 & \pm 0.27 & 0.03 \\
\hline$V \max \left[\mathrm{mm} \cdot \mathrm{s}^{-1}\right]$ & 757 & \pm 138 & 827 & \pm 158 & 0.14 \\
\hline Vmean $\left[\mathrm{mm} . \mathrm{s}^{-1}\right]$ & 284 & \pm 59 & 313 & \pm 48 & 0.10 \\
\hline Diameter $[\mu \mathrm{m}]$ & 6705 & \pm 496 & 6487 & \pm 421 & 0.14 \\
\hline$\Delta \mathrm{D}[\mu \mathrm{m}]$ & 540 & \pm 168 & 529 & \pm 155 & 0.83 \\
\hline $\mathrm{S}$ [\%] & 8.1 & \pm 2.6 & 8.2 & \pm 2.5 & 0.88 \\
\hline $\mathrm{SBP}$ [mm Hg] & 126 & \pm 8 & 124 & \pm 9 & 0.44 \\
\hline $\mathrm{DBP}[\mathrm{mm} \mathrm{Hg}]$ & 76 & \pm 7 & 71 & \pm 9 & 0.08 \\
\hline MAP [mm Hg] & 93 & \pm 6 & 89 & \pm 8 & 0.14 \\
\hline $\mathrm{PP}$ [mm Hg] & 50 & \pm 6 & 53 & \pm 7 & 0.24 \\
\hline HR [beats/min] & 68 & \pm 9 & 64 & \pm 10 & 0.26 \\
\hline $\mathrm{HB}\left[\mathrm{mmol} . \mathrm{L}^{-1}\right]$ & 9.6 & \pm 0.6 & 9.4 & \pm 0.4 & 0.33 \\
\hline $\mathrm{Ht}$ [LL] & 0.45 & \pm 0.029 & 0.44 & \pm 0.022 & 0.25 \\
\hline $\mathrm{HDL}\left[\mathrm{mmol} . \mathrm{L}^{-1}\right]$ & 1.19 & \pm 0.37 & 1.09 & \pm 0.22 & 0.33 \\
\hline Triglyceride $\left[\mathrm{mmol} . \mathrm{L}^{-1}\right]$ & 1.30 & \pm 0.58 & 1.35 & \pm 0.77 & 0.83 \\
\hline Cholesterol $\left[\mathrm{mmol} . \mathrm{L}^{-1}\right]$ & 5.49 & \pm 0.85 & 5.23 & \pm 0.88 & 0.35 \\
\hline$\eta_{0}[\mathrm{mPa} . \mathrm{s}]$ & 1.18 & \pm 0.10 & 1.15 & \pm 0.05 & 0.32 \\
\hline Weight [kg] & 74.3 & \pm 8.7 & 84.6 & \pm 11 & 0.003 \\
\hline Height [m] & 1.77 & \pm 0.063 & 1.81 & \pm 0.67 & 0.05 \\
\hline BMI $\left[\mathrm{kg} / \mathrm{m}^{2}\right]$ & 23.9 & \pm 2.7 & 25.9 & \pm 3.0 & 0.04 \\
\hline
\end{tabular}


The biochemical assays revealed no differences between the smoking and nonsmoking group (HDL: $1.19 \pm 0.37 \mathrm{mmol} / \mathrm{L}$ vs. $1.09 \pm 0.22 \mathrm{mmol} / \mathrm{L}$; Triglyceride: 1.30 $\pm 0.58 \mathrm{mmol} / \mathrm{L}$ vs. $1.35 \pm 0.77 \mathrm{mmol} / \mathrm{L}$; Cholesterol: $5.50 \pm 0.85 \mathrm{mmol} / \mathrm{L}$ vs. $5.24 \pm$ $0.88 \mathrm{mmol} / \mathrm{L})$.

\subsection{Discussion}

This study was undertaken to investigate whether chronic smoking affects wall shear stress in the common carotid artery. No significant difference in peak and mean wall shear stress is found between the smoking and non-smoking subjects. Also peak and mean wall shear rate, arterial diameter and wall properties are similar in the smokers and non-smokers, while blood viscosity is higher in the smoking group.

The results in the present study indicate that chronic smoking does not influence peak and mean wall shear stress in the common carotid artery and, therefore, it might be that the mechanism to regulate these parameters is intact in smokers. Mean wall shear stress depends on the magnitude of blood flow and the internal arterial diameter. Assuming the same blood volume flow to the brain for both smokers and non-smokers, mean wall shear stress can only be regulated by arterial diameter, the latter being similar between the smoking and non-smoking subjects. The similar diameter and vessel wall properties, between the two groups corroborate with the findings in another study of our group (Kool et al. 1993). It has to be pointed out that the measurements in the present study were performed in resting conditions. Our findings are in agreement with those in other studies, in which vasorelaxation (in terms of flow and diameter) was investigated, albeit in the brachial artery (Kiowski et al. 1994, McVeigh et al. 1996, Woo et al. 1997).

The magnitude of wall shear stress affects endothelial cell function and may induce the release of vasoactive substances (Davies 1991) and thus vasorelaxation. Peak and mean wall shear stress are in the normal range (Samijo et al. 1998), and also in agreement with the calculated range of wall shear stress values based on the 
minimum work theory (LaBarbera 1990, Zamir 1977). It is within this range (1.5 \pm $0.75 \mathrm{~Pa}$ ) that vascular homeostasis is maintained, especially endothelial cell function, and arterial wall damage is prevented (LaBarbera 1990, Rodbard 1970, Zamir 1977).

Also, both high and low wall shear stress has been associated with the development of atherosclerosis (Nerem 1995). The findings in our study indicate that in resting conditions the interaction between wall shear stress and endothelial cell function is not necessarily disturbed. Our findings are in agreement with a study performed by Jacobs et al., (Jacobs et al. 1993) in which no significant difference in endothelial cell-dependent or -independent vasorelaxation in the forearm was observed between smokers and non-smokers, indicating that endothelial cell function may still be preserved in smokers. Even an augmented endothelial derived vasorelaxation has been observed in the common carotid artery of rats that were subjected to cigarette smoke (Nene et al. 1997).

Other study, however, indicate that cigarette smoking, nicotine and cigarette smoke extracts all adversely effects endothelial cell function (Blann and McCollum 1993, Cohen 1995). Cigarette smoking inhibits prostacyclin release by endothelial cells (Reinders et al. 1986) and exhibits an impairment of basal (Kiowski et al. 1994), but not stimulated, nitric oxide-mediated vasodilation (McVeigh et al. 1996) in the brachial artery. The discrepancy between these observations and the aforementioned ones might be explained by the duration of smoking. Evidence for this is given by Celemayer et al. (Celemajer et al. 1993), who observed a diminished vasodilation in smoking subjects (compared to former smokers and nonsmokers), which was proportional to the number of years of smoking.

Another explanation for our observations might be the general condition of the smoking subjects. In the present study none of the subjects had detectable atherosclerotic lesions in the common carotid artery or deviating biochemical parameters (HDL cholesterol, triglyceride and total cholesterol were normal). It has been shown that chronic cigarette smoking decreases plasma high density lipoprotein (HDL) cholesterol and total cholesterol levels, independent of age, 
obesity, alcohol use or exercise (Criqui et al. 1980, Garrison et al. 1978). Craig et al. (Craigh et al. 1989) performed a meta-analysis of 54 published studies and showed that smokers had a significantly higher level of total cholesterol, triglycerides and very low density lipoprotein (VLDL) cholesterol as well lower concentrations of HDL cholesterol. The subjects in the present study can thus be regarded as clinically healthy smokers, who are still able to regulate wall shear stress at a normal level in resting conditions.

It has been shown that atherosclerosis preferably starts in areas with low rather than high wall shear rate or wall shear stress (Caro et al. 1971, Chien et al. 1966). The present study shows that wall shear rate and wall shear stress are not significantly different between smokers and non-smokers. It may indicate that the atherogenic effects of smoking can not be explained through an effect on wall shear stress, at least in the common carotid artery, assuming that the sensitivity of the endothelium to wall shear stress is not changed in smokers. Moreover, our data show that the non-significant lower wall shear rate counteracts the effect of a higher blood viscosity in the smoking subjects, indicating that wall shear stress is the regulated parameter. The observed higher blood viscosity in the smoking group is in accordance with previous observations (Nowak et al. 1987, Winniford 1990).

The smoking group has a significantly lower body mass index, which was merely due to a significant difference in weight. This observation is in agreement with other studies in which the relation between body mass index and smoking was investigated (Molarius et al. 1997, Rasky et al. 1996).

In conclusion, in resting conditions peak and mean wall shear stress in the common carotid artery is not significantly different in habitual smokers and non-smokers. Therefore, the role of smoking in atherogenesis has likely to be explained by a direct effect on endothelial function. 


\subsection{References}

Bierman EL. Atherosclerosis and other forms of atherosclerosis. In: Braunwald E, Isselbacher KJ, Petersdorf RG, Wilson JD, Martin JB, Fauci AS, eds. Harrison's principles of internal medicine. London: McGraw Hill Book Company, 1987:10141024.

Blann AD, McCollum CN. Adverse influence of cigarette smoking on the endothelium. Thromb Haemost 1993;70:707-711.

Brands PJ, Hoeks APG, Hofstra L, Reneman RS. A noninvasive method to estimate wall shear rate using ultrasound. Ultrasound Med Biol 1995;21:171-185.

Brands PJ, Hoeks APG, Reneman RS. The effect of echo suppression on the mean velocity estimation range of the if cross-correlation model estimator. Ultrasound Med Biol 1995;21:945-959.

Caro CG, Fitzgerald JM, Schroter RC. Atheroma and arterial wall shear: observation, correlation and proposal of a shear dependent mass transfer mechanism for atherogenesis. Proc Roy Soc London 1971;17B:105-159.

Celemajer DS, Sorensen KE, Georgeakopoulos D, Bull C, Thomas O, Robinson J, Deanfield JE. Cigarette smoking is associated with dose related and potentially reversible impairment of endothelium-dependent dilation in healthy young subjects. Circulation 1993;88:2149-2155.

Chien S, Usami S, Taylor M, Lundberg JL, Gregerson MI. Effects of hematocrit and plasma proteins on human blood rheology at low shear rates. J Appl Physiol 1966;21:81-87.

Cohen RA. The role of nitric oxide and endothelium-derived vasoactive substances in vascular disease. Prog Cardiovasc Dis 1995;38:105-128. 
Cooke JP, Stamler JS, Andon N, Davies PR, Loscalzo J. Flow stimulates endothelial cells to release a nitrovasodilator that is potentiated by reduced thiol. Am J Physiol 1990;28.

Craigh WY, Palomaki GE, Haddow JE. Cigarette smoking and serum lipid and lipoprotein concentrations: an analysis of published data. Br Med J 1989;298:784788.

Criqui MH, Wallace RB, Heiss G, Mishkel M, Schonfeld G, Jones GT. Cigarette smoking and plasma high-density lipoprotein cholesterol: the Lipid Research Clinics Program Prevalence Study. Circulation 1980;62 (suppl IV):70-76.

Davies PF. Mechanical sensing mechanisms: shear stress and endothelial cells. J Vasc Surg 1991;13:729-731.

Davis JW, Shelton L, Watanabe IS. Passive smoking affects endothelium and platelets. Arch Intern Med 1989;149:386-389.

Frangos JA, Eskin SG, Mcintire LV. Flow effects on prostacyclin production by cultured human endothelial cells. Science 1985;227:1477-1479.

Garrison RJ, Kannel WB, Feinleb M, Castelli WP, McNamara PM, Padgett SJ. Cigarette smoking and HDL cholesterol: the Framingham offspring study. Atherosclerosis 1978;30:70-76.

Gibson CM, Diaz L, Kandarpa K, Sacks FM, Pasternak RC, Sandor T, Feldman C, Stone $\mathrm{PH}$. Relation of vessel wall shear stress to atherosclerosis progression in human coronary arteries. Arteriosclerosis and Thrombosis 1993;13:310-315.

Hoeks APG, Samijo SK, Brands PJ, Reneman RS. Assessment of wall shear rate in humans: an ultrasound study. J Vasc Invest 1995;1:108-117. 
Jacobs MC, Lenders JW, Kapma JA, Smits P. Thien T. Effect of chronic smoking on endothelium-dependent vascular relaxation in humans. Clin Sci (Colch) 1993;85:5155.

Kiowski W, Linder L, Stoschitzky K, Pfister M, Burkhardt D, Burkart F, Bühler F. Diminished vascular response to inhibition of endothelium-derived nitric oxide and enhanced vasoconstriction to exogenously administered endothelin-1 in clinically healthy smokers. Circulation 1994;90(1):27-34.

Kool MJF, Hoeks APG, Struijker Boudier HAJ, Reneman RS, van Bortel LCMAB. Short- and long term effects of smoking on arterial wall properties in habitual smokers. J Am Coll Cardiol 1993;22:1881-1886.

LaBarbera M. Principles of design of fluid transport systems in zoology. Science 1990;249:992-1000.

Lekakis J, Papamichael C, Vemmos C, Nanas J, Kontoyannis D, Stamatelopoulos S. Effect of acute smoking on endothelium-dependent brachial artery dilatation in healthy individuals. Am J Cardiol 1997;79:529-531.

McVeigh GE, Lemay L, Morgan D, Cohn JN. Effect of long term smoking on endothelium-dependent responses in humans. Am J Cardiol 1996;78:668-672.

Molarius A, Seidell JC, Kuulasmaa K, Dobson AJ, Sans S. Smoking and realtive body weight: an international perspective from the WHO MONICA Project. J Epidemiol Community Health 1997;51:252-260.

Nene S, Gelabert H, Moore W, Quinones-Baldrich W, Santibanez-Gallerani A, Ignarro L. Cigarette smoking increases endothelial derived vasorelaxation in the rat carotid artery in a dose dependent manner. J Surg Res 1997;71:101-106. 
Nerem RM. Atherosclerosis and the role of wall shear stress. In: Bevan JA, Kaley G, Rubanyi GM, eds. Flow-dependent regulation of vascular function. New York: Oxford University Press, 1995:300-319.

Nowak J, Murray J, Oates JA, FitzGerald GA. Biochemical evidence of a chronic abnormality in platelet and vascular function in healthy individuals who smoke sigarettes. Circulation 1987;76:6-14.

Rasky E, Stronegger WJ, Freidl W. The relationship between body weight and patterns of smoking in women and men. Int J Epidemiol 1996;25:1208-1212.

Reinders $\mathrm{JH}$, Brinkman HJ, van Mourik JA, de Groot PG. Cigarette smoke impairs endothelial cell prostacyclin production. Arteriosclerosis 1986;6:15-23.

Rodbard S. Negative feedback mechanisms in the architecture and function of the connective and cardiovascular tissues. Perspect Biol Med 1970;13:507-527.

Rubanyi GM, Romero JC, Vanhoutte PM. Flow-induced release of endothelium derived relaxing factor. Am J Physiol 1986;250:H1145-H1149.

Samijo SK, Willigers JM, Barkhuysen R, Kitslaar PJEHM, Reneman RS, Brands PJ, Hoeks APG. Wall shear stress in the human carotid artery as function of age and gender. Cardiovasc Res 1998;39:515-522.

Samijo SK, Willigers JM, Brands PJ, Barkhuysen R, Reneman RS, Kitslaar PJEHM, Hoeks APG. Reproducibility of shear rate and shear stress assessment by means of ultrasound in the common carotid artery of young human males and females. Ultrasound Med Biol 1997;23:583-590.

Weaver JPA, Evans A, Walder DN. The effect of increased fibrinogen content on the viscosity of blood. Clin Sci 1969;36:1-10.

Winniford MD. Smoking and cardiovascular function. J Hypertens 1990;8:S17-S23. 
Woo KS, Robinson JT, Chook P, Adams MR, Yip G, Mai ZJ, Lam CW, Sorensen KE, Deanfield JE, Celermajer DS. Differences in the effect of cigarette smoking on endothelial function in chinese and white adults. Ann Intern Med 1997;127:372-375.

Yoshizumi M, Kurihara T, Sugiyama T, Takaku F, Yanagisawa M, Masaki T. Hemodynamic shear stress stimulates endothelin production by cultured endothelial cells. Biochem Biophys Res Comm 1989;161:859-864.

Zamir M. Shear forces and blood vessel radii in the cardiovascular system. J Gen Physiolol 1977;69:449-461. 


\section{Wall shear stress assessment in the common carotid artery of end stage renal failure patients}

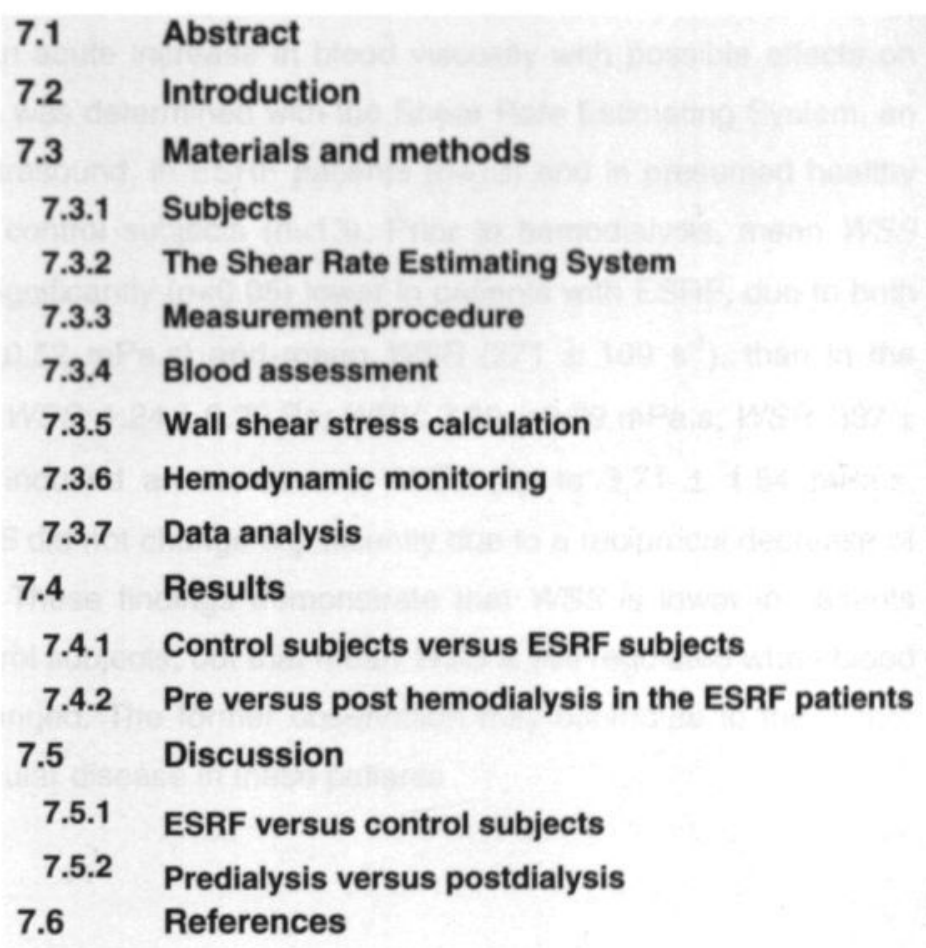

S.K. Samijo, R. Barkhuysen, J.M. Willigers, K.M.L. Leunissen, L.A.F. Ledoux, P.J.E.H.M. Kitslaar, A.P.G. Hoeks. 


\subsection{Abstract}

Under physiological circumstances in the common carotid artery (CCA) mean wall shear stress (WSS), defined as mean wall shear rate (WSR) times local whole blood viscosity (WBV), is maintained at approximately $1.5 \mathrm{~Pa}$. In patients with end stage renal failure (ESRF) whole blood viscosity is low and it is not unlikely that mean WSS is lower in these patients than in control subjects. Moreover, hemodialysis causes an acute increase in blood viscosity with possible effects on WSS. WSS in the CCA was determined with the Shear Rate Estimating System, an apparatus based on ultrasound, in ESRF patients $(n=13)$ and in presumed healthy age and sex-matched control subjects $(n=13)$. Prior to hemodialysis, mean WSS $(0.67 \pm 0.23 \mathrm{~Pa})$ was significantly $(p<0.05)$ lower in patients with ESRF, due to both a lower WBV $(2.80 \pm 0.52 \mathrm{mPa} . \mathrm{s})$ and mean WSR $\left(271 \pm 109 \mathrm{~s}^{-1}\right)$, than in the control subjects (mean WSS: $1.24 \pm 0.20 \mathrm{~Pa}$; WBV: $3.20 \pm 0.29 \mathrm{mPa} . \mathrm{s} ;$ WSR: $387 \pm$ $51 \mathrm{~s}^{-1}$ ). Hemodialysis induced an increase in $W B V$ (up to $3.71 \pm 1.54 \mathrm{mPa} . \mathrm{s}$, $p<0.01)$, but mean WSS did not change significantly due to a reciprocal decrease of mean wall shear rate. These findings demonstrate that WSS is lower in patients with ESRF than in control subjects, but that mean WSS is still regulated when blood viscosity is acutely changed. The former observation may contribute to the higher incidence of cardiovascular disease in these patients

\subsection{Introduction}

Under physiological circumstances wall shear stress in the common carotid artery is on the order of 1.5 Pa (15 dynes/cm²) (Kamiya and Togawa 1980, Rodbard 1970, Samijo et al. 1998, Zarins et al. 1987). According to Poiseuille wall shear stress is related to volume flow and diameter, i.e., the higher volume flow and the smaller diameter are, the higher wall shear stress will be and vice versa. In patients with end stage renal failure (ESRF) blood viscosity is lower, due to volume overload (Feriani et al. 1992, Seyfert et al. 1991) and anemia (Brenner and Lazarus 1987), and arterial end-diastolic diameter is larger than in control subjects (Barenbrock et al. 1993, London et al. 1990). Hence, in these patients a large arterial diameter 
combined with a low blood viscosity may result in a low mean wall shear stress. Moreover, observational studies indicate that the site of preference of atherogenesis coincides with areas of low wall shear stress (Caro et al. 1971, Friedman et al. 1981). Therefore, the higher incidence of cardiovascular diseases in ESRF patients (Lindner et al. 1974, Nicholls et al. 1980) might be related to a prevailing low wall shear stress.

Hemodialysis results in an acute rise in blood viscosity. Studies in animals (Melkumyants and Balashov 1990), in which blood viscosity was deliberately changed, indicate that an acute increase in blood viscosity does not result in a change in mean wall shear stress, but is maintained at a constant level via arterial diameter adaptation. The alteration of the arterial diameter acts as a feedback system to restore mean wall shear stress to its original value to maintain optimal flow conductivity (Kamiya and Togawa 1980). Therefore, it is of interest to know whether ESRF patients, despite their pathological condition, are able to maintain mean wall shear stress at a constant level in response to hemodialysis.

In this light the aim of the present study is twofold. First, it will be investigated whether prior to dialysis wall shear stress in the common carotid artery of ESRF patients is different from that in presumed healthy age and sex matched control subjects. Second, we study whether wall shear stress in the common carotid artery of ESRF patients is maintained when blood viscosity is increased acutely following hemodialysis.

\subsection{Material and methods}

\subsubsection{Subjects}

The study was performed on 13 ESRF patients ( 9 males and 4 females) on a regime of repetitive hemodialysis via an arteriovenous (AV)-fistula for 3 to 4 hours three times a week. The duration of dialysis varied between 3.5 to 5 hours, dependent on the volume status of the patient. The subjects had no history of 
coronary heart disease, cerebrovascular accidents, peripheral arterial disease, diabetes or treated hyperlipidemia and had been on the hemodialysis program for periods ranging from 1 month to 20 years. The ESRF group had an average age of 47 years (range 34 to 61 years), a weight of $74 \mathrm{~kg}$ (range 58 to $97 \mathrm{~kg}$ ) and a height of $170 \mathrm{~cm}$ (range 160 to $188 \mathrm{~cm}$ ). They used medication common for ESRF patients such as vitamin supplements, erythropoietin and ion exchangers. They did not use anti-hypertensive medication. The control group ( 9 males and 4 females) had an average age of 44 years (range 34 to 58 years), a weight of $75 \mathrm{~kg}$ (range 54 to 87 $\mathrm{kg}$ ), and a height of $175 \mathrm{~cm}$ (range 162 to $188 \mathrm{~cm}$ ). They had normal glucose levels, hematocrits, lipid profiles and normal blood pressures ( $\leq 140 / 90 \mathrm{mmHg}$ ). All subjects were aware of the investigational nature of the study and had given written informed consent. The joint medical ethical committee of the Academic Hospital Maastricht and the Maastricht University approved the study.

\subsubsection{The Shear Rate Estimating System (SRES)}

The system used to estimate wall shear rate (SRES) has been described in detail before (Brands et al. 1995, Hoeks et al. 1995). Briefly, an echosystem (Ultramark 9 plus, Advanced Technology Laboratories, Bellevue, WA, USA) with a broad band (5-9 MHz) curved array transducer was used. The reflected acoustic signals have an effective pulse length of nearly 3 periods at $5.3 \mathrm{MHz}$, equivalent to a spatial resolution of $375 \mu \mathrm{m}$. The received wideband digitised $(20 \mathrm{MHz})$ radio-frequent $(\mathrm{rf})$ signals were transferred to a computer through an interface configuration consisting of an internal card in the ATL-system in combination with a custom built plug-in card for the PC. The latter card allows the selective capture of segments of the if signal starting at a preselected depth and with a preselected width. The PC memory presently available limits the recording to 1.2 seconds, which is sufficient to capture data during one complete heartbeat. Data acquisition is initiated with a trigger derived from the top of the R-wave of the ECG, facilitating commencement of the recording at the end of the diastolic phase. A recording consists of $r f$ signals as function of time and depth. On this of matrix an if cross correlation function is applied to calculate the velocity distribution for signal windows with a width of 300 
$\mu \mathrm{m}$ in depth and $10 \mathrm{~ms}$ in time, spaced at $150 \mu \mathrm{m}$ and $5 \mathrm{~ms}$ respectively (50\% overlap). From the velocity distribution the instantaneous shear rate distribution can be calculated by taking the radial derivative at each time instant. Using the same if matrix the change of the diameter in time is calculated from the reflections of the anterior and posterior walls.

\subsubsection{Measurement procedure}

The ESRF patients were examined in the half supine position (normal hemodialysis position). Measurements were performed in the common carotid artery (CCA) contralateral to the arm with the AV-fistula before and immediately after hemodialysis. Investigations started after 5 to 10 minutes of rest. The CCA was investigated, because of its easy access and the symmetric velocity profiles in this artery (Reneman et al. 1985). The carotid bifurcation was visualised first in B-mode to ensure that the common, internal and external carotid arteries were free of plaques. Using the tip of the flow divider as a landmark, the probe position was manipulated until a suitable line of sight ( $\mathrm{M}$-line) could be selected, crossing the artery at an angle of 70 degrees with the longitudinal axis of the artery 2 to $3 \mathrm{~cm}$ proximal to the tip of the flow divider. After positioning the line of interrogation the ultrasound system was switched to M-mode with short transducer activation, to ensure a high resolution, and a high line repetition frequency, where after a recording of the received if signals during one cardiac cycle was made and stored on the hard disk of the computer. This procedure was repeated 15 times with a time interval of 1 to 3 minutes between the measurements.

The control subjects were investigated in the resting supine position and measurements were performed only in the right common carotid artery using the same measurement procedure as in the ESRF patients.

After the measurements, each recording was recalled to identify manually the vessel walls by placing sample volumes, indicated by markers, on the reflections of the anterior and posterior walls on the first if line acquired. The minimal distance 
between the markers was defined as the end-diastolic diameter ( $D$ in $\mathrm{mm}$ ). Then the computer was set to calculate off-line the diameter changes during the cardiac cycle as function of time (distension waveform). The maximum value of this waveform during the cardiac cycle provides the distension (Dist in $\mu \mathrm{m}$ ). From the if signals between the markers the velocity distribution was calculated.

A typical velocity distribution as recorded in an ESRF patient is presented in figure 7.1A. The velocity distribution provides the peak systolic velocity ( $P S V$ in $\mathrm{mm}^{-1} \mathrm{~s}^{-1}$ ) and the time averaged mean velocity $\left(M V\right.$ in $\left.\mathrm{mm}^{-1} \mathrm{~s}^{-1}\right)$ in the centre of the lumen. The latter is comparable with the time-averaged mean frequency of the Doppler signal received with conventional pulsed Doppler systems from the centre of the lumen.

The instantaneous shear rate distribution (figure 7.1B) was derived from the radial derivative of the velocity profile (figure $7.1 \mathrm{~A}$ ) at each time instant.

The average of the maximum values of the shear rates at the anterior and posterior vessel walls are considered as an estimate of instantaneous axial wall shear rate. The spatial averaging procedure was performed to minimise possible effects induced by secondary flows (Brands et al. 1995). The values of wall shear rate at peak systole (peak wall shear rate, PWSR in $\mathrm{s}^{-1}$ ) and shear rate averaged over one cardiac cycle (mean wall shear rate, MWSR in $\mathrm{s}^{-1}$ ) were used for further analysis. From the 15 independent measurements per session only recordings with an axial symmetrical velocity profile were included. Within each measurement session on the average 2 to 4 registrations had to be excluded from further analysis, because they did not meet the criteria.

An earlier study showed that in the CCA of a young population peak WSS and mean WSS could be determined with an intrasession intrasubject variation on the order of $15 \%$ and $12 \%$, respectively. The intersession variability was of the same order (Samijo et al. 1997). Hence, averaging over about 15 measurements provides a precise estimate. 

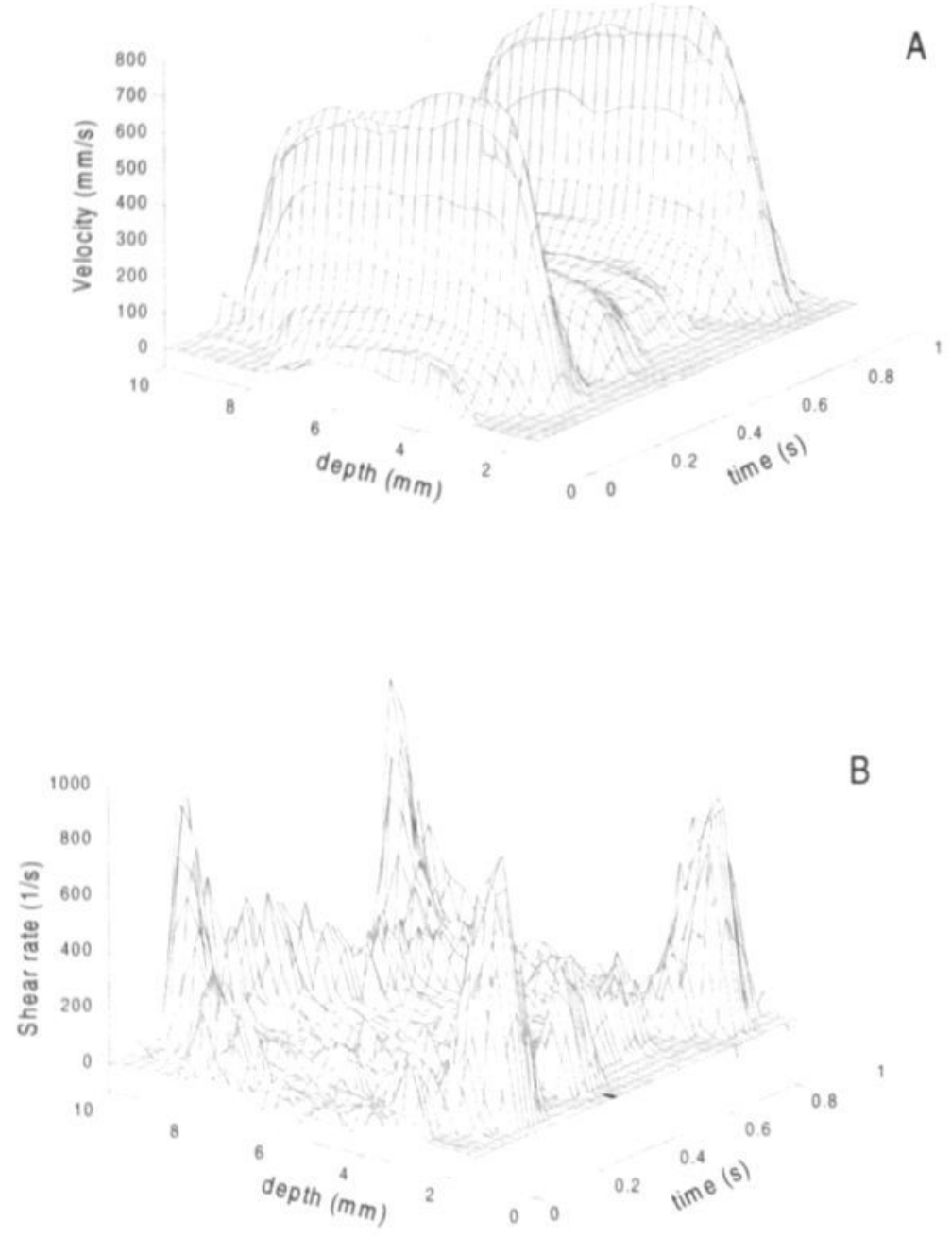

\section{Figure 7.1}

a) The velocity distribution as function of time in the common carotid artery of a patient with end stage renal disease prior to hemodialysis.

b) The shear rate distribution as function of time in the common carotid artery of the same patient prior to hemodialysis. 


\subsubsection{Blood assessment}

Before and after hemodialysis of the ESRF patients, blood was collected from the venous side of the arteriovenous-shunt. In the control subjects blood was collected without stasis from an antecubital vein. Blood samples were taken to determine hematocrit $(H t)$ and plasma viscosity $\left(\eta_{0}\right)$ for the calculation of whole blood viscosity. WBV was determined using an Ostwald micro-viscometer (Schott Gerate GmbH, Hofheim, Germany).

\subsubsection{Wall shear stress calculation}

Using the approximation proposed by Weaver (Weaver et al. 1969), whole blood viscosity ( $W B V$ in $\mathrm{mPa} . \mathrm{s}$ ) was estimated from plasma viscosity ( $\eta_{0}$ in $\mathrm{mPa} . \mathrm{s}$ ), hematocrit ( $H t$ in percentage) and mean wall shear rate in $\mathrm{s}^{-1}$ :

$$
\log W B V=\log \eta_{0}+\alpha \cdot H t
$$

with

$$
\alpha=0.030-0.0076 \log (\text { MWSR) }
$$

To obtain wall shear stress, the measured wall shear rate was multiplied by the calculated whole blood viscosity:

$$
W S S=W S R * W B V
$$

\subsubsection{Hemodynamic monitoring}

In the ESRF group systolic blood pressure (SBP), diastolic blood pressure (DBP), mean arterial pressure (MAP), and heart rate $(H R)$ were determined with a semiautomated oscillometric device (Dinamap; Critikon, Tampa, Florida, USA), which was set to take a recording about every 3-5 minutes in the upperarm contralateral to the arm with the arteriovenous fistula before and after hemodialysis. In the control group blood pressure was measured on the left or right upper arm during the session. 


\subsubsection{Data analysis}

To detect significant differences between the ESRF patients and the control subjects the unpaired Student's t-test was applied. For this comparison only data in the ESRF patients prior to hemodialysis were used. To detect significant differences between pre and post hemodialysis the paired Student's t-test was applied. To investigate relationships between the measured parameters before and after hemodialysis a (multiple) regression analysis was performed on the differences of these parameters. These differences (post minus pre dialysis) are indicated by $\Delta$ as prefix for such a parameter. The significance level was set at $p<0.05$. All statistical analyses were performed with the SPSS statistical software package for Windows, release 6.0 .

\subsection{Results}

\subsubsection{Control subjects versus ESRF subjects (table 7.1)}

Before hemodialysis MWSS was significantly lower in ESRF patients $(0.67 \pm$ $0.23 \mathrm{~Pa})$ than in control subjects $(1.24 \pm 0.20 \mathrm{~Pa})$ as a result of both a lower MWSR and a lower WBV. The lower WBV in the ESRF group before dialysis (2.80 $\pm 0.52 \mathrm{~Pa} . \mathrm{s}$ ) could be attributed to the lower hematocrit and MWSR in these patients, because no significant difference in plasma viscosity could be detected between the ESRF group $(1.16 \pm 0.05 \mathrm{~Pa})$ and the control group (1.16 $\pm 0.07 \mathrm{~Pa}$ ). PWSS was significantly lower in the ESRF than in the control group. PWSR and PSV were not significantly different in the ESRF and the control group, indicating that the difference in PWSS is due to the difference in WBV between the two groups. The diameter of the CCA was significantly larger in the ESRF patients $(7.29 \pm 0.89 \mathrm{~mm})$ than in the control subjects $(6.29 \pm 0.49 \mathrm{~mm})$. Generally higher blood pressures were found in the ESRF group, while heart rate $(H R)$ was the same in both groups. 


\section{Table 7.1}

Measured parameters (mean \pm standard deviation) of the CCA of control subjects $(n=13)$ and of ESRF patients $(n=13) .^{*}$ denotes significant difference between control subjects and ESRF patients. "* denotes significant difference of ESRF patients before and after hemodialysis. Diameter (D), distension (Dist), strain (S), mean (MV), compliance (CC), peak (PSV) and mean (MV) blood flow velocity, peak (PWSR) and mean (MWSR) wall shear rate, peak (PWSS) and mean (MWSS) wall shear stress, systolic (SBP) and diastolic (DBP) blood pressure, pulse pressure (PP), mean (MAP) arterial pressure, heart rate (HR), whole blood (WBV) and plasma viscosity ( $\left.\eta_{0}\right)$.

\section{Control subjects Pre-Dialysis Post-Dialysis}

\begin{tabular}{|c|c|c|c|}
\hline $\mathrm{D}[\mathrm{mm}]$ & $6.29 \pm 0.49$ & $7.29 \pm 0.89^{*}$ & $7.42 \pm 1.02$ \\
\hline Dist [ $\mu \mathrm{m}]$ & $450 \pm 160$ & $479 \pm 128$ & $403 \pm 151^{* *}$ \\
\hline $\mathrm{PSV}\left[\mathrm{mm} \cdot \mathrm{s}^{-1}\right]$ & $734 \pm 152$ & $644 \pm 220$ & $554 \pm 162^{* *}$ \\
\hline $\mathrm{MV}\left[\mathrm{mm} \cdot \mathrm{s}^{-1}\right]$ & $287 \pm 42$ & $204 \pm 70$ * & $170 \pm 66$ \\
\hline PWSR $\left[\mathrm{s}^{-1}\right]$ & $902 \pm 178$ & $815 \pm 337$ & $746 \pm 284$ \\
\hline $\operatorname{MWSR}\left[\mathrm{s}^{-1}\right]$ & $387 \pm 51$ & $271 \pm 109^{*}$ & $234 \pm 150$ \\
\hline PWSS [Pa] & $2.87 \pm 0.54$ & $2.25 \pm 0.65^{*}$ & $2.59 \pm 0.78 *$ \\
\hline MWSS [Pa] & $1.24 \pm 0.20$ & $0.67 \pm 0.23^{*}$ & $0.69 \pm 0.30$ \\
\hline $\mathrm{SBP}$ [mm Hg] & $121 \pm 8$ & $143 \pm 18$ & $123 \pm 21 \quad *$ \\
\hline DBP $[\mathrm{mm} \mathrm{Hg}]$ & $73 \pm 9$ & $80 \pm 15$ & $75 \pm 15$ \\
\hline $\mathrm{PP}[\mathrm{mm} \mathrm{Hg}]$ & $48 \pm 7$ & $63 \pm 10 *$ & $48 \pm 12 *$ \\
\hline MAP [mm Hg] & $90 \pm 7$ & $107 \pm 17$ * & $94 \pm 17^{* *}$ \\
\hline HR [bpm] & $67 \pm 12$ & $74 \pm 11$ & $79 \pm 13$ \\
\hline WBV [mPa.s] & $3.20 \pm 0.29$ & $2.80 \pm 0.52$ * & $3.71 \pm 1.54$ ** \\
\hline $\mathrm{Ht}$ [L/L] & $0.43 \pm 0.03$ & $0.31 \pm 0.05^{*}$ & $0.34 \pm 0.06 *$ \\
\hline$\eta_{0}$ [mPa.s] & $1.16 \pm 0.07$ & $1.16 \pm 0.05$ & $1.26 \pm 0.10^{* *}$ \\
\hline
\end{tabular}




\subsubsection{Pre versus post hemodialysis in the ESRF patients (table 7.1)}

After hemodialysis PWSS increased significantly by about $15 \%$. MWSS, however, remained at the same level $(0.69 \pm 0.30 \mathrm{~Pa})$, despite a significant increase in WBV of on the order of $33 \%$. The latter increase resulted from a significant increase in both hematocrit (10\%) and in plasma viscosity (9\%) (figure 7.2). PWSR and MWSR did not change significantly, but PSV and $M V$ decreased significantly after hemodialysis. The diameter increased by about $2 \%$, but this change just did not reach the level of significance. SBP, PP and MAP decreased significantly, while heart rate did not change.

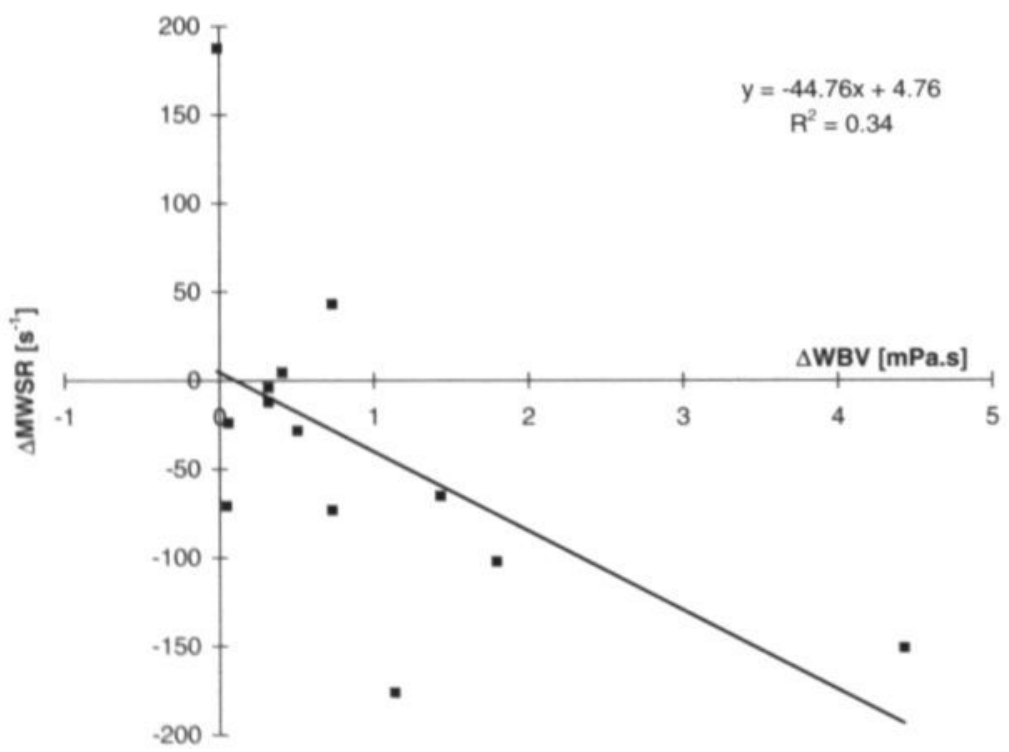

\section{Figure 7.2}

The change in blood viscosity ( $\triangle W B V$ ) and the change in wall shear rate (AMWSR) due to hemodialysis exhibit a significant negative correlation $(r=-0.58$, $p=0.037$ ). This implies that in order to maintain mean wall shear stress constant an increase in blood viscosity is counterbalanced by a decrease in wall shear rate. 
A significant negative correlation $(r=-0.58, p=0.037)$ was found between $\triangle M W S R$ and $\triangle W B V$ (figure 7.2). Notably, after hemodialysis in one of the subjects WBV increased excessively (about $5 \mathrm{mPa}$.s) due to an increase of both $\mathrm{Ht}$ (from 0.40 to $0.47 \mathrm{~L} /$ ) and $\eta_{0}(1.14$ to $1.37 \mathrm{mPa} . \mathrm{s})$, and a pronounced decrease in wall shear rate (from $220 \mathrm{~s}^{-1}$ to $65 \mathrm{~s}^{-1}$ ). Therefore, this patient can be regarded as an outlier, but was maintained in the analysis.

\subsection{Discussion}

\subsubsection{ESRF versus control subjects}

The findings in the present study show that in patients with end stage renal failure (ESRF) mean wall shear stress is on the order of $0.7 \mathrm{~Pa}$, which is about $40 \%$ lower than mean wall shear stress in age and sex matched controls (1.2 Pa). In these patients peak wall shear stress $(2.3 \mathrm{~Pa})$ is also lower than in the control subjects $(2.9 \mathrm{~Pa})$. The low wall shear stress in these patients prior to hemodialysis is due to both a significantly lower whole blood viscosity and a significantly lower wall shear rate. The lower whole blood viscosity mainly results from a lower hematocrit.

The pathophysiological consequences of low wall shear stress for the cardiovascular system is still a matter of debate, but there is increasing evidence that artery wall thickening and atherosclerosis are preferentially initiated in areas of low shear stress (Caro et al. 1971, Friedman et al. 1981, Kornet et al. 1999, Kornet et al. 1998, Zarins et al. 1983). Therefore, it may quite well be that the low peak and mean wall shear stress in ESRF patients, at least partly, contributes to their higher risk of cardiovascular diseases.

The larger diameter of the common carotid artery in ESRF patients prior to dialysis as found in the present study is in accordance with previous observations (Barenbrock et al. 1993, London et al. 1990). The mechanism underlying this increase in diameter is as yet unknown. A possible explanation for the observed diameter enlargement could be the repetitive volume expansion and the concomitantly higher blood pressure, inducing a chronic dilation of elastic arteries as the common carotid artery. Because compliance and strain in the ESRF patients are not significantly different from healthy subjects, remodelling of the common carotid artery rather than a change in arterial wall properties has to be considered. 


\subsubsection{Predialysis versus postdialysis}

After hemodialysis mean wall shear stress does not change significantly and is kept at the relatively low level of $0.7 \mathrm{~Pa}$ via reciprocity of mean wall shear rate and whole blood viscosity. This indicates that in ESRF patients the vascular system is still capable of maintaining mean wall shear stress, despite an acute increase of blood viscosity due to hemodialysis. Experiments on in situ blood-perfused feline femoral arteries have shown that when flow and perfusion pressure are kept constant, a decrease in viscosity by hemodilution and an increase in viscosity by hemoconcentration induce a decrease and an increase in the diameter of the vessels, respectively. These changes were shown to be endothelium dependent (Melkumyants and Balashov 1990, Melkumyants et al. 1989). The observations in the present study indicate that in ESRF patients endothelial cell function is apparently still able to regulate mean wall shear stress adequately, albeit at a lower absolute level. The latter can likely be explained by the increase in diameter of about $2 \%$, although not significantly $(p=0.062)$. The non-significant increase in diameter is probably explained by the decrease in mean arterial pressure from 107 to $94 \mathrm{mmHg}(p<0.05)$, which will counteract the increase in diameter due to the enhanced wall shear stress. To the best of our knowledge, this is the first study showing that in humans mean wall shear stress can be maintained at a certain level, despite an acute increase in whole blood viscosity.

The slight diameter increase after hemodialysis in the present study seems to contrast the results obtained in a previous study, showing vasoconstriction of the common carotid artery (Barenbrock et al. 1993). In the latter study, however, diameter measurements in the ESRF patients were performed about 2 hours after termination of hemodialysis. In the present study arterial diameters were measured immediately after hemodialysis, i.e., at a moment when blood viscosity and, hence, wall shear stress is expected to be at its highest value. Two hours after hemodialysis the vasodilating effect of an increase in wall shear stress may have disappeared leading to vasoconstriction due to the persisting dominating influence of a reduced arterial blood pressure. 
In conclusion the findings in the present study indicate that in patients with end stage renal failure peak and mean wall shear stress in the common carotid artery are lower compared to age and sex matched control subjects but that mean wall shear stress is still regulated despite acutely changed blood viscosity.

\section{Acknowledgement}

We thank Dr. F. de Heer, MD, and Dr. F. van der Zande, MD, for their co-operation in this study.

\subsection{References}

Barenbrock M, Spieker C, Laske V, Baumgart P, Hoeks APG, Zidek W, Rahn KH. Effect of long-term hemodialysis on arterial compliance in end-stage renal failure. Nephron 1993;65:249-253.

Brands PJ, Hoeks APG, Hofstra L, Reneman RS. A noninvasive method to estimate wall shear rate using ultrasound. Ultrasound Med Biol 1995;21:171-185.

Brenner BM, Lazarus JM. Chronic renal failure: pathophysiologic and clinical consequences. In: Braunwald E, Isselbacher KJ, Petersdorf RG, Wilson JD, Martin JB, Fauci AS, eds. Harrison's principles of internal medicine. Hamburg: McGrawHill, 1987:1155-1161.

Caro CG, Fitzgerald JM, Schroter RC. Atheroma and arterial wall shear: observation, correlation and proposal of a shear dependent mass transfer mechanism for atherogenesis. Proc Roy Soc London 1971;17B:105-159.

Feriani M, Kimmel PL, Kurantsin-Mills J, Bosch JP. Effect of renal replacement therapy on viscosity in end stage renal disease patients. Am $\mathrm{J}$ Kidney Dis 1992;19:131-139. 
Friedman MH, Hutchins GM, Bargeron CB, Deters OJ, Mark FF. Correlation between intimal thickness and fluid shear in human arteries. Atherosclerosis $1981 ; 39: 425-436$.

Hoeks APG, Samijo SK, Brands PJ, Reneman RS. Assessment of wall shear rate in humans: an ultrasound study. J Vasc Invest 1995;1:108-117.

Kamiya A, Togawa T. Adaptive regulation of wall shear stress to flow change in the canine carotid artery. Am J Physiol 1980;239:H14-H21.

Kornet L, Hoeks APG, Lambregts J, Reneman RS. In the femoral artery bifurcation, differences in mean wall shear stress within subjects are associated with different intima-media thickness. Arterioscler Thromb Vasc Biol 1999;19:2933-2939.

Kornet I, Lambregts J, Hoeks APG, Reneman RS. Differences in near wall shear rate in the carotid artery within subjects are associated with different intima-media thickness. Arterioscler Thromb Vasc Biol 1998;18:1877-1884.

Lindner A, Charra B, Sherrard D, Scribner BH. Accelerated atherosclerosis in prolonged maintenance hemodialysis. N Engl J Med 1974;290:697.

London GM, Marchais SJ, Safar ME, Genest AF, Geurin AP, Metevier F, Chedid K, London AM. Aortic and large artery compliance in end-stage renal failure. Kidney International 1990;37:137-142.

Melkumyants AM, Balashov SA. Effect of blood viscosity on arterial flow induced dilator response. Cardiovasc Res 1990;24:165-168.

Melkumyants AM, Balashov SA, Khayutin VM. Endothelium dependent control of the arterial diameter by blood viscosity. Cardiovasc Res 1989;23:741-747. 
Nicholls AJ, Edward N, Catto GRD, Engeset J, Macleod M. Accelerated arteriosclerosis in long-term dialysis and renal transplant patients: Fact or fiction? Lancet 1980;1:276-278.

Reneman RS, Van Merode T, Hick P, Hoeks APG. Flow velocity patterns in and distensibility of the carotid artery bulb in subjects of various ages. Circulation $1985 ; 71: 500-509$.

Rodbard S. Negative feedback mechanisms in the architecture and function of the connective and cardiovascular tissues. Perspect Biol Med 1970;13:507-527.

Samijo SK, Willigers JM, Barkhuysen R, Kitslaar PJEHM, Reneman RS, Brands PJ, Hoeks APG. Wall shear stress in the human carotid artery as function of age and gender. Cardiovasc Res 1998;39:515-522.

Seyfert UT, Hauck W, Kirsch J, Kiesewetter H, Albert FW, Wenzel E. Contributions to biorheology during hemodialysis. Biorheology 1991;28:473-481.

Weaver JPA, Evans A, Walder DN. The effect of increased fibrinogen content on the viscosity of blood. Clin Sci 1969;36:1-10.

Zarins CK, Giddens DP, Bharavadj BK, Sottiurai VS, Mabon RF, Glagov S. Carotid bifurcation atherosclerosis: Quantification of plaque localization with velocity profiles and wall shear stress. Circ Res 1983;53:502-514.

Zarins CK, Zatina MA, Giddens DP, Ku DN, Glagov S. Shear stress regulation of artery lumen diameter in experimental atherogenesis. J Vasc Surg 1987;5:413-420. 


\section{Is wall shear stress the same in the common carotid and brachial artery?}

\begin{tabular}{|cl}
\hline 8.1 & Abstract \\
8.2 & Introduction \\
8.3 & Materials and methods \\
8.3.1 & The Shear Rate Estimation System \\
8.3.2 & Measurement procedure in the CCA \\
8.3.3 & Measurement procedure in the BA \\
8.3.4 & Assessment of wall shear rate via Poiseuille's law \\
8.3.5 & Viscosity assessment \\
8.3.6 & Biochemical analysis \\
8.3.7 & Data analysis \\
8.4 & Results \\
8.5 & Discussion \\
8.6 & References
\end{tabular}

S.K. Samijo, J.M. Willigers, R. Barkhuysen, P.J.E.H.M. Kitslaar, R.S. Reneman, A.P.G. Hoeks. 
Wall shear stress in the CCA and BA 


\subsection{Abstract}

According to Murray's law, pertaining to the minimum work model for an optimal conduit system, it can be inferred that mean wall shear rate (WSR) and mean wall shear stress (WSS = WSR times whole blood viscosity) have the same magnitude throughout the arterial tree. However, evidence is lacking that Murray's law indeed holds for human arteries, mainly because of the absence of a reliable technique to assess wall shear rate and stress in vivo. Using a Shear Rate Estimating System (SRES), based on ultrasound, wall shear rate was measured non-invasively in humans to verify Murray's law. We assessed WSR in the elastic common carotid artery (CCA) and the muscular brachial artery (BA) of 12 presumably healthy young male subjects (mean age $34 \pm 4 \mathrm{y}$ ), using the SRES. Peak WSR and mean WSR were significantly higher in the CCA than in the BA $\left(1094 \pm 337 \mathrm{~s}^{-1}\right.$ vs. $839 \pm 181$ $\mathrm{s}^{-1} ; \mathrm{p}<0.01$ and $428 \pm 94 \mathrm{~s}^{-1}$ vs. $227 \pm 87 \mathrm{~s}^{-1} ; \mathrm{p}<0.01$, respectively). Peak WSS did not differ between the CCA and the $\mathrm{BA}(3.05 \pm 0.88 \mathrm{~Pa}$ vs. $3.73 \pm 0.97 \mathrm{~Pa}, \mathrm{p}=0.06)$. Mean WSS in the CCA was significantly higher than in the BA $(1.38 \pm 0.18 \mathrm{~Pa}$ vs. $0.90 \pm 0.20 \mathrm{~Pa}, \mathrm{p}<0.01$ ). These findings demonstrate that peak and mean WSR as well as mean WSS are higher in the CCA than in the BA and that along the arterial tree Murray's law is not applicable.

\subsection{Introduction}

According to literature, the branching vasculature of the mammalian circulatory systems, including the human arterial system, generally obeys Murray's law (Kamiya et al. 1984, LaBarbera 1990, Sherman 1981, Zamir 1977). This law states that in a branching fluid transport system the cube of the radius of a parent vessel equals the sum of the cubes of the radii of the daughter vessels, provided that the fluid is Newtonian. It can then be inferred that blood vessel volume flow is proportional to the cube of the radius. Consequently, mean wall shear stress is constant and the same throughout the transport system (Sherman 1981, Zamir 1977). 
Empirical studies indicate that Murray's law is applicable to the human circulatory system, but other data suggest that this is not necessarily the case (LaBarbera 1990, Sherman 1981). In a previous study (Samijo et al. 1998) we have found that in the common carotid artery mean wall shear stress is on the order of $1.2 \mathrm{~Pa}$ independent of age and gender, a value close to the theoretically predicted value of 1.5 $\mathrm{Pa}$. In the femoral artery bifurcation, however, we found mean wall shear stress to be substantially lower than in the common carotid artery, i.e., $0.36 \mathrm{~Pa}$ in the common femoral artery and $0.55 \mathrm{~Pa}$ in the superficial femoral artery (Kornet et al. 1999).

In the present study we explored the differences in wall shear rate and stress along the arterial tree, if any, by comparing the values in the elastic common carotid artery with those in the muscular brachial artery of presumed healthy volunteers.

The Shear Rate Estimating System (SRES) used is based on ultrasound (Brands et al. 1995, Hoeks et al. 1995) and provides the instantaneous wall shear rate waveform. From the waveform peak and mean wall shear rate and subsequently, peak and mean wall shear stress were estimated, taking into account blood viscosity. The equipment also allows for simultaneous assessment of arterial diameter $(D)$ and the change in diameter during the cardiac cycle (distension waveform).

Wall shear data as assessed with the SRES were compared to those calculated according to Poiseuille' s law to evaluate whether the pulsatile behaviour of blood velocity in arteries indeed modifies mean wall shear rate and stress.

\subsection{Patients and methods}

Twelve presumed healthy male subjects (mean age $34 \pm 4 y$ ) participated in the study. All subjects were non-smokers and normotensive. The subjects were aware of the investigational nature of the study and had given written informed consent. The study was approved by the joint medical ethical committee of the Academic Hospital Maastricht and the Maastricht University. 
The measurements were always performed in the morning. The subjects were examined in the supine position in a climatised room with a temperature of $22^{\circ} \mathrm{C}$ $24^{\circ} \mathrm{C}$. After an acclimatisation period of 10 minutes the measurements were started. The blood pressure oscillometer, a semi-automated oscillometric device (Dinamap; Critikon, Tampa, Florida, USA), was set to take a recording every 5 minutes. Wall shear rate measurements were performed on the right CCA and BA in a random order.

\subsubsection{The Shear Rate Estimation System (SRES)}

The Shear Rate Estimation System (SRES) is based on ultrasound and has been described in detail elsewhere (Brands et al. 1995, Hoeks et al. 1995). Briefly, an echosystem (Ultramark 9 plus, Advanced Technology Laboratories, Bellevue, WA, USA) with a broadband (5-9 MHz) curved array transducer was used to emit and to receive reflected ultrasound signals. The raw digitised $(20 \mathrm{MHz})$ radio-frequency $(\mathrm{rf})$ signals received were transferred to a personal computer $(P C)$ through an interface configuration consisting of an internal card in the ATL-system in combination with a custom built plug-in card for the PC. The latter card allows capturing selectively segments of the if signals starting at a preselected depth and with a preselected width. To assess the instantaneous blood velocity distribution along a selected line of observation with high axial resolution, the echosystem was switched to a wide band $\mathrm{M}$-mode with a high pulse repetition frequency $(10 \mathrm{kHz})$. The returned acoustic signals had an effective pulse length of 3 periods at $5.3 \mathrm{MHz}$, which is equivalent to a spatial resolution of $375 \mu \mathrm{m}$. Each velocity estimate was based on half overlapping data segments of $300 \mu \mathrm{m}$ in depth and $10 \mathrm{~ms}$ in time and was calculated by means of a modelled cross correlation function for the if signals (Brands et al. 1995). Data acquisition was initiated synchronously with a trigger derived from the top of the R-wave of the ECG signal, facilitating the detection of the maximum (systolic) and mean velocity (in $\mathrm{mm} \cdot \mathrm{s}^{-1}$ ) as well as the end-diastolic arterial diameter $(D$ in $\mathrm{mm})$ and distension waveform. The PC memory presently available limits the recording duration to 1.2 seconds, which is sufficient to capture data over one complete heartbeat. 

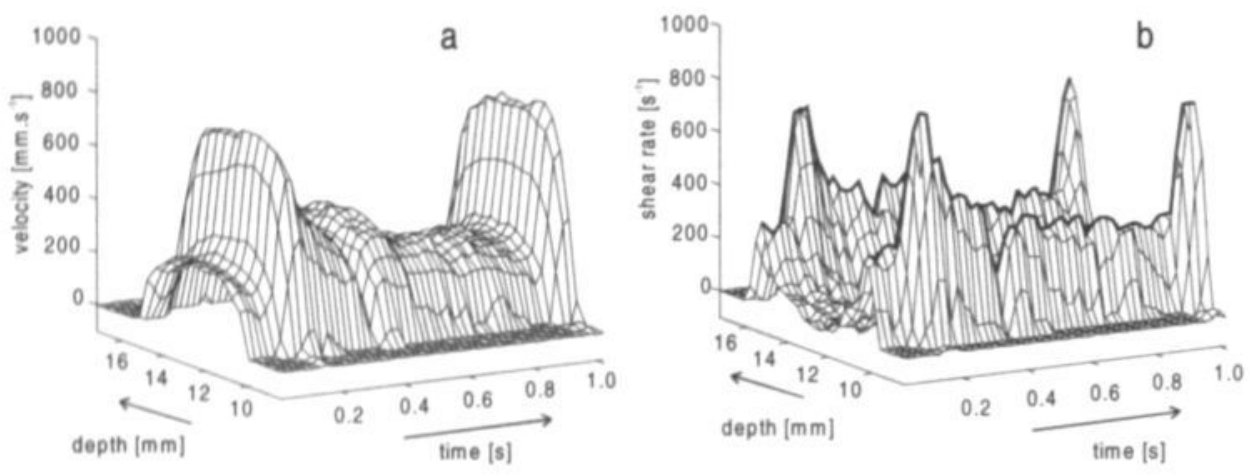

Figure 8.1

Velocity (a) and shear rate distribution (b) in the common carotid artery of a subject.
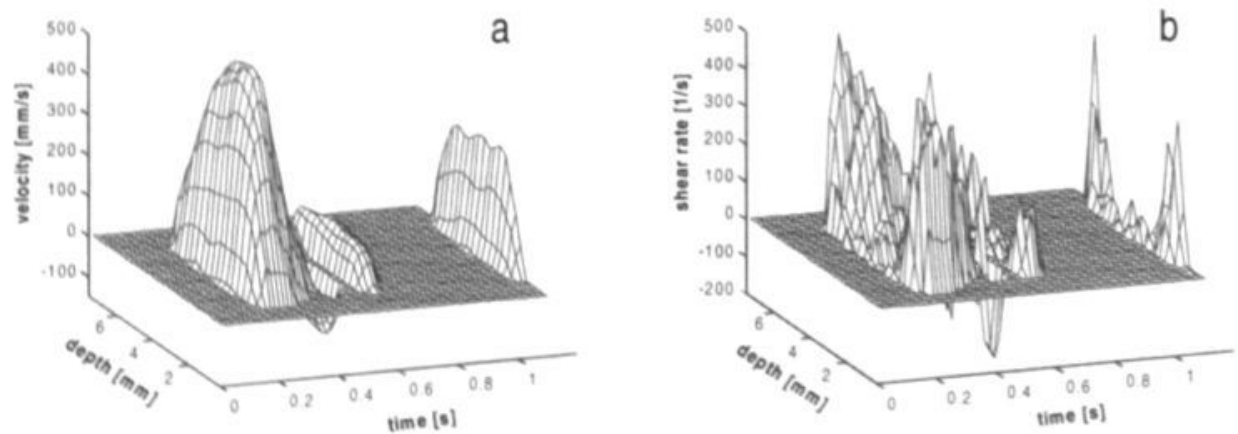

Figure 8.2

Velocity (a) and shear rate distribution (b) in the brachial artery of the same subject as shown in figure $8.1 \mathrm{a}$ and $8.1 \mathrm{~b}$. 
Processing of the received $i$ signals as function of time provides both the distension waveform and the velocity distribution as function of depth and time. The peak value of the diameter change as function of time gives the distension ( $\Delta D$ in $\mu \mathrm{m})$. Typical time-dependent velocity distributions in the common carotid artery (CCA) and in the brachial artery (BA) of a subject are given in figure 8.1a and figure 8.2a, respectively. The velocity distribution provides peak systolic velocity ( $P S V$ in $\left.\mathrm{mm} . \mathrm{s}^{-1}\right)$ and mean velocity $\left(M V\right.$ in $\left.\mathrm{mm} \cdot \mathrm{s}^{-1}\right)$, averaged over one heart cycle, in the centre of the lumen. The latter is comparable with the mean velocity derived from a Doppler signal observed in the centre of the lumen with conventional pulsed Doppler systems.

The instantaneous shear rate distribution follows from the radial derivative of the velocity profile at each site and each time instant. Typical recordings of the shear rate distribution in the CCA and $\mathrm{BA}$, are shown in figure $8.1 \mathrm{~b}$ and figure $8.2 \mathrm{~b}$, respectively.

The average of the maximum values of the derivatives in the vicinity of the anterior and posterior vessel walls is considered as an estimate of wall shear rate in an artery. The averaging procedure is performed to minimise possible effects induced by secondary flows (Brands et al. 1995). Peak wall shear rate at peak systole $\left(P W S R\right.$ in $\mathrm{s}^{-1}$ ) and mean wall shear rate (the time averaged shear rate over one cardiac cycle; MWSR in $\mathrm{s}^{-1}$ ) were used for further analysis.

\subsubsection{Measurement procedure in the CCA}

The CCA was visualised in B-mode with the head of the subject slightly tilted in the contra lateral direction. The common, internal and external carotid arteries, on both the left and right side, were evaluated for the presence of plaques. Measurements were performed on the right side only. The tip of the flow divider was used as a landmark, where after the probe position was manipulated until a suitable line of sight could be selected, crossing the artery at an angle of 70 degrees with the longitudinal axis of the artery 2 to $3 \mathrm{~cm}$ proximal to the tip of the flow divider. After positioning the line of observation the ultrasound system was switched to $\mathrm{M}$-mode at a high pulse repetition frequency $(10 \mathrm{kHz})$, whereafter a recording was made. This procedure was repeated 15-20 times with a time interval of 1 to 2 minutes between the measurements. 


\subsubsection{Measurement procedure in the BA}

The right BA was visualised in B-mode with the arm and hand in the dorsal position. Subsequently, a suitable line of sight was selected, crossing the artery at an angle of 70 degrees with the longitudinal axis of the artery, and the ultrasound system was switched to M-mode, where after a recording was made. The measurement procedure was repeated $15-20$ times with a time interval of 1 to 2 minutes between the measurements.

Because of motion artefacts (movements of the artery with respect to the probe) in both the CCA and the BA during each measurement session approximately 1 to 3 registrations had to be excluded. The data of the remaining registrations were used to compute the means per artery per session.

Averaging over about 15 measurements provides a precise estimate, because in a previous study from our institute the intrasession and intrasubject variability was found to be $15 \%$ and $12 \%$, respectively (Samijo et al. 1997).

\subsubsection{Assessment of wall shear rate via Poiseuille's law}

To assess differences between wall shear stress as determined with the SRES and as determined according to Poiseuille's law, if any, wall shear rate was also calculated (CWSR), assuming a parabolic velocity profile, by means of the following equation:

$$
C W S R=\frac{4 V_{\max }}{D}
$$

where $V_{\max }$ is the (averaged) peak systolic blood flow velocity in the centre of the artery and $D$ is the measured internal diameter of the artery. The angle of observation was $70^{\circ}$. 


\subsubsection{Viscosity assessment}

At the end of the session blood was collected for determination of hematocrit ( $\mathrm{Ht}$ ) and plasma viscosity $\left(\eta_{0}\right)$. The latter were used to calculate whole blood viscosity using the approximation proposed by Weaver (Weaver et al. 1969):

$\log W B V=\log \eta_{0}+\alpha \cdot H t$

with

$$
\alpha=0.030-0.0076 \log \text { (MWSR) }
$$

where $W B V$ is whole blood viscosity in $\mathrm{mPa} . \mathrm{s}, \eta_{0}$ plasma viscosity in $\mathrm{mPa} . \mathrm{s}, \mathrm{Ht}$ hematocrit in percentage, and MWSR mean wall shear rate in $\mathrm{s}^{-1}$.

This approximation properly accounts for the effect of local MWSR on WBV, i.e., a lower shear rate results in a higher blood viscosity.

WSS was calculated from the following relation:

$$
W S S=W S R^{*} W B V
$$

\subsubsection{Biochemical analysis}

Blood samples were obtained without stasis from an antecubital vein for determination of hematocrit, haemoglobin, glucose, high density lipoprotein (HDL), low density lipoprotein (LDL), triglycerides and total cholesterol using standard autoanalysing techniques. Plasma viscosity was determined using an Ostwald microviscometer (Schott Gerate GmbH, Hofheim, Germany).

\subsubsection{Data analysis}

For comparison of the data in the brachial and the common carotid artery the paired Student's t-test was used. Values were expressed as mean \pm standard deviation (SD). A p-value less than 0.05 was considered as statistically significant. Linear regression was employed to study the relations, between 2 parameters, if any. $A$ significant relationship was present if the $95 \%$ confidence interval excluded zero with $p<0.05$. All statistical analyses were performed with the SPSS statistical software package for Windows, release 6.0 . 


\subsection{Results}

The data are presented in table 1. PWSS was higher in the BA than in the CCA, but this difference just did not reach the level of significance. PWSR, MWSS and MWSR were significantly lower in the BA than in the CA. The different findings of $P W S S$ and $P W S R$ in the CCA and BA emphasizes the interaction between MWSR and $W B V$, which is reflected by a significant higher WBV in the BA than in the CCA.

$D$ and $\triangle D$ were smaller in the BA than in the CCA. CMWSR was significantly lower in the BA than in the CCA, while CMWSS was at the same level in both arteries.

An interesting observation is that CMWSR and CMWSS are significantly lower $(\mathrm{p}<$ 0.001) than MWSR and MWSS, respectively, in both the BA and the CCA. Thus, both wall shear rate and wall shear stress are underestimated when determined based on Poiseuille's law.

\section{Table 8.1}

Values of the parameters as assessed in the CCA and the BA. Data are presented as mean values and standard deviations between parentheses. Significances are given in p-values; $n s=$ not significant. CMWSR and CMWSS = MWSR and MWSS according to Poiseuille's law.

CCA

$\begin{array}{ll}\text { PWSS } & {[\mathrm{Pa}]} \\ \text { MWSS } & {[\mathrm{Pa}]} \\ \text { PWSR } & {\left[\mathrm{s}^{-1}\right]} \\ \text { MWSR } & {\left[\mathrm{s}^{-1}\right]}\end{array}$

WBV [Pa.s]

D $[\mathrm{mm}]$

$\Delta \mathrm{D} \quad[\mu \mathrm{m}]$

CMWSS [Pa]

CMWSR [ $\mathrm{s}^{-1}$ ]

$3.05(0.88)$
$1.38(0.18)$
$1094(337)$
$428(94)$
$3.3(0.3)$
$6.8(0.5)$
$800(426)$
$0.56(0.09)$
$174(39)$

BA

$3.73(0.97)$

$0.90(0.20)$

839 (181)

$226(87)$

$4.2(0.8)$

$4.5(0.4)$

105 (58)

$0.58(0.12)$

145 (53)

\section{Significance}

$$
=0.06
$$$$
<0.01
$$

$<0.01$

$<0.01$

$<0.01$

$<0.01$

$<0.01$

ns

$=0.04$ 


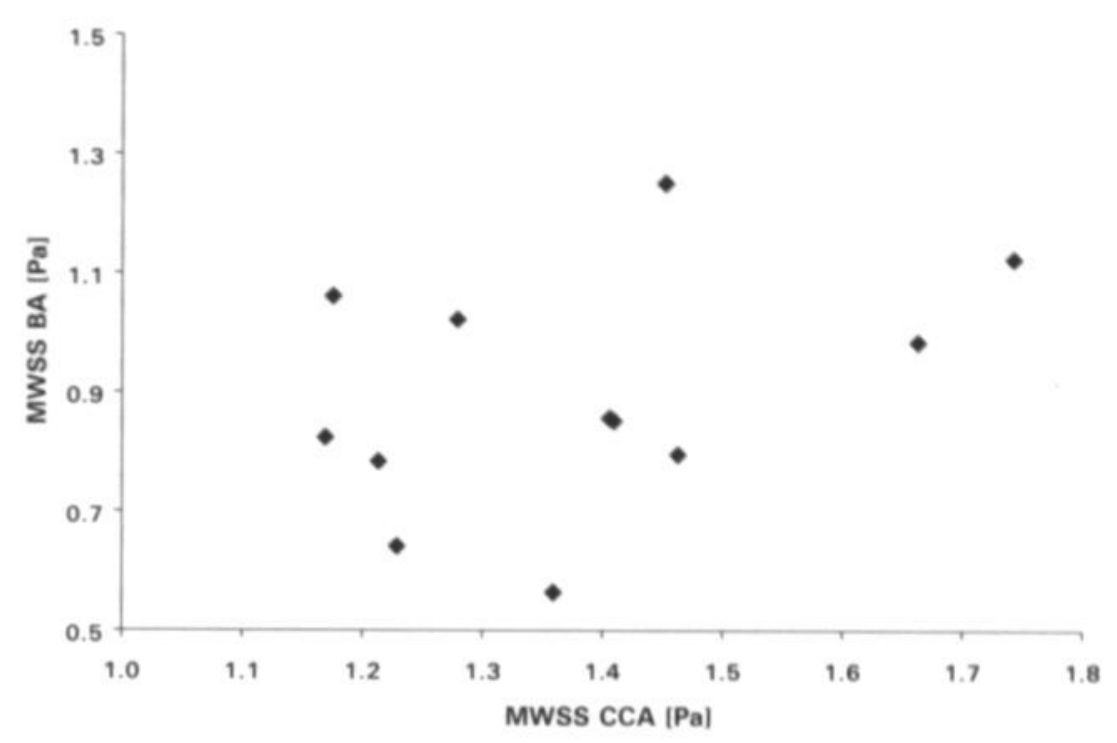

\section{Figure $\mathbf{8 . 3}$}

MWSS in the CCA plotted against MWSS in the BA.

In both the CCA and the BA linear regression analysis showed no relationship between diameter and measured peak or mean wall shear stress (data not shown). Also no relationship was found between MWSS in the CCA and MWSS in the BA (figure 8.3). In all subjects, haemoglobin, hematocrit, glucose, HDL, LDL, triglycerides and total cholesterol values were within the normal ranges.

\subsection{Discussion}

The findings in this study show that in presumed healthy male subjects measured mean wall shear stress and mean and peak wall shear rate are lower in the muscular brachial artery than in the elastic common carotid artery. Peak wall shear stress tends to be higher in the brachial than in the common carotid artery. Actual mean wall shear rate and mean wall shear stress are underestimated when calculated according to Poiseuille's law. 
A higher peak wall shear stress in the brachial artery is explained by relating wall shear stress to the function of the (muscular) brachial artery. Compared to the common carotid artery the brachial artery supplies in rest a region with a relatively high impedance, causing the local (volume) flow velocity waveform to be more dependent on the duration of ejection and the timing of the pressure wave reflection from peripheral sites. In the brachial artery most of the volume flow is conducted in the systolic phase (O'Rourke and Avolio 1980) and thus a greater peak wall shear rate is induced. For the remaining part of the cardiac cycle the volume flow is close to zero, resulting in a lower mean wall shear rate and stress value than in the common carotid artery. Apparently the nature of the distal vascular bed also governs the mean level of wall shear stress. Statements with respect to the physiological regulation, for example, in physical exercise should be considered in that perspective (Kamiya et al. 1984, Kamiya and Togawa 1980, Langille and O'Donnel 1986). Whether a higher peak wall shear stress in the brachial artery has physiological consequences remains to be studied.

The significantly lower mean wall shear stress in the brachial than in the common carotid artery indicates that mean wall shear stress is not at the same level along the arterial tree. In corroboration, it was found that mean wall shear stress at the posterior wall of the common and superficial femoral artery is on the order of $0.36 \mathrm{~Pa}$ and $0.55 \mathrm{~Pa}$, respectively (Kornet et al. 1999). This low level in both the common and superficial femoral artery can again be attributed to a relatively high peripheral impedance inducing pressure reflections at these two locations, i.e., a longer duration of negative flow resulting in a low mean wall shear rate and stress in these arteries.

Generally it can be concluded that mean wall shear stress is not constant along the human arterial system, which is in disagreement to Murray's law. Our findings, however, are in agreement with the observations of LaBarbera (LaBarbera 1990). He stated, from an evolutionary point of view, that in a real system of vessels containing a flow of fluid, wall shear stress can not be constant everywhere in the system and local wall shear stress must depart from the average value. The regulation of arterial diameter is, at least partially, related to mean wall shear stress 
in both the common carotid and the brachial artery, by a negative feedback mechanism that alters the diameter so as to maintain local wall shear stress within a limited range of values. The intersubject variations in the setpoint are corroborated by our observation that there is no linear relation between mean wall shear stress and arterial diameter. To what extent intra- and inter-subject differences in diameter regulation exist between elastic and muscular arteries remains to be studied.

That mean wall shear stress is a locally determined hemodynamic variable is supported by the finding that no correlation exists between mean wall shear stress in the common carotid artery and mean wall shear stress in the brachial artery. Our findings indicate that, besides different "set points" of wall shear stress in the arterial and venous system (LaBarbera 1990) different set points of wall shear stress could also exist in different arterial territories. Moreover, it might be expected that the gain of the control system varies over the arterial regions, i.e., the same proportional increase in flow velocity induces a different relative diameter adaptation.

Obviously, the level of mean wall shear stress in the brachial artery is still in the range according to the minimum work theory (Kamiya et al. 1984, Zamir 1977), while the levels in the femoral artery (Kornet et al. 1999) are not. This could be explained as follows: femoral (skeletal) muscle capillaries allow large changes in the conductance of the system, so that greatly varying volume flows can be driven by a relatively constant pressure gradient. In the resting femoral muscle only a minority of the capillaries are utilised at a given moment, so $\Sigma r^{3}$ for the total capillary bed would be less than the $\Sigma r^{3}$ for supplying arterial vessels (Sherman 1981), implicating that the femoral artery does not obey Murray's law. On the other hand, it is still unclear how local mean wall shear stress interacts with arterial diameter in the femoral artery.

Another interesting note is that mean wall shear stress calculated via Poiseuille's law did not show a significant difference between the common carotid and brachial artery, showing the significance of the time dependent behaviour of wall shear stress. In an earlier study (Hoeks et al. 1995) it was already stated that in the common carotid artery mean wall shear stress assessed via Poiseuille's law is 
underestimated. In this study it is found that the latter observation also holds for the brachial artery. Also, our findings show that when wall shear stress would be assessed via Poiseuille's law another interpretation would be made regarding the behaviour of wall shear stress in vivo for different territories.

In conclusion, this study shows that mean wall shear stress is lower in the brachial artery than in the common carotid, which indicates that mean wall shear stress regulation varies over the vascular tree. Moreover, the mean wall shear stress computed according to a presumed parabolic velocity profile (Poiseuille) deviates from the actually measured one and may lead to false conclusions about the local regulation of vascular diameter.

\subsection{References}

Brands PJ, Hoeks APG, Hofstra L, Reneman RS. A noninvasive method to estimate wall shear rate using ultrasound. Ultrasound Med Biol 1995;21:171-185.

Brands PJ, Hoeks APG, Reneman RS. The effect of echo suppression on the mean velocity estimation range of the if cross-correlation model estimator. Ultrasound Med Biol 1995;21:945-959.

Hoeks APG, Samijo SK, Brands PJ, Reneman RS. Assessment of wall shear rate in humans: an ultrasound study. J Vasc Invest 1995;1:108-117.

Kamiya A, Bukhari R, Togawa T. Adaptive regulation of wall shear stress optimizing vascular tree function. Bulletin Math Biol 1984;46:127-137.

Kamiya A, Togawa T. Adaptive regulation of wall shear stress to flow change in the canine carotid artery. Am J Physiol 1980;239:H14-H21. 
Kornet L, Hoeks APG, Lambregts J, Reneman RS. In the femoral artery bifurcation, differences in mean wall shear stress within subjects are associated with different intima-media thickness. Arterioscler Thromb Vasc Biol 1999;19:2933-2939.

LaBarbera M. Principles of design of fluid transport systems in zoology. Science 1990;249:992-1000.

Langille BL, O'Donnel F. Reductions in arterial diameter produced by chronic decreases in blood flow are endothelium-dependent. Science 1986;231:405-407.

O'Rourke MF, Avolio AP. Pulsatile flow and pressure in human systemic arteries: studies in man and in a multibranched model of the human systemic arterial tree. Circ Res 1980;46:363-372.

Samijo SK, Willigers JM, Barkhuysen R, Kitslaar PJEHM, Reneman RS, Brands PJ, Hoeks APG. Wall shear stress in the human carotid artery as function of age and gender. Cardiovasc Res 1998;39:515-522.

Samijo SK, Willigers JM, Brands PJ, Barkhuysen R, Reneman RS, Kitslaar PJEHM, Hoeks APG. Reproducibility of shear rate and shear stress assessment by means of ultrasound in the common carotid artery of young human males and females. Ultrasound Med Biol 1997;23:583-590.

Sherman TF. On connecting large vessels to small. J Gen Physiol 1981;78:431453.

Weaver JPA, Evans A, Walder DN. The effect of increased fibrinogen content on the viscosity of blood. Clin Sci 1969;36:1-10.

Zamir M. Shear forces and blood vessel radii in the cardiovascular system. J Gen Physiol 1977;69:449-461. 
Wall shear stress in the CCA and BA 
Chapter 9

General discussion
9.1 Discussion
9.2 Conclusions
9.3 Recommendations for future research
9.4 References 
General discussion 


\subsection{Discussion}

The importance of wall shear stress has been recognised only in the past decades when it became obvious that this physical parameter has important local biological effects. Wall shear stress plays a significant role in local vascular homeostasis and thus also a role in vascular diseases such as atherosclerosis and intimal hyperplasia. The main problem concerning wall shear stress is the practical inability to measure wall shear stress in vivo, without disturbance of flow, and so, non-invasively in humans.

The aim of the studies in this thesis study was to assess wall shear stress noninvasively in the common carotid and brachial artery of humans. We used a specially designed ultrasonic measurement system, named the Shear Rate Estimating System (SRES). The application of ultrasound in the assessment of wall shear stress is possible as wall shear stress is defined as wall shear rate times blood viscosity, two easier assessable parameters. The time dependent wall shear rate was estimated by calculating the maximal first derivative of the velocity profiles in radial direction as function of time. Blood viscosity was assessed by calculating whole blood viscosity with the formulae proposed by Weaver et al. (Weaver et al. 1969) using hematocrit and plasma viscosity, the two main factors that determine whole blood viscosity (Nichols and O'Rourke 1990).

Our strategy in this thesis study was to divide the study into five parts:

1. To evaluate the SRES in terms of reproducibility, validity, and limitations.

2. To determine physiological wall shear stress levels in the common carotid artery including the effects of age and gender.

3. To evaluate the effect of a risk factor for atherosclerosis, as smoking, if any, on wall shear stress.

4. To study the effect of low whole blood viscosity on wall shear stress in patients with terminal kidney insufficiency on hemodialysis.

5. To investigate whether wall shear stress in the muscular brachial artery is at the same level as in the elastic common carotid artery, thereby testing the applicability of Murray's and Poiseuille's laws. 
The SRES is the first non-invasive apparatus that is able to assess arterial wall shear rate in vivo. This implies that the measurement system could not be validated with another in vivo system. In vitro validity experiments were performed by Gijssen et al. who found good agreement between the SRES and numerical measurements in pulsatile as well as in non-pulsatile conditions (Gijssen et al. 1998). From these studies it was concluded that wall shear rate measured with the SRES was a good estimate for the true arterial wall shear rate. The next step was to investigate the applicability of the SRES in the common carotid artery in humans. The common carotid artery was chosen because of its easy access. This artery is superficially located, is relatively straight, thus causing minimal flow disturbances. Moreover, extensive experience in ultrasonically assessing the common carotid artery has been built up by our group.

The evaluation of the SRES started by determining the reliability of the system. This was tested in terms of intra- and intersubject variability and of short and long term reproducibility. It became clear that for peak and mean wall shear rate the average intrasubject intrasession variability was on the order of $15 \%$ and $12 \%$, respectively. The intersubject intrasession variability for peak wall shear rate and mean wall shear rate was about $16 \%$ and $11 \%$, respectively. The intersubject intrasession variability decreased over the days indicating a diminished biological variance due to acquaintance of the subjects during the measurement sessions. However, average peak and mean wall shear rate remained the same over the days. Generally speaking, peak wall shear rate can be determined with a higher variability (about $15 \%$ ) than mean wall shear rate (variability about $12 \%$ ). This leads to the conclusion that wall shear rate in a human population can be assessed within one session with a moderate, but constant variability. The higher variability in peak wall shear rate may be due to biologic variability. Therefore, a subject must be relaxed during the measurements. The measurement variability depends, of course, for a great deal on the skills of the investigator.

Part of the measurement variability can be attributed to the SRES as the system could not measure during more than one single heartcycle during one registration. If the latter would consist of several consecutive heartbeats, regression to the mean 
would take place resulting in a lower measurement variability. In the reproducibility study, it could not be determined which percentage of the variability had to be attributed to the physiologic variability.

The main limitations of the SRES are the same as those of generally used ultrasound systems, namely the spatial and time resolution. The former is always a compromise between the emission frequency and the depth of interest in the body. For a greater depth of investigation the emission frequency should be lower. Consequently, the ultrasonic wavelength is larger and the axial resolution would be worse for similar quality factor. In our study the resolution of the SRES is on the order of 250-300 micrometers. The time resolution is on the order of $10 \mathrm{~ms}$. The required resolution limits the application to such peripheral arteries as the common carotid, the femoral and the brachial artery. Thus, absolute internal arterial diameters are determined within limitations of about $300 \mu \mathrm{m}$. However, diameter changes (vessel wall movements) within one cardiac cycle are assessed with a precision of a few microns. Knowing that in acute conditions arteries can dilate or constrict by less than 10 percent, the SRES will fail to detect any (acute) vasoconstriction or vasodilatation. However, such measurements will be possible by 1) recording several heart beats during one registration or 2) holding the ultrasonic probe steady on a robot arm which allows continuous repetitive registration of blood flow velocity profiles.

Another limiting condition of the SRES is that blood flow velocity, and thus wall shear rate, is assessed along a single line through the (three-dimensional) artery of interest. Consequently, in the studies performed it is assumed first, that the measurements are performed in the centre of the artery and second, that laminar flow conditions exist. The latter implies that when secondary flows are present an error can be made in the assessment of wall shear rate. Thus, the SRES can only be applied in arteries that are relatively straight such as the common carotid artery. During the project the applicability of the SRES has been extended to the brachial and femoral artery. In these arteries secondary flows are present. For the brachial artery it is expected that secondary flows are relatively small, while for the femoral artery only wall shear rate at the far wall (looking from the surface of the body) has 
been used for analysis. Measurement errors will be made when wall shear stress is determined in curved or bending arteries such as in the bulbus of the internal carotid artery, nearby atherosclerotic plaques or in artificially created arteries such as arteriovenous fistulas.

In general, peak wall shear rate can be assessed more reliably than mean wall shear rate, because diastolic (minimum) shear rate cannot be determined accurately. This is due to the relatively high cut off frequency (higher threshold) and at diastole the ultrasonic signal/noise ratio of the SRES is so low that the information regarding minimal blood flow velocity is not reliably processed by the software algorithms and hardware.

Knowing the specifications and properties of the SRES the study progressed to the next phase. We investigated physiologic wall shear stress in the common carotid artery as function of age (varying between 10 and 60 years) and gender in a cross-sectional population study. It was observed that peak and mean wall shear stress gradually decreased with age. The decrease in peak wall shear stress was more pronounced in males than in females where the observed decrease in peak wall shear rate was related to a decrease in systolic blood flow velocity. Per decade no significant difference in peak and mean wall shear stress was found between the sexes. The main observation in this study was the strong negative correlation between mean wall shear stress and diameter, superseding over the contribution of age. It can be inferred that with increasing age an attempt is made to maintain storage capacity, indicating that cardiac afterload is the first priority in the arterial system. The exact interaction between wall shear stress and storage capacity remains to be elucidated. The interaction between arterial diameter and wall shear stress could not explicitly be studied as factors such as ageing, gender, hemodynamic conditions and life style are influencing the outcome. To accurately study the effect of ageing on wall shear stress a longitudinal study, in which subjects are followed over time, should be performed. The present study indicates, however, that wall shear stress plays a more important role in acute hemodynamic conditions rather than chronic processes such as ageing. This opinion is supported by the direct relationship between wall shear stress and nitrate oxide (NO). This 
biochemical substance is a potent vasodilator with a short half-life time (about a few seconds), playing a role in acute processes (Moncada et al. 1991). Therefore, studies addressing the direct interaction between wall shear stress and diameter are needed, e.g., ischemia-reperfusion studies, or intervention studies with biochemical vasodilators or vasoconstrictors.

In the common carotid artery mean wall shear stress was on the order of $1.2 \mathrm{~Pa}, \mathrm{a}$ value in agreement with earlier performed mathematical studies and studies based on the Pouiseulle law (Kamiya et al. 1984, Zamir 1977). It implies that, by combining this absolute value with findings of in vitro studies where endothelial cell were stimulated with different values of shear stress, theories can be developed about the mechanisms to maintain vascular homeostasis. It can be concluded that at a value of $1.2 \mathrm{~Pa}$, wall shear stress interferes with, for example mitogen activity, permeability and modulation of thrombotic events of endothelial cells (Galbusera et al. 1997, Noria et al. 1999, Takahashi and Berk 1996). However, further investigations are required to elude, whether aside of mean wall shear stress, also pulse (peak minus minimum), minimum as well as peak wall shear stress are important modulating factors. However, first, the SRES measurement method must be improved by enhancing measurement capacity (more beats within one registration), three-dimensional measurements and real time continuous registration.

The aim of the third investigation was to determine whether wall shear stress would be influenced by a pathologic circumstance, such as smoking. It is known that smoking is a contributing factor for developing atherosclerosis (Howard et al. 1998, Strong and Richards 1976). We came to the conclusion that there was no significant difference in peak and mean wall shear stress between long-time smokers and nonsmokers. The weak point of this study is that the exact number of cigarettes (which are sometimes changing within a subject) and the number of smoking years could not be accounted for. It is known that chronic smoking causes damage to the endothelial cell (Blann and McCollum 1993) and has hemodynamic effects (McVeigh et al. 1996, Zhu and Parmley 1995). Our findings indicate that the atherogenic effects of chronic smoking can not be explained by a direct effect on wall shear stress, at least in the common carotid artery. It can not be excluded that chronic smoking affects wall shear stress in other arteries in a different way. 
The next step was to investigate whether patients, who are at high risk to develop atherosclerosis, namely patients with terminal renal insufficiency. We studied the effect of a chronically decreased blood viscosity (due to a decreased hematocrit) on wall shear stress and the effect of an acutely increased whole blood viscosity (after hemodialysis) on wall shear stress and diameter of the common carotid artery in these patients. It was found that basic peak $(2.3 \mathrm{~Pa})$ and mean wall shear stress $(0.7 \mathrm{~Pa})$ were lower compared to age matched control subjects. Hemodialysis increased peak wall shear stress due to the increase in blood viscosity, but mean wall shear stress remained at the same level as before hemodialysis. The measured low wall shear stress in patients with terminal renal insufficiency might attribute to the early development of atherosclerosis in these patients, by affecting endothelial function in a negative manner. The weakness of this study was the small and rather inhomogenous group of patients regarding age, the variable period that patients were on hemodialysis and a difference, although small, in hemodialysis regimens. Nevertheless, it was observed that mean wall shear stress was maintained at a constant level, despite acute changes in whole blood viscosity and blood pressure. This implies that mean wall shear stress is a parameter to be regulated. To what part the low wall shear stress or the frequent changes of wall shear stress during hemodialysis are responsible for the development of atherosclerosis in hemodialysis patients remains to be elucidated. It might quite well be that patients with terminal renal failure are more susceptible to the development of atherosclerosis for at least two reasons, namely a lower wall shear stress and/or different functioning of the endothelial cells. In accordance, it has been found that chronic renal failure is associated with a low nitric oxide production (Blum et al. 1998).

The fifth study was performed to investigate whether the type of artery and the vascular territory affect the level of wall shear stress. Based on theoretical assumptions, wall shear stress is presumed to be a constant value in the arterial system (Kamiya et al. 1984, Rodbard 1975) and even between different zoological systems (LaBarbera 1990). Therefore, we investigated whether wall shear stress is at the same level in the brachial and the common carotid artery. It was found that peak wall shear stress was not significantly higher $(3.7 \pm 1 \mathrm{~Pa}$ vs. $3.1 \pm 0.9 \mathrm{~Pa}$, 
$\mathrm{p}=0.06$ ) in the brachial artery than in the common carotid artery, while mean wall shear stress $(0.9 \pm 0.2 \mathrm{~Pa}$ vs. $1.4 \pm 0.2 \mathrm{~Pa})$ was significantly lower in the brachial than in the common carotid artery. Our observations are supported by other observations, showing that in the common and superficial femoral arteries wall shear stress is about $0.36 \mathrm{pa}$ and $0.55 \mathrm{~Pa}$, respectively (Kornet et al. 1999). These findings indicate that in human arteries mean wall shear stress is not the same along the arterial tree, which is in disagreement to Murray's Law. The explanation might be that the level of wall shear stress depends on the type and function of the artery, which is related to the nature of the distal vascular bed. Moreover, these observations might indicate that wall shear stress regulation, including its interaction with the arterial wall, depends on the localisation of the arterial tree.

\section{2 Conclusions}

After the development of the SRES in 1995 (Brands et al. 1995) it has been successfully employed to measure wall shear rate, thereby allowing the assessment of wall shear stress when blood viscosity is taken into account. Peak wall shear rate can be assessed with an intrasubject intrasession variation of $15 \%$. Mean wall shear rate can be assessed with an intrasubject intrasession variation of $12 \%$. The SRES is limited in its application in spatial resolution (of about $300 \mu \mathrm{m}$ ) due to the inherent limitations of ultrasound. Furthermore, the apparatus can only be used for relatively straight arteries and in arteries where secondary flows are minimal.

Our studies show that peak wall shear stress in the common carotid artery is about 3.3 $\mathrm{Pa}$ in the second decade decreasing to $2.5 \mathrm{~Pa}$ in the sixth decade of life. In contrast mean wall shear stress remained more or less at a level of $1.2 \mathrm{~Pa}$ with a minor age effect. It seems that ageing and gender have no important effect on mean wall shear stress in this artery.

Chronic smoking, which is a risk factor for developing atherosclerosis, does not influence wall shear stress in resting conditions. However, in pathological circumstances where whole blood viscosity is low as in patients on hemodialysis, 
mean wall shear stress is about $40 \%$ lower $(0.7 \mathrm{~Pa})$ than in control subjects. In these patients acute viscosity changes, due to hemodialysis, do not influence mean wall shear stress.

Furthermore, mean wall shear stress varies along the human arterial tree as it was found that mean wall shear stress is lower in the muscular brachial artery than in the elastic common carotid artery $(0.9 \mathrm{~Pa}$ vs. $1.35 \mathrm{~Pa})$, which is disagreement to Murray's law.

\subsection{Recommendations for further research}

Although the clinical applicability of the SRES is still limited, the research potential is wide. Studies with the SRES are in its infancy. Firstly the SRES is still under development and improvement of hardware and software are aimed at a better resolution and improving the applicability of the system. Possible improvements should include registration of more heart beats within one measurement or allowing continuous recording. Also stereotactic measurements would allow threedimensional registration of blood flow leading to a better insight into the magnitude of wall shear stress, its three dimensional time dependent behaviour and local interaction with the vessel wall.

Another improvement could be the assessment of whole blood viscosity. Future studies should use cone or plate viscometers to better assess blood viscosity, and so, wall shear stress. Studies could be performed in patients with blood viscosity syndromes e.g. Polycytemia Vera and Waldenströms disease.

Longitudinal studies should be undertaken to investigate the effect of ageing and to study the role of wall shear stress in various arteries of atherosclerotic risk groups such as patients with hypertension, patients with hyperhomocysteinemia, diabetes mellitus or hypercholesterolemia. In addition, intervention studies could be performed to study the effect of different drugs on wall shear stress in the various arteries of risk groups. 
Studies could be performed regarding the effect of acute viscosity changes on wall shear stress and its effect on vessel wall characteristics such as diameter, strain and distensibility. In this regard one could think of blood donating procedures.

An important phenomenon in vascular biology is the relationship between wall shear stress and acute and/or chronic arterial remodelling. Such relationships can be studied by means of the SRES. Hypercarboxia could be used to elucidate the interaction between wall shear stress and acute vasodilatation in the common carotid artery. In the brachial artery this interaction could be studied during ischemia-reperfusion with or without pharmacological intervention. Also remodelling of the brachial artery after creating an AV-fistula for hemodialysis could be studied in relation to changes in wall shear stress, if any.

In future the SRES system might be used for monitoring wall shear stress/wall shear rate conditions in vascular surgery. As wall shear stress is related to intimal hyperplasia, i.e., smooth muscle cell proliferation, e.g., after bypass grafting, the behaviour and level of wall shear stress has implications for the way of constructing vascular conduits such as in AV-fistulae and peripheral or coronary bypasses. Thereby a physiological wall shear stress may be achieved via operation techniques as well as the grafting material used. Moreover, when a physiological wall shear stress level is not achieved, preventive medication could be given to reduce intimal proliferation. Meanwhile wall shear rate or wall shear stress may be monitored.

Thus starting from here, many clinical studies can be performed with the SRES, while simultaneously the SRES must be improved to attain a better resolution and, therefore, a wider applicability. 


\subsection{References}

Blann $\mathrm{AD} ; \mathrm{McC}$ Collum $\mathrm{CN}$. Adverse influence of cigarette smoking on the endothelium. Thromb Haemost 1993;70:707-711.

Blum M;Yachnin T;Wollman Y;Chernihovsky T;Peer G;Grosskopf I;Kaplan E;Silverberg D;Cabili S;laina A. Low nitric oxide production in patients with chronic renal failure. Nephron 1998;79:265-268.

Brands PJ;Hoeks APG;Hofstra L;Reneman RS. A noninvasive method to estimate wall shear rate using ultrasound. Ultrasound Med Biol 1995;21:171-185.

Galbusera M;Zoja C;Donadelli R;Paris S;Morigi M;Benigni A;Figliuzzi M;Remuzzi G;Remuzzi A. Fluid shear stress modulates von Willebrand factor release from human vascular endothelium. Blood 1997;90(4):1558-1564.

Gijssen FJH;Brands PJ;van de Vosse FN;Janssen JD. Assessment of wall shear rate measurements with ultrasound. J Vasc Invest 1998;4:187-196.

Howard G;Wagenknecht LE;Burke GL;Diez-Roux A;Evans GW;McGovern P. Cigarette smoking and progression of atherosclerosis. The atherosclerosis risk in communities (ARIC) study. JAMA 1998;279:119-124.

Kamiya A;Bukhari R;Togawa T. Adaptive regulation of wall shear stress optimizing vascular tree function. Bulletin Math Biol 1984;46:127-137.

Kornet L;Hoeks APG;Lambregts J;Reneman RS. In the femoral artery bifurcation, differences in mean wall shear stress within subjects are associated with different intima-media thickness. Arterioscler Thromb Vasc Biol 1999;19:2933-2939.

LaBarbera M. Principles of design of fluid transport systems in zoology. Science 1990;249:992-1000. 
McVeigh GE, Lemay L, Morgan D, Cohn JN. Effect of long term smoking on endothelium-dependent responses in humans. Am J Cardiol 1996;78:668-672.

Moncada S, Palmer RM, Higgs EA. Nitric oxide: physiology, pathophysiology and pharmacology of nitric oxide. Pharmacol Rev 1991;43:109-142.

Nichols WW, O'Rourke MF. The nature of flow of a fluid. In: Nichols WW, O'Rourke MF, eds. McDonald's blood flow in arteries. London: Edward Arnold, 1990:12-53.

Noria S, Cowan DB, Gotlieb AI, Langille BL. Transient and steady-state effects of shear stress on endothelial cell adherens junctions. Circ Res 1999;856:504-514.

Rodbard S. Vascular Caliber. Cardiology 1975;60:4-49.

Strong JP, Richards ML. Cigarette smoking and atherosclerosis in autopsied men. Atherosclerosis 1976;23:451-476.

Takahashi M, Berk BC. Mitogen-activated protein kinase (ERK 1/2) activation by shear stress and adhesion in endothelial cells. Essential role for a herbimycinsensitive kinase. J Clin Invest 1996;98(11):2623-2631.

Weaver JPA, Evans A, Walder DN. The effect of increased fibrinogen content on the viscosity of blood. Clin Sci 1969;36:1-10.

Zamir M. Shear forces and blood vessel radii in the cardiovascular system. J Gen Physiolol 1977;69:449-461.

Zhu BQ, Parmley WW. Hemodynamic and vascular effects of active and passive smoking. Am Heart J 1995;130:1270-1275. 


\title{
Glossary
}

\author{
Abbreviations
}

Nomenclature 


\section{Abbreviations}

\begin{tabular}{|c|c|}
\hline$A / D$ & Analog to Digital \\
\hline AV-fistula & Arterio-venous Fistula \\
\hline BA & Brachial Artery \\
\hline BAEC & Bovine Aortic Endothelial Cells \\
\hline bFGF & Fibroblast Growth Factor \\
\hline BMI & Body Mass Index \\
\hline B-mode & Brightness Mode \\
\hline BPAEC & Bovine Pulmonary Aortic Endothelial Cells \\
\hline $\mathrm{CC}$ & Compliance Coefficient \\
\hline CCA & Common Carotid Artery \\
\hline $\mathrm{CCM}$ & Cross Correlation Model \\
\hline CLK & Clock \\
\hline CMWSS & Calculated Mean Wall Shear Stress \\
\hline D & Internal Diameter \\
\hline DBP & Diastolic Blood Pressure \\
\hline EC & endothelial cell \\
\hline ECG & Electrocardiogram \\
\hline EDCF & Endothelial Derived constricting factor \\
\hline EDRF & Endothelial Derived Relaxing Factor \\
\hline EP & Emitted Pulses \\
\hline ESRF & End Stage Renal Failure \\
\hline ET & Emission Trigger \\
\hline ET-1 & Endotheline-1 \\
\hline HDL & High Density Lipoprotein \\
\hline $\mathrm{Ht}$ & Hematocrit \\
\hline HUVEC & Human Umbilical Vein Endothelial Cell \\
\hline ICAM-1 & Inter Cellular Adhesion Molecule-1 \\
\hline LDL & Low density lipoprotein \\
\hline MAP & Mean Arterial Pressure \\
\hline $\mathrm{MHz}$ & MegaHertz \\
\hline M-mode & Motion Mode \\
\hline
\end{tabular}


MV

MWSR

MWSS

NO

PAEC

PAI-1

PDGF

PGI

PP

PRF

PSV

PTCA

PTFE

PV

PWSR

PWSS

if

$\mathrm{S}$

SBP

SD

SMC

SNR

SRES

TGF

tPA

VC

VCAM-1

VSMC

WBV

WSR

WSS
Mean Velocity

Mean wall shear rate

Mean wall shear stress

Nitric oxide

Porcine Endothelial Cells

Plasminogen Activator Inhibitor-1

platelet Derived Growth factor

Prostaglandine

Pulse Pressure

Pulse Repetition Frequency

Peak Systolic Velocity

Percutaneous Transluminal Coronair Angiography

Polytetrafluroethane

plasma viscosity

Peak wall shear rate

Peak wall shear stress

radiofrequent

Strain

Systolic Blood Pressure

Standard Deviation

Smooth muscle cell

Signal to Noise Ratio

Shear Rate Estimating System

transforming Growth Factor

tissue Plasminogen

Variation Coefficient

Vascular Cellular Adhesion Molecule-1

Vascular Smooth Muscle Cell

Whole blood viscosity

Wall shear rate

Wall shear stress 


\section{Nomenclature}

$\alpha$

$\eta$

$\eta_{0}$

$\gamma$

$\gamma_{w}$

$\tau$

$\tau_{w}$

$\lambda$

$\varphi$

$c$

$f_{c}$

$f_{d}$

$r$

$s$

$\Delta t$

$v$

$\bar{v}$

$V_{m}$

$v(r)$

$\Delta d$

$\Delta D$

$\Delta P$

$d B$

D

$P$

$R$

$n$

Q
Womersly parameter

[Pa.s] viscosity

[Pa.s] plasma viscosity

$\left[\mathrm{s}^{-1}\right]$

shear rate

$\left[\mathrm{s}^{-1}\right]$

[Pa]

[Pa]

[ $\mu \mathrm{m}]$

[rad]

[m.s $\left.\mathrm{s}^{-1}\right]$

[Hz]

[Hz]

[m]

[m]

[s]

[m.s $\left.\mathrm{s}^{-1}\right]$

[m.s $\left.{ }^{-1}\right]$

[m.s $\left.\mathrm{s}^{-1}\right]$

$\left[\mathrm{m} . \mathrm{s}^{-1}\right]$

[m]

[m]

[Pa]

wall shear rate

shear stress

wall shear stress

wavelength

angle between ultrasound beam and direction of motion

sound velocity

carrier frequency

Doppler frequency

radial position

distance

time period

velocity

mean velocity

maximal velocity in centre of vessel

velocity distribution as function of radial position

difference in depth

distension

pulse pressure (systolic minus diastolic pressure)

decibel

[m] diastolic diameter

[Pa] pressure

[mm] Internal radius

bluntness factor

[ml] flow volume 
Summary 
Summary

198 


\section{Summary}

Chapter 1 is a general introduction regarding the clinical background of this research project: atherosclerosis. This disease affects the arterial system where aside of biochemical also local biomechanical and hemodynamic processes, such as wall shear stress, are playing a significant role. Wall shear stress is the tangential force exerted by the flowing blood on the inner vessel wall. Wall shear stress is for practical reasons difficult to determine in vivo and even non-invasively in humans. As wall shear stress is defined as wall shear rate times blood viscosity, two easier assessable parameters, an indirect estimation of wall shear stress can be made. The objectives of this thesis were to determine the reliability of a especially developed ultrasonic system (Shear Rate Estimating System,SRES) which is able to assess wall shear rate non-invasively and, by measuring blood viscosity, to assess wall shear stress in the common carotid and brachial artery in humans using the SRES.

Chapter 2 describes historical notes regarding the importance of wall shear stress in the vascular system and the discovery that wall shear stress is kept at a constant level of $1.5 \mathrm{~Pa}$ via lumen diameter adaptation. In addition, it became clear that wall shear stress is capable to influence biochemical processes, even on a genetic level. Research showed a direct interaction between wall shear stress, vessel wall changes (remodelling) and vessel wall diseases such as intimal hyperplasia and atherosclerosis.

Chapter 3 describes the general principles of pulsed ultrasound and an outline of the used ultrasonic system, named the Shear Rate Estimating System (SRES). The in vitro validation with Laser Doppler and numerical calculations showed that the measurements of wall shear rate with the SRES agree with the expectations.

Chapter 4 describes the reproducibility of the SRES in young presumably healthy men and women. It is found that wall shear rate and, taken into account whole blood viscosity, wall shear stress can be determined reliable. The average intrasubject intrasession variability is about $12 \%$ for mean wall shear rate and about 
$15 \%$ for peak wall shear rate. A good short and medium term intersubject intersession variability was found. These figures are the same for both and left common carotid artery. It is concluded that within one session wall shear rate can be determined reliably.

Chapter 5 In this chapter the main purpose was to determine the peak and mean wall shear stress as function of age as it is known that ageing is a risk factor for developing atherosclerosis. In women peak wall shear stress decreased with age from 3.3 to $2.5 \mathrm{~Pa}$. In men peak wall shear stress decreased with age from 4.3 to 2.6 $\mathrm{Pa}$. In women mean wall shear stress decreased with age from 1.3 to $1.1 \mathrm{~Pa}$. In men mean wall shear stress decreased with age from 1.5 to $1.2 \mathrm{~Pa}$. Mean wall shear stress values are in the range compatible with the minimum work theory. It remained unclear how arterial diameter, vessel wall elasticity and blood flow interact to maintain a constant mean wall shear stress level.

Chapter 6 In this chapter it was investigated whether in chronic smoking male subjects wall shear stress would be different from male non-smoking subjects. It is known that smoking is a risk factor in developing atherosclerosis The results showed that there was no significant difference in wall shear stress between smoking an non-smoking subjects. It is more likely that smoking has a biochemical effect rather than a direct effect on wall shear stress.

Chapter 7 In this chapter wall shear stress was determined in patients with chronic renal failure which were on hemodialysis. This population has a high risk for developing atherosclerosis. We investigated whether this patient group had a different wall shear stress. Moreover, it was questioned whether an acuut increase in blood viscosity because of hemodialysis would result in a higher wall shear stress. It was found that these patients have a lower wall shear stress of about 0.7 $\mathrm{Pa}$ due to both a lower whole blood viscosity as well as a lower wall shear rate than control subjects. However, these patients are still capable, despite their disease, to maintain the (lower) wall shear stress at a constant level. It is concluded that the lower wall shear stress in this population might be another factor to develop earlier athersoclerosis. 
Chapter $\mathbf{8}$ In this chapter the preliminary results are shown of the comparison of wall shear stress in the elastic common carotid artery and the muscular brachial artery in presumably healthy male subjects. It is found that in the brachial artery peak wall shear stress (about $3.7 \mathrm{~Pa}$ ) is nearly significant higher in the brachial artery, while mean wall shear stress (about $0.9 \mathrm{~Pa}$ ) was significantly lower compared to the common carotid artery. These findings were attributed to the characteristic blood flow velocity waveform within one heart beat. It is generally concluded that in an artery wall shear stress depends on its location and function of that artery which is in turn dependent on the vascular bed the artery supplies

Chapter 9 In this chapter we discussed our observations and concluded that with the SRES wall shear rate and wall shear stress can be assessed reliably. Moreover, the measurement system provides the ability to investigate wall shear stress in vivo, thereby allowing a widespread of future investigations. 
Samenvatting 


\section{Samenvatting}

Hoofdstuk 1 geeft een algemene inleiding en beschrijt de doelstelling van het onderzoek dat in dit proefschrift beschreven is namelijk: atherosclerose. Bij deze ziekte van het arterieël systeem zijn niet alleen biochemische, maar ook locale biomechanische en hemodynamische processen betrokken, waaronder de afschuifspanning. De afschuifspanning is de wrijvingskracht, per oppervlakteeenheid, van het stromend bloed op de vaatwand. Het blijkt in de praktijk moeilijk te zijn om deze fysische parameter bij mensen in vivo en bovendien non-invasief te bepalen. Daar de afschuifspanning gedefinieerd is als het product van afschuifsnelheid en bloedviscositeit, twee eenvoudiger te bepalen parameters, is het mogelijk een schatting te maken van de afschuifspanning. We onderzochten of het mogelijk was de afschuifsnelheid in de arteria carotis communis (halsslagader) van mensen met behulp van ultrageluid betrouwbaar te meten en, omdat tevens de bloedviscositeit bepaald werd, een schatting te maken van de afschuifspanning aan de vaatwand in de halsslagader en (in een latere fase van de studie ook in) de armslagader.

Hoofdstuk 2 beschrijtt hoe het belang van de rol van de afschuifspanning in het vasculaire systeem in de loop van de afgelopen jaren steeds meer werd onderkend. Men kwam tot de bevinding dat de afschuifspanning aan de vaatwand in een slagaderlijk bloedvat op een zeker niveau van 1.5 Pa gehandhaafd wordt d.m.v. diameter- en/of vaatwandveranderingen. Bovendien bleek dat de hoogte van de afschuifspanning invloed heeft op biochemische en zelfs genetische processen. Onderzoek wees uit dat er een rechtstreekse interactie bestaat tussen afschuifspanning en vaatwandaanpassingen (remodelling) alsmede vaatziektes zoals intima hyperplasie en atherosclerose .

Hoofdstuk 3 beschrijt de algemene principes van gepulst ultrageluid en in het verlengde daarvan de basisprincipes van ons meetinstrument, genaamd Shear Rate Estimating System afgekort SRES. Ook wordt de in vitro validatie met Laser Doppler beschreven. Het blijkt dat het met behulp van de SRES heel goed mogelijk is een goede schatting te maken van de afschuifsnelheid aan de vaatwand. 
Hoofdstuk 4 beschrijt de reproduceerbaarheid van de metingen uitgevoerd met de SRES in de halsslagader bij jonge gezonde vrouwen en mannen. Uit deze studie blijkt dat de afschuifsnelheden betrouwbaar gemeten kunnen worden. De gemiddelde variantie van de gemiddelde afschuifsnelheid binnen een persoon is ongeveer $12 \%$, onafhankelijk van het geslacht, terwijl de variantie van de maximale afschuifsnelheid binnen een persoon rond de $15 \%$ is. Bovendien blijkt dat ook op langere termijn (7 dagen) de maximale en gemiddelde afschuifsnelheden alsook de afschuifspanning (door tevens de bloed viscositeit te bepalen) betrouwbaar gemeten kan worden.

Hoofdstuk 5 In dit hoofdstuk wordt antwoord gegeven op de vraag hoe de maximale en gemiddelde afschuifspanning in de halsslagader zich gedraagt als functie van de leeftijd. Dit gezien het verouderingsproces het risico op hart- en vaatziekten verhoogd. Bovendien is het van belang te onderzoeken wat nu precies de fysiologische "normaalwaarden" zijn. Het blijkt dat de maximale (systolische) afschuifspanning bij vrouwen daalt met de leeftijd van 3.3 naar $2.5 \mathrm{~Pa}$. De maximale (systolische) afschuifspanning bij mannen daalt met de leeftijd van 4.3 naar 2.6 Pa. De gemiddelde afschuifspanning bij vrouwen daalt met de leeftijd van 1.3 naar 1.1 $\mathrm{Pa}$. De gemiddelde afschuifspanning bij mannen daalt met de leeftijd van 1.5 naar 1.2 $\mathrm{Pa}$. Deze gemeten gemiddelde afschuifspanning is in overeenkomst met waardes berekend volgens een mathematisch model in de literatuur. Het blijft onduidelijk welke interacties er bij het verouderen precies plaats vinden tussen afschuifspanning, vatdiameter, vaatwandelasticiteit en bloedvolumeverandering om de gelijk blijvende gemiddelde afschuifspanning te verklaren.

Hoofdstuk 6 In dit hoofdstuk wordt onderzocht of bij chronisch rokende mannen er sprake is van een afwijkende afschuifspanning in de halsslagader t.o.v. nietrokende proefpersonen, aangezien roken een risicofactor is voor het ontstaan van slagaderverkalking. Er blijken geen significante verschillen in afschuifspanning in de halslagader te bestaan tussen rokende en niet-rokende mannen. Mogelijk heeft chronisch roken eerder een biochemisch effect op de vaatwand dan een merkbare verandering in afschuifspanning in de halsslagader. 
Hoofdstuk 7 In dit hoofdstuk werd de afschuifspanning bepaalt bij patiënten met terminale nierinsufficiëntie die dialyse-afhankelijk zijn. Deze groep werd onderzocht omdat deze patiënten een verhoogd risico hebben op slagaderverkalking. Bovendien werd onderzocht of een toename in bloedviscositeit als gevolg van de dialyse zou resulteren in een veranderde gemiddelde afschuifspanning. Het blijkt dat bij deze patiënten, voorafgaand aan de dialyse, een verlaagde gemiddelde afschuifspanning bestaat van $0.7 \mathrm{~Pa}$ op basis van zowel een verlaagde viscositeit alsmede een verlaagde afschuifsnelheid. Bovendien blijkt dat ook na dialyse de gemiddelde afschuifspanning gehandhaafd blijft. Hypothetisch kan een verlaagde afschuifspanning bijdragen tot het eerder ontwikkelen van slagaderverkalking bij dergelijke patiēnten.

Hoofdstuk 8 beschrijt de resultaten van het vergelijken van de afschuifspanning in de halsslagader (elastisch vat) en de armslagader (musculair vat) bij gezonde jonge mannen. Deze studie werd gestart aangezien op theoretische gronden wordt gesteld dat de afschuifspanning in het slagaderlijk systeem overal gelijk zou zijn. Het blijkt dat de maximale (systolische) afschuifspanning hetzelfde is (rond de 3.7 $\mathrm{Pa})$ terwijl in de armslagader de gemiddelde afschuifspanning (0.90 Pa) significant lager is dan in de halsslagader (1.38 Pa). Een mogelijke verklaring hiervoor is dat de afschuifspanning afhankelijk is van het type slagader (elastisch of musculair).

Hoofstuk 9 sluit het proefschrift af met een algemene discussie over onze bevindingen en waarbij onze belangrijkste conclusies zijn:

1. Dat we de arteriële afschuifspanning m.b.v ultrageluid betrouwbaar kunnen bepalen.

2. Dat de gemiddelde afschuifspanning in de halsslagader ongeveer $1.2 \mathrm{~Pa}$ bedraagt, welke onafhankelijk is van leeftijd en geslacht.

3. Dat chronisch roken geen direct effect heeft op de afschuifspanning in de halsslagader (gemeten bij mannen).

4. Dat bij patiënten met terminale nierinsufficiëntie een verlaagde afschuifspanning van $0.7 \mathrm{~Pa}$ bestaat die constant blijt zowel vóór als ná hemodialyse.

5. Dat de afschuifspanning in de armslagader lager is dan in de halsslagader.

Daarna worden potentiële mogelijkheden voor verbetering van de meetapparatuur en methoden alsook voor verdere onderzoek aangereikt. 
Samenvatting 


\section{About the author}

Curriculum vitae

Publications 


\section{Curriculum vitae}

Stefano Kliwon Samijo werd geboren op 14 maart 1965 te Paramaribo, Suriname. In 1984 behaalde hij het eindexamen VWO aan de Algemene Middelbare School (AMS) te Paramaribo. Daarna vertrok hij naar Nederland. Wegens uitloting begon hij aan de studie informatica aan de Hoge School Twente. In 1986 kon hij starten met de studie geneeskunde aan de Universiteit Maastricht. In 1990 behaalde hij het doctoraal examen, waarna in juni 1993 het artsexamen volgde. In juni 1993 trad hij in dienst als Assistent in opleiding (AIO) aan de Universiteit Maastricht bij de vakgroep Biofysica, onderafdeling ultrageluid, behorende tot de Cardiovascular Research Institute Maastricht (CARIM). In september 1997 trad hij in dienst van de vakgroep Heelkunde van het aZM als assistent geneeskundige niet in opleiding (AGNIO), om vervolgens te starten met de opleiding chirurgie in augustus 1998 te Heerlen, opleider Dr.P.R.G. Brink. In augustus 2000 werd de opleiding orthopedie aangevangen (opleider Dr. H.H. de Boer en Dr. A. Tonino) Atrium ziekenhuis te Heerlen. Hij is gelukkig getrouwd met Nicole Theunissen, cytologisch analiste en vader van Maarten en Laurens. 


\section{Publications}

Samijo SK, Willigers JM, Brands PJ, Barkhuysen R, Reneman RS, Kitslaar PJEHM, Hoeks APG. Reproducibility of shear rate and shear stress assessment by means of ultrasound in the common carotid artery of young human males and females. Ultrasound Med Biol 23 (4):583-590,1997.

Samijo SK, Willigers JM, Barkhuysen R, Kitslaar PJEHM, Reneman RS, Brands PJ, Hoeks APG. Wall shear stress in the human common carotid artery as function of age and gender. Cardiovasc Res 39:515-522, 1998.

Samijo SK, Barkhuysen R, Willigers JM, Kitslaar PJEHM, Reneman RS, Hoeks APG. Chronic smoking does not affect the basal level of wall shear stress. J Vasc Invest 4:117-122, 1998.

Hoeks APG, Samijo SK, Brands PJ, Reneman RS. Assessment of wall shear rate in humans: an ultrasound study. J Vasc Invest 1:108-117, 1995.

Hoeks APG, Samijo SK, Brands PJ, Reneman RS. Noninvasive determination of shear rate distribution across the arterial lumen. Hypertension 26:26-33, 1995.

Reneman RS, Brands PJ, Samijo SK, Hoeks APG. Determination of wall shear rate. Archives of acoustics 20:57-63, 1995.

Engelberts I, Samijo SK, Leeuwenberg JFM, Van der Linden CJ, Buurman WA. A role for ELAM-1 in the pathogenesis of MOF during septic shock.

J Surg Res 53 (2):136-144, 1992.

Engelberts I, Hoof SCJ, Samijo SK, Buurman WA, Van der Linden CJ. Generalised inflammation during peritonitis evidenced by intracutaneous E-Selectin expression. Clin Immunol Immunopathol 65 (3):330-334, 1992. 
Nawoord 


$-\infty=$




\section{Nawoord}

Het tot stand komen van een proefschrift is nooit alleen het resultaat van de inspanningen van één persoon. Ook met dit proefschrift is dat zo. Vele mensen hebben op allerlei fronten een substantiële bijdrage geleverd. Het is dan mij ook een eer om al die mensen op deze plaats publiekelijk te bedanken.

Op de eerste plaats Prof. dr. ir. Arnold P.G. Hoeks. Hij heeft dit project uitgeschreven met als doelstelling om de afschuifspanning als functie van leeftijd en geslacht te bepalen. Daarnaast heeft hij mij altijd de vrijheid gegeven om diverse zijpaden te bewandelen. Hij zorgde ervoor dat het mij niet ontbrak aan zowel wetenschappelijke steun als aan financiële middelen (uit het zoveelste potjel). Dat heb ik altijd zeer gewaardeerd. Ik was altijd zeer onder de indruk van zijn scherpe blik ten aanzien van het analyseren van data. Speciaal wil ik hem bedanken voor zijn steun en geduld in de laatste jaren.

Prof. dr. Peter J.E.H.M. Kitslaar. Hij is degene die altijd achter mij gestaan heeft met het geduld en de kritische blik van een vader. De vaak logische verbeteringen in het manuscript werkten verhelderend. Ook wil ik hem danken voor de steun buiten de wetenschappelijke inspanningen om.

Prof. dr. Robert S. Reneman. Hij weliswaar pas later actief betrokken geraakt in het project, toch zijn bijdrage is van groot belang geweest. Zijn karakteristieke (en gevreesde) rode correcties zal ook ik niet vergeten. Bij het schrijven van andere manuscripten zal ik altijd het gevoel hebben dat u (je) meekijkt. Ik heb er veel van geleerd. Hartelijk dank.

Dr. W. Buurman die zich mijn lot aantrok na het afstuderen en mij in contact bracht met de bovengenoemde promotoren. Dank voor de goede adviezen en begeleiding bij de eerste contacten met de wetenschap.

Prof. dr. K. Leunissen hoofd nefrologie Azm. Hem wil ik danken voor de medewerking om onderzoek op de hemodialyseafdeling te mogen doen. Zijn enthousiasme en gemotiveerdheid werkte aanstekelijk. 
Dr. ing. Peter Brands die de ultrageluidsapparatuur ontwikkelde, waarvan ik zo goed gebruik heb mogen en kunnen maken. Ik ben blij dat ik aan de genoemde verwachting heb kunnen voldoen zoals je in jouw proefschrift hebt vermeld. Tevens wil ik je vrouw en zoon bedanken, die zo bereidwillig waren om als proefpersonen te fungeren.

Ing. Jean Willigers. Jij bent, zoals ik je al altijd op de werkvloer heb genoemd, een echte slavendrijver, maar ook een echte maat. Volgens mij slaagt elke AlO'er met jou aan zijn of haar zijde. De vele heftige (= Willigersiaanse) discussies, jouw toewijding en tomeloze energie zijn van zeer groot belang geweest in slagen van dit proefschrift. Jij stond me met raad en daad bij zowel binnen als buiten de werktijden. Ik ben blij dat je nu ook meer tijd hebt voor Esther en mijn naamgenoot. Veel geluk met je tweede kindje. Esther Willigers wil ik bedanken voor het secretariële werk.

Dr. ir. Léon Ledoux. Bedankt voor je bijdrage in de artikelen. Jouw kritische blik en bedenksels zijn heel wat waard geweest. Ook wil ik je bedanken voor jouw steun op diverse fronten, ondanks dat je niet primair bij het project betrokken was. Speciale dank voor jouw hulp bij de lay-out van het proefschrift. Dat je zo van het Surinaamse eten zou genieten en dat je alsnog naar de Surinaamse eethuisjes in Amsterdam zou gaan had ik nooit gedacht! (zie proefschrift Léon)

Drs. Richard Barkhuyzen. Bedankt voor je hulp en je assistentie. Dat je je zo belangeloos hebt ingezet voor het project heb ik zeer gewaardeerd. Veel succes met je carrière als kaakchirurg.

Dr. Leo Hofstra die mij wees op het belang van shear stress in de vasculaire biologie.

Dr. Dick Slaaf wil ik bedanken de waardevolle discussies. De golfballen zijn goed van pas gekomen en ik hoop ooit nog een goede golf tegenstander te zijn. Prof. dr. ir. Theo Arts dank ik voor zijn lessen in de fysica. Als een leerling zijn leraar een punt zou mogen geven zou hier een 10 op zijn plaats zijn. 
Dr. Christine Willekes bedankt voor de lessen in de echografie en discussies. Frank, Jons, Jacqelien, Roel, inmiddels allen gepromoveerd, bedankt voor de gezellige tijd op de afdeling.

Lucien van Haarlem, secretaresse Biofysica, bedankt voor alle secretariële ondersteuning door de jaren heen.

Dank aan het personeel van de afdeling hemodialyse Azm en aan de patiënten daar die bereid waren als proefpersoon te fungeren. De verpleegkundigen maakten er nooit een probleem van als ik met de apparatuur langskwam. Bovendien werd er altijd een speciaal plekje gecreëerd. Het was zeer gezellig.

Mijn proefpersonen dank ik, omdat ik zonder hen nooit de data had kunnen verzamelen die zo essentieel zijn voor het onderzoek. Speciaal dank ik 't Gilde voor proefpersonen van de oudere generatie, stagiaires van de HTS die het "slachtoffer" werden van, zeker in het begin, langdurige metingen. Een speciaal woord van dank gaat naar het personeel van de medische bibliotheek van de Universiteit Maastricht die ook als proefpersoon hebben gefungeerd. Dank aan de plasma donoren van de bloedbank.

Ik dank mijn huidige opleider Dr. H.H. de Boer en de leden van de maatschap Orthopedie in Heerlen (Dr. A. Tonino, Dr. Meyers, Dr. Schaafsma en Dr. M. van de Linde) dat zij mij de gelegenheid hebben gegeven om het proefschrift af te ronden.

Drs. Stefan Köhnen voor zijn steun, waardevolle discussies en raad tijdens de studie.

Dr. A. Froon chirurg, bedankt voor je hulp, vriendschap en motivatie bij het afronden van het proefschrift.

Ik dank oom Paidjo en tante Agaath Todirijo alsmede oom Henk en tante Ans Todirijo voor hun steun tijdens de studie. 
Tante Gin en Oom Ro (mijn tweede ouders), Romana en Melanie hebben door de jaren gezorgd voor mijn (tweede) thuis. Bedankt voor de steun al die jaren. Jullie steun heeft zeker bijgedragen aan het tot stand komen van dit proefschrift.

Lieve $\mathrm{Pa}$ Jo en Ma Riekie Theunissen, bedankt voor de belangstelling die jullie altijd hebben gehad. Jullie staan altijd klaar voor ons, ook als ik wéér bezig was met het proefschrift. $\mathrm{Pa}$ Jo bedankt voor praktische oplossingen als ik weer eens vast zat met de printer of computer. Dank voor de ontboezemingen omtrent de lifttechnologie. Ook Luc Theunissen bedank ik voor de ondersteuning bij problemen met de computer.

Lieve grootouders, bedankt voor uw vooruitziende blik. $U$ heeft als contractarbeiders zonder huis of land gezwoegd voor een betere toekomst voor uw kinderen en kleinkinderen. Opa Palijo, uw wens dat uw (klein)kinderen het ver zouden schoppen in de maatschappij is werkelijkheid geworden.

Lieve $\mathrm{Pa}$ en $\mathrm{Ma}$, met een paar zinnen kan ik jullie nooit genoeg bedanken voor alles wat jullie voor me gedaan hebben. Toch moet ik dat hier proberen. Jullie hebben altijd in mij geloofd; jullie stonden onvoorwaardelijk achter mij in mijn beslissing om in Nederland geneeskunde te gaan studeren, ook al betekende dit dat we jarenlang van elkaar gescheiden zouden zijn. De drie koeien moesten worden verkocht om het vliegticket te kunnen betalen. Maar daar bleef het niet bij: Hoe zwaar is het niet geweest om vanuit het door de economische crisis geteisterde Suriname jaar in jaar uit jullie zoon in het o zo dure Nederland te steunen? Het is daarom dat ik dit proefschrift aan jullie opdraag; het is ook van jullie! Heel erg bedankt - Matur Nuwon! Mijn broers Meo en Lens, mijn zusje Cindy: Bedankt voor al jullie steun; jullie offers worden niet vergeten.

Nicole, Maarten en Laurens het is af!!!

Lieve Nicole, bedankt voor je toewijding en zorg, ook in dit deel van mijn leven!!

\section{Steven}



